\title{
Tabularia
}

\section{Écrire l'histoire des abbés du Mont Saint-Michel 2. Robert de Torigni, ses outils, ses sources et sa méthode de travail}

Writing History of the abbots of Mont Saint-Michel

2. Robert of Torigni, his tools, his sources and his working method

Scrivere la storia degli abati del Mont Saint-Michel

2. Roberto di Torigni, i suoi strumenti, le sue fonti e il suo metodo di lavoro

\section{Stéphane Lecouteux}

\section{OpenEdition}

Journals

Édition électronique

URL : http://journals.openedition.org/tabularia/2973

DOI : $10.4000 /$ tabularia.2973

ISSN : 1630-7364

Éditeur :

CRAHAM - Centre Michel de Boüard, Presses universitaires de Caen

Référence électronique

Stéphane Lecouteux, "Écrire l'histoire des abbés du Mont Saint-Michel

2. Robert de Torigni, ses outils, ses sources et sa méthode de travail », Tabularia [En ligne], Sources en ligne, mis en ligne le 22 mai 2018, consulté le 01 mai 2019. URL : http://journals.openedition.org/ tabularia/2973 ; DOI : 10.4000/tabularia.2973 



\title{
Écrire l'histoire des abbés du Mont Saint-Michel
}

2. Robert de Torigni, ses outils, ses sources et sa méthode de travail

\author{
Writing History of the abbots of Mont Saint-Michel \\ 2. Robert of Torigni, his tools, his sources \\ and his working method
}

\author{
Scrivere la storia degli abati del Mont Saint-Michel \\ 2. Roberto di Torigni, i suoi strumenti, le sue fonti \\ e il suo metodo di lavoro
}

\author{
Stéphane LECOUTEUX \\ Bibliothèque patrimoniale d'Avranches \\ stephane.lecouteux@avranches.fr
}

Résumé:

Maîtriser le temps fut l'un des enjeux majeurs pour les chroniqueurs et les historiens du Moyen Âge. Cette enquête sur la méthode adoptée par Robert de Torigni pour composer sa chronique des abbés du Mont Saint-Michel met en lumière les trois étapes préliminaires indispensables à sa rédaction: mise à jour du catalogue des abbés, interpolation d'annales préexistantes et création de nouvelles annales en marge de tables de comput (annales pascales). Elle révèle également que des Annales pascales $d u$ Bec et surtout trois annales montoises - composées peu après 1035, en 1116 et en 1154 - ont servi de sources pour structurer l'œuvre. La chronique des abbés du Mont Saint-Michel repose donc sur plusieurs couches rédactionnelles plus anciennes, puis a servi à son tour de source aux historiens médiévaux et modernes pour façonner l'histoire de ce prestigieux monastère. De même que l'abbaye du Mont Saint-Michel est constituée de plusieurs strates de constructions successives et forme aujourd'hui un véritable «millefeuille architectural», son histoire, élaborée en plusieurs phases, repose sur un «millefeuille rédactionnel».

Mots-clés: Mont Saint-Michel, Robert de Torigni, abbés, abbatiats, annales, chronique, ère chrétienne, millésime, année de l'incarnation

\section{Abstract:}

Mastering time was one of the major issues for chroniclers and historians of the Middle Ages. This investigation into the method adopted by Robert of Torigni to compose his chronicle of the abbots of Mont Saint-Michel highlights the three preliminary stages essential to its writing: updating the catalog of abbots, interpolation of pre-existing annals and building new records on the sidelines of "comput" tables (Easter annals). It also reveals that the Easter Annals of Le Bec and especially three Annals of Mont Saint-Michel - composed shortly after 1035, in 1116 and in 1154 - served as sources for structuring the work. The chronicle of the abbots 
of Mont Saint-Michel is therefore based on several older editorial layers, and has in turn served medieval and modern historians to shape the history of this prestigious monastery. Just as the abbey of Mont Saint-Michel is made up of several layers of successive buildings and forms today an accumulation of architectural layers, its history, elaborated in several phases, rests on an accumulation of editorial layers.

Keywords: Mont Saint-Michel, Robert of Torigni, abbots, annals, chronicle, Christian era, vintage, year of the incarnation

Riassunto:

Padroneggiare il tempo fu una delle sfide maggiori per i cronisti e gli storici del Medioevo. Questa indagine sul metodo utilizzato da Roberto di Torigni per comporre la sua cronaca degli abati del Mont Saint-Michel mette in luce le tre tappe preliminari indispensabili ai fini della redazione: aggiornamento della lista degli abati, interpolazione di annali preesistenti e creazione di nuovi annali in margine alle tavole di computo (annales pascales). Questa disamina rivela anche che degli Annales pascales del Bec e soprattutto tre annales del Mont - composti poco dopo il 1035, nel 1116 e nel 1154 - sono stati utilizzati come fonti per strutturare l'opera. La cronaca degli abati del Mont Saint-Michel poggia dunque su diversi strati redazionali più antichi ed è poi servita a sua volta agli storici medievali e moderni come fonte per fabbricare la storia di questo prestigioso monastero. Cosi come l'abbazia del Mont Saint-Michel è costituita da strati di costruzioni succedutisi e sovrappostisi nel tempo al punto da formare oggi una vera e propria «millefoglie architettonica», allo stesso modo la sua storia, elaborata in fasi diverse, poggia su una "millefoglie redazionale».

Parole chiave: Mont Saint-Michel, Roberto di Torigni, abati, abbaziati, annales, cronaca, era cristiana, millesimo, anno dell'incarnazione

\section{Introduction $^{1}$}

Malgré les pertes irréversibles subies par le chartrier et les archives de l'abbaye du Mont Saint-Michel ${ }^{2}$, nous conservons encore une documentation abondante provenant de ce monastère. Les manuscrits médiévaux et modernes issus de

1. Les résultats présentés dans ces lignes approfondissent l'enquête menée lors de ma thèse de doctorat (Lecouteux, 2015, t. II, annexe $\mathrm{n}^{\circ}$ 7, p. 285-336). Ils ont fait l'objet d'une conférence co-animée avec Pierre Bouet lors de l'École d'été Biblissima 2016 (Avranches, $1^{\mathrm{er}}$ septembre 2016): "Qui furent les abbés du Mont Saint-Michel? Le témoignage d'une chronique médiévale (ms Avranches, Bibl. patrimoniale, 213, ff. 178r-181v - De abbatibus)». Je tiens tout particulièrement à remercier Thomas Bisson, Pierre Bouet, Olivier Desbordes, Véronique Gazeau et Marie-Agnès Lucas-Avenel pour la relecture attentive de ce texte, ainsi que pour les améliorations proposées.

2. Ces documents, conservés aux Archives départementales de la Manche, à Saint-Lô, furent presque tous détruits en 1944. De nombreuses chartes originales, ainsi que des copies anciennes, ont disparu à cette occasion. Quelques documents originaux et des copies médiévales et modernes ont malgré tout été préservés (voir Keats-Rohan, 2006, p. 26-27 et 34-35; Poulle, Bouet et Desbordes, 2009, p. 12). Par chance, le précieux cartulaire de l'abbaye n'était pas conservé au même endroit que les archives, mais à la bibliothèque municipale (aujourd'hui patrimoniale) d'Avranches (ms 210), ce qui a permis de préserver en copie une partie non négligeable des sources diplomatiques anciennes du Mont Saint-Michel. L'état de ce dossier complexe sera prochainement présenté par Marie Bisson dans les Annales de Normandie. 
l'ancienne bibliothèque monastique constituent l'essentiel de cette documentation ${ }^{3}$. Grâce à ces sources, il est possible d'établir de manière très précise la façon dont a procédé le premier auteur du De abbatibus, c'est-à-dire Robert de Torigni, pour composer cette «chronique» des abbés du Mont Saint-Michel ${ }^{4}$. Cette situation exceptionnelle nous permet de suivre pas à pas les différentes phases indispensables à l'auteur pour l'élaboration de son texte. Admis pour ainsi dire dans son atelier de travail, il devient dès lors possible de mettre en évidence les préoccupations qui ont guidé sa démarche d'historien ${ }^{5}$.

Cet article vise avant tout à éclairer la méthode de travail d'un chronographe du XII e siècle, dont l'œuvre majeure, une Chronique, connut par ailleurs un grand succès dans l'ensemble de l'espace anglo-normand ${ }^{6}$. Cette étude semble d'autant plus utile que l'abbé Robert de Torigni (1154-1186) procède très vraisemblablement de la même manière que nombre d'annalistes, de chroniqueurs et d'historiens actifs entre le IX ${ }^{e}$ et le $\mathrm{XIV}^{e}$ siècle. Comme l'a montré Bernard Guenée dans son ouvrage de référence Histoire et culture historique dans l'Occident médiéval, ces auteurs furent, comme lui, confrontés à de multiples difficultés lors de leur quête d'une meilleure maitrise du temps ${ }^{7}$. Pour mener à bien leurs entreprises, ils eurent généralement recours aux mêmes outils: des catalogues de puissants et des tables de comput ${ }^{8}$, c'est-à-dire

3. Depuis avril 2017, les reproductions numériques des 203 manuscrits du Mont Saint-Michel (dont 199 médiévaux) conservés à la bibliothèque patrimoniale d'Avranches sont consultables sur le site de la Bibliothèque virtuelle du Mont Saint-Michel (BVMSM) : https://www.unicaen.fr/ bvmsm/. Un colloque international centré sur l'étude de ces manuscrits se tiendra à Avranches et au Mont Saint-Michel du 5 au 7 septembre 2018: "Autour de la Bibliothèque virtuelle du Mont Saint-Michel. État des recherches sur l'ancienne bibliothèque monastique» (co-organisation Marie Bisson et Stéphane Lecouteux). Voir le site officiel du colloque: https://bvmsm2018. sciencesconf.org/.

4. Se reporter à la première partie de cet article (LeCouteux, 2017, en particulier p. 3-14).

5. Pour éclairer cette démarche, nous avons en outre la chance de conserver l'édition de la lettre que Robert de Torigni, alors prieur du Bec, adressa au prieur Gervais de Saint-Céneri vers 1152. Cette lettre est l'occasion de présenter un véritable programme méthodologique dans lequel Robert de Torigni précise les informations à rechercher et à donner, ainsi que le type de sources à solliciter (DelisLe, 1872-1873, t. 2, p. Xv et 338-340; GuenéE, 1980, p. 157).

6. Le succès de l'œuvre, évalué par Bernard Guenée sur la base des dix-huit manuscrits connus de Léopold Delisle, mérite d'être reconsidéré (GuenéE, 1980, p. 25 et carte nº 5 p. 259, 265 et 270). Thomas Bisson, qui finalise actuellement la réédition critique et la traduction anglaise de la Chronique de Robert de Torigni, a en effet repéré une trentaine de copies de ce texte: vingt-sept manuscrits conservés (dont vingt-six médiévaux) et trois autres aujourd'hui perdus.

7. À ce sujet, voir GuenÉE, 1980, p. 147-162; LeCOUTEUX, 2011, p. 91-19o. Ce thème sera l'un des axes de recherche du colloque international de Cerisy «Maîtriser le temps et façonner l'histoire. Les historiens normands aux époques médiévale et moderne» organisé du 25 au 29 septembre 2019 (co-organisation Stéphane Lecouteux et Fabien Paquet). Voir le site officiel du colloque: https:// cerisy2019.sciencesconf.org/.

8. Ces tables de comput se présentent le plus souvent sous la forme de tables pascales (tables destinées à calculer la date mobile de Pâques). Ces dernières sont généralement accompagnées en marge de repères chronologiques sous forme de notes. Ces notes marginales constituent ce que les historiens modernes appellent des annales pascales (elles sont traditionnellement éditées sans les tables pascales leur servant de support). 
des tables de correspondances destinées à établir des synchronismes entre les différents systèmes de datation alors en usage ${ }^{9}$.

Trois étapes préparatoires furent nécessaires afin de réunir les matériaux et de produire des outils indispensables à la rédaction du De abbatibus. Nous allons successivement les passer en revue, puis étudier l'usage que Robert de Torigni a fait de ces matériaux et de ces outils pour exploiter au mieux les autres sources à sa disposition (étape 4). Afin de fournir quelques repères utiles, je présenterai au préalable un stemma faisant apparaître les dépendances entre les textes qui seront mentionnés au cours de ma démonstration (figure $\left.\mathrm{n}^{\circ} 1\right)^{10}$.

\section{Étape 1 : établissement des successions abbatiales (mise à jour du catalogue des abbés du Mont Saint-Michel)}

Robert de Torigni a d'abord cherché à établir les successions abbatiales, qui devaient constituer l'épine dorsale de son œuvre et servir ainsi de trame à son récit. Cette première étape, indispensable, était relativement aisée à réaliser, vu qu'il disposait pour cela d'un catalogue des abbés du Mont Saint-Michel remontant sans doute à la fin du XI ${ }^{e}$ ou au début du XII ${ }^{e}$ siècle ${ }^{11}$. Celui-ci fut vraisemblablement enrichi régulièrement, après le décès de chaque abbé, au moment de l'accession de son successeur. L'auteur du De abbatibus révèle incidemment l'existence de ce catalogue lorsqu'il est amené à parler de la mort de Richard de la Mouche et de Robert Hardi à l'année 1153: «je n'ajoute pas ces deux personnes au catalogue des abbés, parce qu'elles ne se sont jamais acquittées, ni à l'église, ni au réfectoire, de la fonction abbatiale». S'il ne les ajoute pas, c'est donc qu'il passe directement de l'abbé Geoffroy - mort en décembre 1150 ou janvier 1151 et peut-être déjà inscrit dans le catalogue - à son propre abbatiat, qui débute en mai 1154. Ce catalogue, tenu à jour dès 1154 par Robert de Torigni en personne, ne nous est pas parvenu. Il en existe cependant une copie contemporaine sous le titre Nomina abbatum sancti Michaelis de periculo maris dans le ms Paris,

9. L'année de l'incarnation (c'est-à-dire l'année de la naissance du Christ), qui sert de point d'origine à l'ère chrétienne, ne s'impose que lentement comme référentiel de datation au cours du Moyen Âge. Entre le VI ${ }^{e}$ et le XIII ${ }^{e}$ siècle, l'usage de l'ère chrétienne coexiste encore avec plusieurs autres systèmes de datation, tels que l'indiction, l'année de règne du souverain, etc. (GUenéE, 1980, p. 147-164, en particulier p. 154-164; GuyotjEANnin et TocK, 1999, p. 41-109; Guyotjeannin, 2011, p. 37-59; Lecouteux, 2011, p. 91-190). Je tiens à remercier Laurent Morelle, qui m'a invité à présenter les résultats de mes recherches sur les sources annalistiques lors de l'Assemblée générale de la Société de l'Histoire de France (École nationale des chartes, 22 juin 2017): "Une source d'histoire à revisiter: annales pascales et annales mineures du Moyen Âge».

10. Le lecteur pourra suivre plus aisément la démonstration qui suit en se reportant aux reproductions des manuscrits cités dans ce stemma et dans le texte (reproductions numériques accessibles grâce aux hyperliens pointant sur les sites de la Bibliothèque virtuelle du Mont Saint-Michel [BVMSM, université de Caen], de la Bibliothèque virtuelle des manuscrits médiévaux [BVMM, IRHT] et Gallica $[\mathrm{BnF}])$.

11. Pour la datation de ce catalogue, voir l'étape suivante (étape 2). 


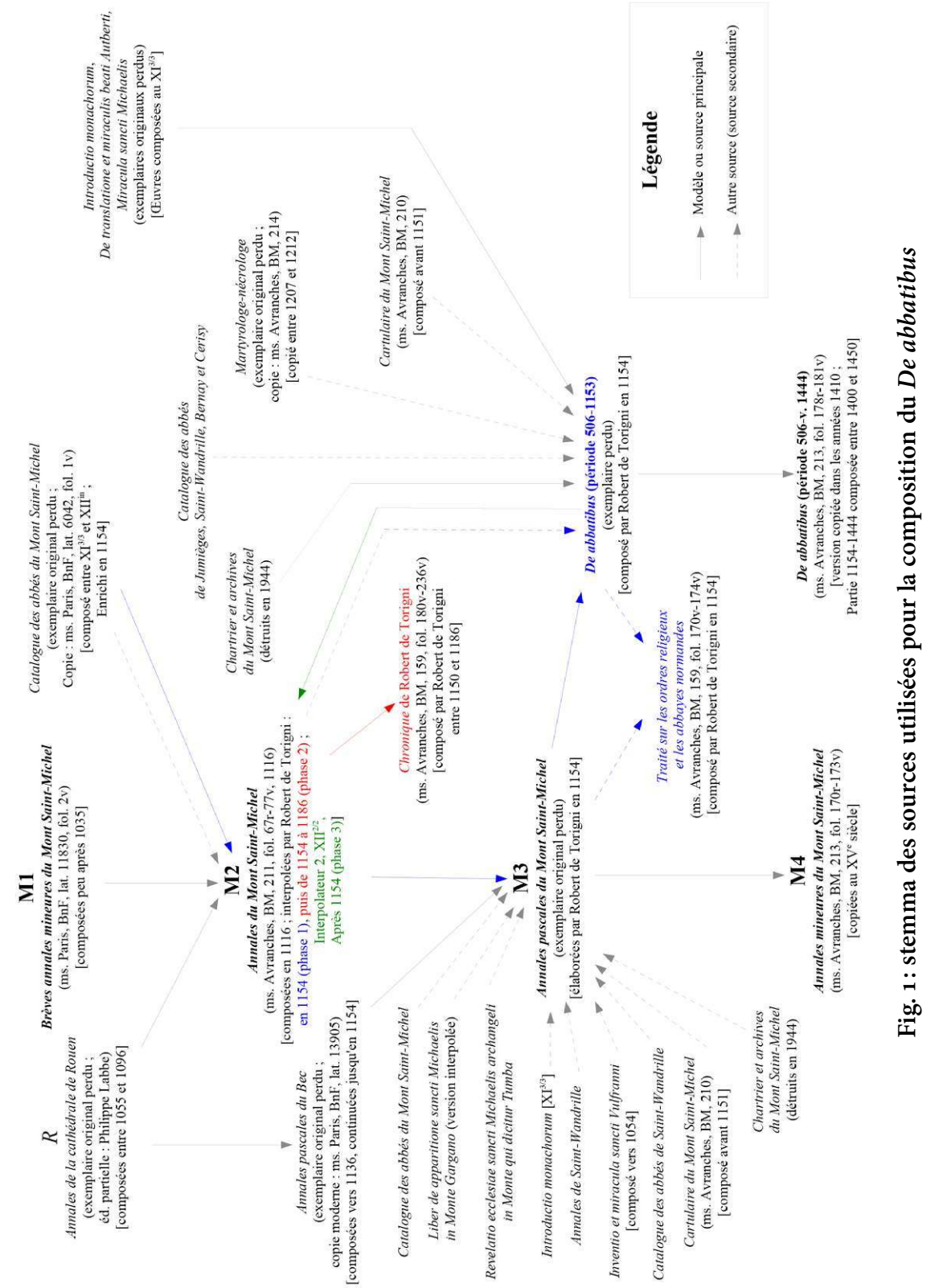

Tabularia «Documents», «Sources en ligne», 2018, p. 1-68, 22 mai 2018 
BnF, lat. 6042 , fol. $1 \mathrm{v}$, col. $4-5^{12}$. Cette liste abbatiale, écrite de première main jusqu'à l'abbé Robert de Torigni inclus ${ }^{13}$ et insérée dans un volume renfermant l'Histoire d'Angleterre de Henri de Huntingdon que fit transcrire l'abbé du Mont pour son monastère ${ }^{14}$, présente plusieurs particularités. Outre qu'elle n'enregistre pas Richard de la Mouche et Robert Hardi, comme dans le De abbatibus, elle comporte surtout une inversion de l'ordre des abbatiats pour Aumode (10271032) et Thierry (1023-1027), cinquième et sixième abbés du Mont. Or cette inversion ne fut pas sans incidence lors de l'élaboration de la période 1023-1033 du De abbatibus, comme nous aurons l'occasion de le vérifier en étudiant les étapes suivantes. De plus, ce catalogue se présente comme une simple liste de noms; il ne précise ni le début, ni la fin, ni même simplement la durée de chaque abbatiat, ce qui constitua une difficulté supplémentaire pour l'auteur lorsqu'il voulut établir avec précision la chronologie de la succession des abbés du Mont Saint-Michel.

\section{Étape 2: établissement des chronologies abbatiales (interpolation des Annales du Mont Saint-Michel)}

À partir de ce catalogue des abbés du Mont Saint-Michel, Robert de Torigni s'est efforcé de préciser les chronologies abbatiales en fixant la date d'accession de chaque abbé ${ }^{15}$. Comme son catalogue ne lui fournissait pas ces informations, il fut contraint de les rechercher ailleurs, principalement dans les archives et les livres de son monastère. Certaines dates lui étaient déjà fournies par les Annales du Mont Saint-Michel (M2 = ms Avranches, Bibliothèque patrimoniale, 211, fol. $67-77 v)^{16}$. Toutefois, Robert de Torigni ne s'est pas contenté d'exploiter ces

12. Ce catalogue des abbés du Mont Saint-Michel figure au milieu d'un ensemble de listes de même nature. "Au commencement et à la fin de la copie de Henri de Huntingdon que Robert avait fait exécuter pour l'abbaye du Mont Saint-Michel, il ajouta ou fit ajouter 33 catalogues d'archevêques, d'évêques et d'abbés, dont 25 subsistent» (Delisle, 1872-1873, t. 2, p. xv). Avec les listes des abbés du Bec et de Jumièges (cette dernière est perdue), il s'agit de l'un des trois catalogues d'abbés à avoir été inscrits dans les gardes de ce volume (cf. la table de contenu: ms Paris, BnF, lat. 6042, fol. 1r). Notons que le catalogue des abbés du Mont Saint-Michel suit immédiatement ceux des évêques des sept évêchés normands (Rouen, Coutances, Sées, Bayeux, Avranches, Lisieux et Évreux) et qu'il précède celui des abbés du Bec (monastère d'origine de Robert de Torigni).

13. La liste des abbés inscrits de première main commence à Mainard I (965/966-991) et se termine à Robert de Torigni (1154-1186). Elle comporte quinze noms: Mainard I, Mainard II, Hildebert [I], Hildebert [II], Aumode, Thierry, Suppon, Raoul, Renouf, Roger [I], Roger [II], Richard, Bernard, Geoffroy et Robert. Les abbés Martin [de Furmendi] (1187-1191), Jourdain (1191-1212) et Raoul [des Isles] (1212-v. 1228?) ont été ajoutés ultérieurement par deux autres mains.

14. Voir Delisle, 1872-1873, t. 1, p. lv-lxi et t. 2, p. xv; Pohl, 2014, p. 64-70. Au sujet de la faible réception de cette œuvre en Normandie, voir STIRnEmann, 1993.

15. Seule la date de début d'abbatiat est généralement spécifiée par Robert de Torigni: la date de fin d'abbatiat lui importe peu - la période de vacance constitue donc en quelque sorte le prolongement de l'abbatiat précédent.

16. Les notes sur les abbés du Mont Saint-Michel figurent aux fol. 73v-76. Sur ces annales, voir le travail précurseur d'Emmanuel Poulle (Poulle, 2003). L'auteur ignore toutefois que ces annales montoises dérivent des Annales de la cathédrale de Rouen, ce qui limite la portée de certaines de ses conclusions. 
annales comme sources; il les a aussi utilisées comme support pour reporter les dates d'accession des abbés qu'il est parvenu à retrouver dans d'autres documents.

Dans leur état actuel, les Annales du Mont Saint-Michel (M2) restent assez complexes à exploiter, car elles sont constituées de plusieurs couches rédactionnelles. Le texte primitif, écrit d'une seule main en 1116 par un moine anonyme du Mont Saint-Michel ${ }^{17}$, a en effet été complété et corrigé lors d'interpolations et de continuations successives réalisées au cours du XII ${ }^{\mathrm{e}}$ siècle $^{18}$. Afin de distinguer chaque couche rédactionnelle, un examen paléographique est indispensable. Il doit permettre de distinguer les mains des copistes, puis de restituer l'état du document au moment où Robert de Torigni l'exploita pour composer le De abbatibus en 1154 .

Les Annales du Mont Saint-Michel (M2) dérivent des Annales de la cathédrale de Rouen. L'annaliste de 1116 a reproduit la plupart des notes héritées de cette source, mais il a aussi ajouté de nombreux renseignements relatifs à l'histoire de son monastère. Son écriture caroline, qui comporte des lettres ascendantes et descendantes biseautées (et parfois légèrement fourchues), est encore assez arrondie, mais elle est déjà plus compacte et anguleuse que celle des copistes $\mathrm{du} \mathrm{XI}^{\mathrm{e}}$ siècle. Nous nous trouvons dans une phase de transition vers l'écriture pré-gothique. Le copiste utilise une encre brune relativement foncée, mais comportant par endroits des nuances plus ou moins claires. Afin de mesurer la précision et la fiabilité des informations montoises introduites par ce premier annaliste ${ }^{19}$, il convient de passer en revue ses notes en s'efforçant d'identifier ses sources $^{20}$. Trois périodes peuvent être ainsi distinguées :

1. Pour la partie la plus ancienne, antérieure à 1040, l'annaliste a reproduit trois événements précisément datés que lui fournissaient les premières annales de l'abbaye (Brèves annales mineures du Mont Saint-Michel, élaborées peu après 1035: M1 = ms Paris, BnF, lat. 11830, fol. 2v ${ }^{21}$.

17. Pour cette datation, voir l'étape suivante (étape 3).

18. Les additions postérieures à 1173 , ajoutées sur les fol. $76 \mathrm{v}-77 \mathrm{~V}$, ne seront pas prises en compte lors de cette enquête. Certaines mentions sur la succession des abbés du Mont Saint-Michel sont contemporaines (mort et succession de Robert de Torigni en 1186; mort et succession de Jourdain en 1212), d'autres sont des ajouts postérieurs, sans doute contemporains de la continuation du De abbatibus (insertion de durées et de rangs d'abbatiat).

19. Seuls les événements relatifs au Mont Saint-Michel introduits par l'annaliste en 1116 retiennent ici mon attention.

20. Pour déterminer la fiabilité et la précision des dates fournies dans les annales, j'utilise la méthode mise au point au cours de ma thèse de doctorat: Lecouteux, 2015, t. 2, annexe $n^{\circ} 7$, p. 147-166 (voir surtout p. 161-166). La description de cette méthode fera prochainement l'objet d'un article.

21. La reproduction de ce manuscrit n'étant pas encore disponible sur Gallica, une reproduction du feuillet contenant ces annales est fournie en fin d'article (planche $\mathrm{n}^{\circ} \mathrm{I}$ ). Sur les Brèves annales $d u$ Mont Saint-Michel, voir Lecouteux, 2015, t. 2, annexe $n^{\circ}$ 7, p. 199-214 et surtout Lecouteux, sous presse. 


\begin{tabular}{|c|c|}
\hline $\begin{array}{l}\text { Brèves annales mineures } \\
\text { du Mont Saint-Michel } \\
(\mathrm{M} 1=\mathrm{ms} \text { Paris, BnF, } \\
\text { lat. 1183o, fol. 2v) }\end{array}$ & $\begin{array}{l}\text { Annales du Mont Saint-Michel } \\
\left(\mathrm{M}_{2}=\mathrm{ms} \text { Avranches, }\right. \\
\text { Bibl. patrimoniale, 211, fol. 67-77v) }\end{array}$ \\
\hline $\begin{array}{l}\text { 965. Auctoratum est sacro scripto, } \\
\text { tam a domno papa Iohanne quam } \\
\text { a Lothario, Francorum rege, ut } \\
\text { monasterium Montis Sancti Michaelis } \\
\text { perpetualiter insigniatur ordine } \\
\text { monachili utque nullus nomine } \\
\text { vel officio abbatis fungatur ibi nisi } \\
\text { quem idem monachi de suis elegerint } \\
\text { praeesse sibi. }\end{array}$ & $\begin{array}{l}\text { 965. Auctoratum est hoc sacro scripto, } \\
\text { tam a donno Iohanne papa quam a } \\
\text { Lothario, Francorum rege, ut } \\
\text { monasterium Montis Sancti Michaelis } \\
\text { perpetualiter insigniatur ordine } \\
\text { monachili et ut nullus nomine vel } \\
\text { officio abbatis fungatur ibi nisi } \\
\text { quem idem monachi de suis elegerint } \\
\text { praeesse sibi }{ }^{22} \text {. }\end{array}$ \\
\hline $\begin{array}{l}\text { 1023. inc }[\text { h] oatum est hoc novum } \\
\text { monasterium a Richardo secundo } \\
\text { comite et Hildeberto abbate; qui } \\
\text { abbas ipso anno obiit. }\end{array}$ & $\begin{array}{l}\text { 1023. hoc anno inchoatum est hoc } \\
\text { novum monasterium a Richardo } \\
\text { secundo comite et Hildeberto abbate; } \\
\text { qui abbas ipso anno obiit. Eodem } \\
\text { anno abbas [nom gratté et remplacé } \\
\text { par Suppo] suscepit hanc abbatiam }{ }^{23} \text {. }\end{array}$ \\
\hline 1033. Suscepit Suppo hanc abbatiam. & $\begin{array}{l}\text { 1033. Ordinatus est abbas Suppo huius } \\
\text { loci }{ }^{24} \text {. }\end{array}$ \\
\hline
\end{tabular}

2. Pour le milieu et la seconde moitié du XI $\mathrm{XI}^{e}$ siècle (période 1040-1100), l'annaliste ne fournit plus que de brèves informations sur les successions abbatiales, sans doute obtenues grâce à des témoins âgés et à des traditions orales encore vivaces. Suivant les notes, l'auteur écrit en effet de 30 à 70 ans après que les événements rapportés se sont produits, ce qui rend leur datation assez approximative. Ainsi, la précision des dates fournies, lorsqu'elle peut être vérifiée, n'a été donnée qu'à une ou deux années près ${ }^{25}$. Et l'on peut considérer que ce fut aussi le cas des autres dates aujourd'hui non vérifiables. L'annaliste place ainsi ${ }^{26}$ :

22. Ms Avranches, Bibl. patrimoniale, 211, fol. 73v. Dans son édition des annales M2, L. Delisle rapporte par erreur cette note à l'année 960: il a ignoré le signe de renvoi «:B:» tracé par le copiste à l'année 965 (cf. Delisle, 1872-1873, t. 2, p. 217 et 235).

23. Ms Avranches, Bibl. patrimoniale, 211, fol. 74v. La note de M1 a été complétée par le nom du successeur d'Hildebert II grâce au catalogue des abbés du Mont Saint-Michel. La liste abbatiale était cependant déjà erronée en 1116 puisqu'elle donnait Aumode avant Thierry (Aumode est en effet le nom qui a été gratté, puis remplacé par celui de Suppon dans M2, lors d'un remaniement opéré dans la seconde moitié du XII ${ }^{e}$ siècle: voir la démonstration ci-dessous). Cf. DeLISLE, $1872-1873$, t. 2 , p. 219 et $235-236$.

24. Ms Avranches, Bibl. patrimoniale, 211, fol. 74v (cf. Delisle, 1872-1873, t. 2, p. 220 et 236).

25. Nous y reviendrons lors de l'étude des deux prochaines étapes (étapes 3 et 4 ).

26. Ms Avranches, Bibl. patrimoniale, 211, fol. 74V et fol. $75 \mathrm{r}$ (cf. Delisle, 1872-1873, t. 2, p. 220 et 222). 
- l'accession de Raoul en 1048, du vivant de Suppon: Hoc anno abbas Radulfus suscepit hanc abbatiam vivente Suppone;

- la mort du même Raoul, toujours du vivant de Suppon, en 1060: Obiit Radulfus abbas, vivente Suppone;

- la mort de Suppon en 1061: Obiit donnus abbas Suppo;

- la mort de Renouf et l'accession de Roger en 1085: Eodem anno obiit donnus Rannulfus, abbas et monachus huius loci, pię memoriae. Huic successit Rogerius Cadomensis, non electione monachorum, sed vi terrenę potestatis.

3. Enfin, pour la période 1100-1116, l'annaliste est désormais contemporain des faits rapportés, auxquels il semble avoir personnellement assisté. Ses notes annalistiques font l'objet de récits plus développés et circonstanciés, tandis que les dates fournies redeviennent plus précises. L'auteur signale successivement:

- l'apparition de l'archange Michel sous la forme d'une colonne lumineuse/brillante en 1102: Hoc anno visus est a nonnullis prope ac procul positis sanctus Michael archangelus, prout credimus, in figura columpne rutilantis, nocte scilicet ultime sue festivitatis, penitrasse basicam (sic) huius montis ${ }^{27}$;

- l'effondrement d'une partie du monastère l'année suivante, en 1103: Hoc anno pars non modica ęcclesię Montis Sancti Michaelis corruit in Sabbato vigilię Paschę, [a] monachis more solito matutinis peractis. In cuius ruina portio quedam dormitorii monachorum non minima destructa atque eversa est cum omnibus thoris et pannis, monachis tamen in eisdem requiescentibus gratia Dei et patrocinio sancti Michaelis absque lesione liberatis ${ }^{28}$;

- les circonstances du remplacement de l'abbé Roger I par Roger II en 1106: Hoc ętiam anno Rotgerius Cadomensis, abbas huius loci, fecit capi de monachis nostris a rege Anglorum et distribui per abbatias Normannię. Qua re indignatione non modica commoti sunt cęteri monachi, regem adierunt eique desolationem et expoliationem extirpationemque sui loci viva racione ostenderunt. Quo audito, rex mandavit

27. Ms Avranches, Bibl. patrimoniale, 211, fol. $75 \mathrm{~V}$ (cf. Delisle, 1872-1873, t. 2, p. 223-224). Notons au passage l'emploi du terme rutilantis, remplacé dans les écrits du milieu du XII ${ }^{\mathrm{e}}$ siècle (sans doute déjà dans $\mathrm{M}_{3}{ }^{*}$, puisque c'est cette forme qui est adoptée dans $\mathrm{M}_{4}$ et dans le De abbatibus) par ignae (sic: on attend igneae) : la colonne brillante/éclatante - qui doit donc sans doute à l'origine avoir été perçue comme une colonne lumineuse - est devenue une colonne de feu sous la plume de Robert de Torigni - sans doute afin de favoriser le rapprochement avec le miracle survenu peu après 992 sous l'abbé Mainard II du Mont et l'évêque Norgod d'Avranches.

28. Ms Avranches, Bibl. patrimoniale, 211, fol. 75v (cf. Delisle, 1872-1873, t. 2, p. 223). Dans son édition, L. Delisle a rapporté par erreur cette note à l'année 1100 (il n'y a pourtant aucun signe de renvoi à cette date). 
abbati ut ad se apud Cadomum veniret, monachisque praecipiens ut cum eo redirent. Ierunt utrique. Quibus coram rege positis, sciens abbas se reum in omnibus existere, cum monachis contendere noluit; verum propria sponte nulloque cogente, regi baculum pastoralem reddidit ac dimisit. Huic successit Rotgerius, quidam monachus Gemmeticensis, rursum non voluntate neque electione monachorum, sed vi regię potestatis ${ }^{29}$;

- l'incendie de l'église abbatiale en 1112: Hoc anno combusta est hęc aecclesia Sancti Michaelis igne fulmineo cum omnibus officinis monachorum, monachis tamen gratia Dei nullam lesionem pacientibus, VII kalendas maii, feria VI ebdomade Paschę, monachis matutinas canentibus $^{30}$.

Tel était l'état des données montoises insérées de première main lors de la copie des Annales du Mont Saint-Michel (M2) en 1116. Une brève continuation fut réalisée dès l'année suivante, en 1117, par une autre main usant d'une encre brune beaucoup plus claire ${ }^{31}$. Puis ces annales furent délaissées pendant plusieurs dizaines d'années, jusqu'au milieu du XII siècle. Elles se présentaient encore sous cette forme lorsque Robert de Torigni commença à les interpoler en 1154. Il convient néanmoins de distinguer plusieurs phases d'interpolations et de continuations entreprises par ses soins à partir de cette époque. L'écriture anguleuse de Robert de Torigni évolue d'ailleurs sensiblement suivant le type d'intervention qu'il opère.

Les plus anciennes informations ajoutées de la main de Robert de Torigni concernent exclusivement les abbés du Mont Saint-Michel (ajouts de débuts d'abbatiat et de rangs d'abbé en chiffres romains: ms Avranches, Bibl. Patrimoniale, 211, fol. 73v-75v). Il s'agit de prises de notes rapides, se réduisant à quelques mentions très brèves (phrases sans verbe, constituées de un à quatre mots systématiquement abrégés). Elles ont manifestement été insérées avec hâte et sans souci de présentation. Ces interpolations «brouillonnes» ont été introduites au sein d'annotations préexistantes au moyen d'une encre souvent très noire, et donc facile à repérer. Elles s'appuient sur le catalogue des abbés $\mathrm{du}$ Mont Saint-Michel et sont à mettre en relation directe avec l'élaboration des matériaux indispensables à la rédaction du De abbatibus (première phase d'interpolation, en 1154):

- ajout de Mainard I, premier abbé en 965: Mainard(us) <.I.>, .I. $a b b(a) s^{32}$;

29. Ms Avranches, Bibl. patrimoniale, 211, fol. 75v (cf. Delisle, 1872-1873, t. 2, p. 224). Dans son édition, L. Delisle a rapporté par erreur cette note à l'année 1105 .

30. Ms Avranches, Bibl. patrimoniale, 211, fol. $75 \mathrm{v}$ (cf. Delisle, 1872-1873, t. 2, p. 225).

31. Ms Avranches, Bibl. patrimoniale, 211, fol. $75 \mathrm{v}$ (cf. DelisLe, 1872-1873, t. 2, p. 225).

32. Ms Avranches, Bibl. patrimoniale, 211, fol. 73v (cf. Delisle, 1872-1873, t. 2, p. 217; PoHL, 2014, p. 71). Robert déduit la date de l'accession de Mainard des Brèves annales mineures du Mont Saint-Michel (M1) ou de l'Introductio monachorum, qui donnent toutes deux la date de 965 pour le diplôme du roi Lothaire et rapportent à cette époque le remplacement des chanoines par des moines. 
- ajout de Mainard II, deuxième abbé en 991: Mainard(us) <.II.>, <.II.> $a b b(a) s^{33}$

- ajout d'Hildebert I, troisième abbé en 1009: Hild(e)b(er)t(us)<.I.>, .III ${ }^{(u s)}$. $a b b(a) s^{34}$

- précision du rang du successeur d'Hildebert II (dont le nom, aujourd'hui illisible, a été gratté et surchargé), cinquième abbé en 1023: . $V^{(u s)}$;

- précision du rang de Suppon, septième abbé en 1033: .VII ${ }^{(u s) .35}$;

- précision du rang de Raoul, huitième abbé en 1048: .VIII ${ }^{(u s) . ~}{ }^{36}$;

- ajout de Renouf, neuvième abbé en 1063: Ran(n)ulf(us), <.IX $X^{(u s)}$. $>a b b(a) s^{37}$;

- précision du rang de Roger [I], dixième abbé en 1085: . $X^{(u s) .38}$;

- précision du rang de Roger [II], onzième abbé en 1106: .XI. ${ }^{39}$;

- ajout de Roger [II], onzième abbé en 1106: Rog(erius), <.XI.>abb(a) $s^{40}$;

- ajout de Richard, douzième abbé en 1124: Ric(ardus), abb(a)s.XII. ${ }^{41}$;

33. Ms Avranches, Bibl. patrimoniale, 211, fol. 74 (cf. Delisle, 1872-1873, t. 2, p. 218; PoHL, 2014, p. 71). La source ayant fourni à Robert de Torigni la date précise de l'accession de Mainard II est inconnue: il s'agit de la seule accession abbatiale de la période 965-1106 dont la source utilisée par Robert de Torigni n'a pu être déterminée avec précision. Sans doute disposait-il d'un document, aujourd'hui perdu, lui donnant la mort de Mainard I, premier abbé du Mont Saint-Michel, en 991. Mainard I est cité dans une charte de Maieul de Cluny reproduite dans le cartulaire du monastère (ms Avranches, Bibl. patrimoniale, 210, fol. 55-55v; Poulle, Bouet et Desbordes, 2009, $\mathrm{n}^{\circ}$, p. 381; LAPORTE, 1967, p. 270; KeATS-ROHAN, 2000, p. 164-167; GANDY, 2016, p. 20-22). Il apparait aussi dans une charte du comte de Rennes Conan datée de 990 (KeAts-Rohan, 2006, ${ }^{\circ} 3$, p. 192-193; Poulle, Bouet et Desbordes, 2009, no 2, p. 382; Gulllotel, 2014, ${ }^{\circ}$ 6, p. 161-167).

34. Ms Avranches, Bibl. patrimoniale, 211, fol. 74 (cf. DeLISLE, 1872-1873, t. 2, p. 219; PoHL, 2014, p. 71). Précisons que Robert de Torigni avait d'abord ajouté l'accession de l'abbé Hildebert [I] à l'année 1002, puis que, s'étant ravisé, il a gratté cette première inscription (lecture encore partiellement lisible à la lampe de Wood). La date de l'accession d'Hildebert I en 1009 était connue de Robert de Torigni grâce à un diplôme de Richard II établi à cette date et reproduit dans le cartulaire (ms Avranches, Bibl. patrimoniale, 210, fol. 71v-72v; Fauroux, nº 12, p. 85-86; Poulle, Bouet et Desbordes, 2009, p. 386).

35. Ms Avranches, Bibl. patrimoniale, 211, fol. 74v (ajouté au-dessus d'abbas, en interligne).

36. Ms Avranches, Bibl. patrimoniale, 211, fol. $74 \mathrm{~V}$ (ajouté au-dessus de Radulfus, en interligne; cf. РонL, 2014, p. 71).

37. Ms Avranches, Bibl. patrimoniale, 211, fol. 75 (cf. Delisle, 1872-1873, t. 2, p. 221; PoHL, 2014, p. 71). Connaissant la date des décès de Raoul et de Suppon, données par ces mêmes annales respectivement en 1060 et 1061, ainsi que l'existence d'une période de vacance d'environ deux ans à la suite du décès de Raoul, Robert de Torigni a placé l'accession de Renouf en 1063. Il corrigera toutefois ces dates erronées lors de la rédaction du De abbatibus.

38. Ms Avranches, Bibl. patrimoniale, 211, fol. 75 (ajouté au-dessus de Rogerius, en interligne).

39. Ms Avranches, Bibl. patrimoniale, 211, fol. 75v (ajouté au-dessus de Rotgerius, en interligne).

40. Ms Avranches, Bibl. patrimoniale, 211, fol. 75v (cf. DelisLe, 1872-1873, t. 2, p. 224; PoHL, 2014, p. 71). Cette addition fait doublon avec la note précédente : elle a été ajoutée par Robert de Torigni simplement pour faciliter la lecture de cette information, noyée à la fin d'une longue note en marge de gauche.

41. Ms Avranches, Bibl. patrimoniale, 211, fol. $75 \mathrm{~V}$ (cf. Delisle, 1872-1873, t. 2, p. 225; PoHL, 2014, p. 71). 
- ajout de Bernard, treizième abbé en 1131: Bernard(us) m(onachus) Becci, $<. X I I I .>a b b(a) s^{42}$.

En 1154, Robert de Torigni était ainsi parvenu à établir les débuts d'abbatiat de onze des treize premiers abbés du Mont Saint-Michel, qui se succédèrent à la tête de l'abbaye entre 965 à 1131. Il ne connaissait cependant pas le début des abbatiats des quatrième et sixième abbés, qui correspondent à Hildebert II et à Thierry dans le catalogue des abbés du Mont Saint-Michel lui servant de source. Il est intéressant de noter que Robert de Torigni préféra laisser ces deux lacunes dans sa chronologie abbatiale plutôt que de chercher à tout prix à combler ces manques, en insérant des dates approximatives ou arbitraires.

Robert de Torigni compléta ces mêmes annales en ajoutant, en plusieurs fois - on observe en effet l'usage de plusieurs types d'encres et de plumes -, des informations souvent utiles à la rédaction de sa Chronique (seconde phase d'interpolation: ajouts effectués entre 1154 et 1186, sans doute majoritairement avant 1174$)^{43}$. Ayant affaire tantôt à des interpolations, tantôt à des continuations, il me parait utile de bien distinguer ces deux types d'interventions:

1. Les additions portant sur les fol. $74-75 \mathrm{~V}$ correspondent à nouveau à des prises de notes rapides, insérées sans grand soin au sein d'annotations préexistantes. Ces nouvelles interpolations de Robert de Torigni se réduisent là encore à des mentions brèves et abrégées:

- ajout de l'accession d'Hildebert II, quatrième abbé, en 1017: Hildeb(er)t(us)<.II.>, .IIII ${ }^{(u s)} \cdot a b b(a) s^{44}$;

- ajout de la mort du comte Richard II en 1026: O(biit) Ricard(us).II ${ }^{(u s)} .{ }^{45}$;

42. Ms Avranches, Bibl. patrimoniale, 211, fol. 75 v (cf. Delisle, 1872-1873, t. 2, p. 225; PoHL, 2014, p. 71).

43. Les informations ajoutées après 1154 n'apparaissent ni dans les Annales pascales du Mont Saint-Michel $\left(\mathrm{M}_{3}{ }^{*}\right)$, composées dès 1154 à partir de $\mathrm{M}_{2}$, ni dans les Annales mineures $d u$ Mont Saint-Michel $\left(\mathrm{M}_{4}\right)$ qui reproduisent les précédentes, ni dans le De abbatibus, qui utilise $\mathrm{M}_{3}{ }^{*}$ comme source. Contrairement aux annales $\mathrm{M}_{1}, \mathrm{M}_{2}$ et $\mathrm{M}_{4}$, pour lesquelles nous conservons des manuscrits originaux, les Annales pascales du Mont Saint-Michel sont perdues. Le signe * figurant à la suite de leur désignation sert à rappeler qu'il s'agit d'une œuvre reconstituée (voir l'étape 3).

44. Ms Avranches, Bibl. patrimoniale, 211, fol. 74 (cf. Delisle, 1872-1873, t. 2, p. 219; PoHL, 2014, p. 71). Cette addition est postérieure à 1154 (encre proche des autres additions de Robert de Torigni, mais plus brune et virant légèrement vers le bordeaux). Cela explique pourquoi l'auteur du De abbatibus ignore quand Hildebert II succéda à son oncle Hildebert I. On peut se demander pour quelle raison Robert de Torigni n'a pas ajouté par la suite cette information dans son De abbatibus: est-ce une simple omission, estimait-il la précision de cette date insuffisamment fiable pour l'y faire figurer, ou bien n'a-t-il jamais retouché le De abbatibus après 1154?

45. Ms Avranches, Bibl. patrimoniale, 211, fol. $74 \mathrm{~V}$ (cf. Delisle, 1872-1873, t. 2, p. 219, n. 2 ; PoHL, 2014, p. 71). Robert de Torigni utilise ici une plume plus fine que lors de ses interpolations antérieures. Ce sont les Brèves annales mineures du Mont Saint-Michel du ms Paris, BnF, lat. 11830, fol. 2v (M1, cf. planche $\mathrm{n}^{\circ} \mathrm{I}$ ) qui constituent la source de cette note et qui permettent d'apporter une précision à l'entrée de l’année 1026, copiée de première main en 1116 (cf. DelisLe, 1872-1873, t. 2, p. 236. Voir la figure $\mathrm{n}^{\circ} 2$ ). 
- ajout de la mort du comte Richard III et de l'évêque d'Avranches Maugis en 1027: O(biit) Ricard(us).III ${ }^{(u s)}$. (et) Mangis(us) ep(is)c(opus) abric (ensis) ${ }^{46}$;

- correction sur grattage de la mention sur la mort de l'empereur Conrad en 1039: O(biit) Corrad(us) imp(erato)r ${ }^{47}$;

- correction sur grattage du nom du comte de Mortain en 1106: Will $(\mathrm{elm}) \mathrm{u}(\mathrm{m})^{48}$;

- ajout de la mort du duc de Normandie Robert Courteheuse en 1134: $O$ (biit) Rob(ertus), dux norm(annorum) ${ }^{49}$.

2. Les additions apportées sur le folio 76 peuvent cette fois être considérées comme des continuations, puisque leur auteur est le premier (et le seul) à avoir annoté cette page couvrant la période 1135-1173. L'écriture y est généralement plus posée et un peu plus soignée que lors des interpolations effectuées sur les feuillets précédents. Ces notes ont été inscrites de manière contemporaine, ou quasi contemporaine, entre 1154 et 1173, dans le contexte de la rédaction de la Chronique de Robert de Torigni. S'il existe de très fortes probabilités pour que Robert soit l'auteur de ce texte, il est en revanche plus difficile d'affirmer qu'il s'agit bien de son écriture ${ }^{50}$. L'abbé du Mont aurait en effet pu faire appel à un copiste travaillant sous ses ordres et sous sa dictée, comme il le fit lors de la rédaction de sa Chronique ${ }^{51}$. Je pense pour ma part que, malgré quelques divergences indéniables, l'écriture de cette continuation présente aussi des analogies évidentes avec les interpolations

46. Ms Avranches, Bibl. patrimoniale, 211, fol. 74 v (cf. DelisLe, 1872-1873, t. 2, p. 219, n. 2; PoHL, 2014, p. 71; Allen, 2009, p. 37 et 45-51; Allen, 2012, p. 65). Même plume fine que celle utilisée pour l'insertion de la note précédente. Ce sont les Brèves annales mineures du Mont Saint-Michel du ms Paris, BnF, lat. 1183o, fol. 2v ( $\mathrm{M} 1$, cf. planche $\mathrm{n}^{\circ} \mathrm{I}$ ) qui constituent la source de cette note et qui permettent de corriger l'entrée de l'année 1026, copiée de première main en 1116 (cf. DeLISLE, $1872-1873$, t. 2, p. 236. Voir la figure $\mathrm{n}^{\circ}$ 2).

47. Ms Avranches, Bibl. patrimoniale, 211, fol. $74 \mathrm{~V}$ (cf. DeLISLE, 1872-1873, t. 2, p. 220 ; correction non attribuée à Robert de Torigni par B. Pohl).

48. Ms Avranches, Bibl. patrimoniale, 211, fol. $75 \mathrm{~V}$ (cf. DeLISLE, 1872-1873, t. 2, p. 224; correction non attribuée à Robert de Torigni par B. Pohl). Dans son édition, L. Delisle a rapporté par erreur cette note à l'année 1105.

49. Ms Avranches, Bibl. patrimoniale, 211, fol. 75v. Texte omis par L. Delisle dans son édition. B. Pohl n'attribue pas cette addition à Robert de Torigni (Delisle, 1872-1873, t. 2, p. 220; PoHL, 2014, p. 71)

50. Léopold Delisle a été tenté d'attribuer cette main à Robert de Torigni, mais il reste prudent; les auteurs du catalogue des manuscrits datés attribuent sans réserve cette main à Robert; Benjamin Pohl met en revanche en doute cette attribution; il envisage l'intervention de plusieurs mains, dont peut-être celle de Robert (DelisLe, 1872-1873, t. 2, p. xvi et 207-208; Garand, Grand et Muzerelle, 1984, p. 77; PoHL, 2014, p. 71-72, n. 93).

51. Le manuscrit d'auteur de sa chronique (ms Avranches, Bibliothèque patrimoniale, 159) ne comporte que peu d'interventions de sa main: Robert de Torigni a fait appel à plusieurs copistes, et il s'est contenté de relire, de corriger et de compléter ponctuellement leur travail (РоHL, 2014, p. 54-58). 
opérées sur les feuillets précédents par Robert ${ }^{52}$. Nous pourrions avoir affaire à un même copiste, travaillant avec plus ou moins de soin et surtout avec plus ou moins d'empressement, car opérant dans un contexte de rédaction différent ${ }^{53}$. Le large espace resté vierge, dépourvu d'annotations antérieures et disponible dans les marges de part et d'autre de la table pascale, a également pu favoriser l'insertion séquentielle d'informations contemporaines ainsi que l'adoption d'une écriture plus régulière, s'inscrivant dans le prolongement de la réglure. Ces éléments pourraient expliquer les variations d'écriture observables entre les brèves interpolations d'événements anciens ajoutées rapidement par Robert de Torigni aux fol. $73 \mathrm{~V}-75 \mathrm{~V}$ et les continuations plus nombreuses et plus développées inscrites de manière contemporaine ou quasi contemporaine sur le fol. 76 , que je pense devoir également attribuer à Robert.

Une comparaison de ces variations d'écriture à celles que nous observons aussi chez Orderic Vital ${ }^{54}$ et chez Hugues de Flavigny ${ }^{55}$ - deux auteurs pour lesquels nous avons la chance de conserver plusieurs textes autographes - est riche d'enseignements. Cette approche comparative permet d'observer qu'un travail d'interpolation, se réduisant le plus souvent à des prises de notes rapides insérées dans un texte plus ancien, est très souvent exécuté sans grand soin et avec une écriture plus ou moins «brouillonne». Il s'agit généralement de notes personnelles, non nécessairement destinées à être lues par d'autres lecteurs. Au contraire, un travail de copie ou de mise au propre, au cours duquel le scribe accorde manifestement une plus grande attention à la qualité de sa calligraphie afin de garantir une meilleure lisibilité à son texte, induit l'adoption d'une écriture plus posée, plus soignée et plus régulière. Selon moi, ces comportements différenciés, adaptés au type de travail produit, expliquent les variations d'écriture que nous observons tant chez Orderic Vital et Hugues de Flavigny que chez Robert de Torigni. Dans tous les cas, l'écriture la moins soignée apparaît lorsque ces historiens effectuent des interpolations dans des

52. Ms Avranches, Bibl. patrimoniale, 211, fol. 76 (années 1135-1173): nombreuses additions d'une même main que j'attribue à Robert de Torigni (Lecouteux, 2017, p. 10 n. 40-43). Pour un avis différent, voir POHL, 2014, p. 71-72, n. 93.

53. Les interpolations aux fol. $73 \mathrm{v}-75 \mathrm{~V}$ ont été réalisés en 1154 dans le contexte de la rédaction du De abbatibus; les continuations au fol. 76 ont été réalisées entre 1154 et 1173 dans le contexte de la rédaction de la Chronique.

54. Comparer par exemple la main «brouillonne» de ses interpolations dans les Annales de SaintÉvroult (ms Paris, BnF, lat. 10062, fol. 154V) avec sa main plus posée et soignée dans sa copie des Gesta Normannorum ducum de Guillaume de Jumièges (ms Rouen, Bibl. mun., Y. 14 [1174], fol. 116). Cf. Lecouteux, 2015, planche XIIa.

55. Comparer par exemple l'écriture rapide et moins soignée de ses nombreuses interpolations insérées dans les Annales de Saint-Bénigne de Dijon (ms Dijon, Bibl. mun., 448, fol. 52-59v), que l'on retrouve ponctuellement dans des additions insérées en marge et en interligne dans l'exemplaire autographe de sa Chronique universelle (ms Berlin, Staatsbibl., Phillipps 1870), avec l'écriture plus posée et soignée de sa première rédaction de cette chronique, ainsi que celle de la charte qu'il a copiée le 24 mai 1096 (Bayeux, Bibl. mun., titres scellés nº 9). Cf. Lecouteux, 2015, planches XXIa, XXIb et XXIc. 
annales (insertion de notes en marge ou en interligne de tables chronologiques). Ces historiens considéraient donc ces textes davantage comme des outils de travail, indispensables pour fixer des repères chronologiques, et non comme des œuvres à part entière. Les annales pascales doivent d'ailleurs être perçues non comme des œuvres littéraires, mais comme un ensemble d'événements repères permettant d'établir des synchronismes avec d'autres systèmes de datation ${ }^{56}$. Il s'agit donc d'instruments de travail utiles tant aux notaires qu'aux chronographes et aux historiens. C'est sans doute ce qui explique la présence de notes autographes d'auteurs célèbres, tels Adémar de Chabannes, Orderic Vital, Hugues de Flavigny et Robert de Torigni, en marge de nombreuses tables pascales $^{57}$.

Les notes inscrites par Robert de Torigni sur le fol. 76 concernent peu l'abbaye du Mont Saint-Michel ${ }^{58}$. Je me bornerai à transcrire celles relatives aux abbés de ce monastère, qui furent ajoutées dès $1154^{59}$. Précisons que les rangs de ces abbés, contemporains de l'auteur, n'ont cette fois pas été mentionnés:

- décès de Bernard et accession de Geoffroy en 1149: O(biit) B(er)nard(us), abb(as) Mo(n)t(is), (et) successit Gauf(ridus), m(onachus) e(ius)d(em) loci ${ }^{60}$;

- décès de Geoffroy en 1150: O(biit) Gauf(ridus), abb(as) $M o(n) t(i s)^{61}$;

- élection et accession de Robert de Torigni en 1154: Rob(ertus) d(e) Torign(eio), $m$ (onachus) Becci, el(e)ct(us) ab o(mn)i (con)ventu Mo(n)ti(s), f(a)ct(u)s(est) $a b b(a s) e i(u s) d(e m) l o c i^{62}$.

56. Ces tables fournissent très souvent des correspondances entre l'année de l'incarnation, l'indiction, le comput pascal (épactes, concurrents, date de Pâques, cycle de la lune, etc.) et des notes marginales précisant les années de règne de puissants laïques (empereurs, rois, ducs, comtes, etc.) ou ecclésiastiques (papes, évêques, abbés, etc.), ainsi que des repères mnémotechniques (événements de la vie personnelle de l'auteur, conflits, guerres, épidémies, phénomènes climatiques ou astronomiques, etc.).

57. À ce sujet, Lecouteux, 2011, p. 91-19o. Ce constat permet de relativiser et de reconsidérer le jugement sévère formulé par Michael McCormick à l'égard de ce type de source: «Sur le double plan de la richesse de vocabulaire et de la complexité (par là, de la diversité) de la syntaxe, les annales pascales font bien pauvre figure. [...] Rappelons la pauvreté culturelle qui pouvait marquer les milieux où naquirent les annales pascales. L'auteur, en s'efforçant de combler les lacunes de sa culture littéraire et afin d'éviter les bévues, emploie une langue stéréotypée. Les annales nous confrontent avec une langue très simple et au surplus, pétrie de clichés» (MCCORMICK, 1975, p. 31).

58. Delisle, $1872-1873$, t. 2, p. 225-229.

59. Ces informations, reproduites en 1154 dans les Annales pascales du Mont Saint-Michel $\left(\mathrm{M}_{3}{ }^{*}\right)$, se retrouvent en effet aussi bien dans les Annales mineures du Mont Saint-Michel (M4) que dans le De abbatibus, qui dérivent toutes deux de $\mathrm{M}_{3}{ }^{*}$.

60. Ms Avranches, Bibl. patrimoniale, 211, fol. 76 (cf. Delisle, 1872-1873, t. 2, p. 226; PoHL, 2014, p. 71-72, n. 93).

61. Ms Avranches, Bibl. patrimoniale, 211, fol. 76 (cf. Delisle, 1872-1873, t. 2, p. 226; PoHL, 2014, p. 71-72, n. 93).

62. Ms Avranches, Bibl. patrimoniale, 211, fol. 76 (cf. DelisLe, 1872-1873, t. 2, p. 227 ; PoHL, 2014, p. 71-72, n. 93). 
Robert de Torigni n'est toutefois pas le seul à avoir interpolé les Annales $d u$ Mont Saint-Michel (M2). Un second interpolateur est intervenu, lui aussi au cours de la seconde moitié du XII ${ }^{\mathrm{e}}$ siècle (troisième phase d'interpolation). Il connaissait le De abbatibus, et c'est sur la base de cette œuvre qu'il a effectué une correction et deux ajouts sur la période 1023-1033. Toutefois, comme ce second interpolateur a opéré après 1154, ses corrections n'apparaissaient pas dans les Annales pascales du Mont Saint-Michel $\left(\mathrm{M}_{3}{ }^{*}\right)^{63}$, composées à cette dernière date, et ne furent pas non plus reportées dans le De abbatibus. Ce second interpolateur a visiblement voulu concilier les informations transmises dans les Annales $d u$ Mont Saint-Michel (M2) avec celles fournies par le De abbatibus. Il a surtout cherché à préciser les successions abbatiales décrites trop vaguement à son goût dans ces deux sources pour la période 1023-1033. Toutefois, comme il n'avait pas conscience de l'inversion d'Aumode et de Thierry dans la liste abbatiale et qu'il opérait avec moins de prudence et de scrupule que ne l'avait fait Robert de Torigni avant lui, il ne contribue finalement qu'à embrouiller une situation déjà devenue fort confuse sur cette période. Il effectue ainsi:

- le remplacement du nom de l'abbé inscrit de première main par celui de Suppon (surcharge sur grattage) dans la note de l'année $1023^{64}$;

- l'ajout du début de l'abbatiat d'Aumode, cinquième abbé, en 1030: Almodus, .V. $a b b(a) s^{65}$

- l'ajout du début de l'abbatiat de Thierry, sixième abbé, en 1031: Theodericus, .VI. $a b b(a) s^{66}$.

63. Les Annales mineures du Mont Saint-Michel (M4) transmettent en effet le texte des Annales du Mont Saint-Michel (M2) copié dans les Annales pascales du Mont Saint-Michel $\left(\mathrm{M}_{3}{ }^{*}\right)$ avant l'intervention du second interpolateur, donc sans les corrections apportées par celui-ci.

64. Ms Avranches, Bibl. patrimoniale, 211, fol. 74v. Le nom de l'abbé primitivement inscrit a été gratté et surchargé par Suppo; le rang au-dessus d'abbas (.V.), qui avait été ajouté par Robert de Torigni, a aussi été gratté mais reste lisible. C'est la mention de Suppon, introduite dans le paragraphe de l'année 1023 du De abbatibus - cette œuvre est la première à faire intervenir Suppon au Mont dès 1023 (avant 1154, les sources annalistiques montoises ne le mentionnaient qu'en 1033) -, qui a provoqué la décision d'opérer ce remaniement.

65. Ms Avranches, Bibl. patrimoniale, 211, fol. 74v (cf. Delisle, 1872-1873, t. 2, p. 219). Nous ignorons les raisons qui ont poussé l'interpolateur à introduire Aumode en 1030. Ce dernier n'est mentionné dans le cartulaire du Mont que dans une charte de 1032, accordée par le duc Alain III de Bretagne au Mont Saint-Michel (ms Avranches, Bibl. patrimoniale, 210, fol. 46-47; Keats-Rohan, 2006, nº 23, p. 104-105; Poulle, Bouet et Desbordes, 2009, nº 21, p. 396-397; GuILlOTEL, 2014, n' 22, p. 209-211).

66. Ms Avranches, Bibl. patrimoniale, 211, fol. 74v (cf. DelisLe, 1872-1873, t. 2, p. 219). L'introduction d'Aumode en 1030 incite l'interpolateur à ajouter son successeur supposé (d'après le catalogue des abbés du Mont Saint-Michel) entre 1030 et 1033. Il avait le choix entre 1031 et 1032, mais nous ignorons les raisons de l'insertion à la première date, Thierry n'étant mentionné dans le cartulaire du Mont que dans une charte non datée d'Ansger et Hervé (ms Avranches, Bibl. patrimoniale, 210, fol. 47-48; Keats-Rohan, 2006, n 24, p. 106-107; Poulle, Bouet et Desbordes, 2009, $\left.\mathrm{n}^{\mathrm{o}} 14, \mathrm{p} .390\right)$. 


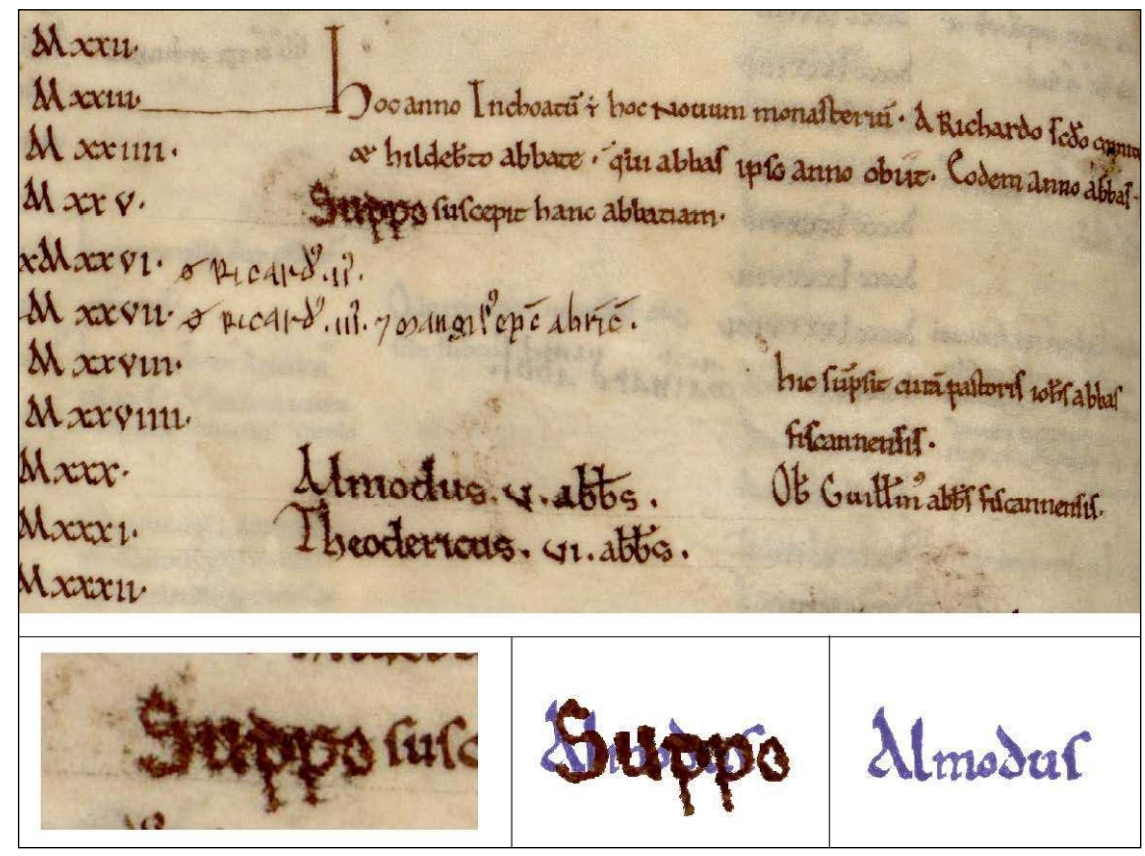

Fig. 2 : l'interpolation du nom de l'abbé ayant succédé à Hildebert II en 1023 dans les Annales du Mont Saint-Michel (M2 = ms 211, fol. 74v)

Aucune des trois informations introduites par les soins de ce second interpolateur n'est avérée. Ses interventions fautives et tardives doivent donc être écartées de notre enquête, qui se place au moment de la composition du De abbatibus (première phase d'interpolation). Il convient donc d'étudier les feuillets $73 \mathrm{v}-76$ du ms $211(\mathrm{M} 2)$ dans l'état où ils se trouvaient avant l'intervention de ce second interpolateur, mais aussi avant les additions effectuées par Robert de Torigni après 1154 .

Revenons donc au grattage et à la surcharge «Suppo» dans le passage mentionnant la succession d'Hildebert II à l'année 1023. Comment retrouver le nom de l'abbé inscrit à l'origine à cet endroit, avant l'intervention du second interpolateur? Par chance, celui-ci n'a effectué qu'un grattage superficiel et de médiocre qualité avant de surcharger l'ancien texte (figure $\mathrm{n}^{\circ}{ }_{2}$ ).

Un examen rapide permet déjà d'observer aisément les vestiges de deux lettres sous le nom «Suppo»: une longue barre verticale correspondant à l'ascendante d'une lettre partiellement lisible s'observe dans la partie droite $\mathrm{du}$ "S"; la partie supérieure d'un "d" oncial est encore nettement visible au-dessus du premier "p". Ce double déchiffrement apporte de précieux indices sur le nom de l'abbé du Mont qui avait été primitivement inscrit à cet endroit par l'annaliste en 1116. Parmi les restitutions possibles, on retiendra Hildebertus, Theodericus et Almodus, trois noms portés par les prédécesseurs 
de Suppon, qui présentent tous un "d" en milieu ou en fin de nom ainsi qu'une lettre avec ascendante verticale en première, deuxième ou troisième position: un "h" et un "l" pour Hildebert, un "h" pour Thierry et un "l" pour Aumode. Il serait tentant de penser que Thierry est la bonne lecture, car nous savons depuis les travaux de Dom Laporte que c'est Thierry qui succéda à Hildebert II en 1023. Cependant, Aumode reste un candidat sérieux, puisque le catalogue des abbés du Mont du XII e siècle le donne - par erreur - comme le successeur d'Hildebert II. De plus, sauf à envisager l'usage d'abréviations drastiques, Hildebertus et Theodericus semblent trop longs pour que les signes suivant le "d" oncial puissent s'inscrire entièrement dans un espace aussi réduit que celui qui sépare le premier "p" de Suppo de suscepit, ce qui ouvre déjà une première piste solide en faveur d'Almodus.

Avant de céder à des conclusions hâtives, le mieux est encore de procéder à un examen minutieux du grattage pour tenter de déterminer lequel de ces différents noms avait été primitivement tracé, ou si un autre nom pourrait être éventuellement envisagé. On devine, en effet, d'autres traces d'encre plus anciennes en bordure de plusieurs des lettres formant le nom Suppo. Le parchemin tâché en de nombreux endroits et la tendance de l'encre de l'interpolateur à baver et à se répandre en suivant les fibres du parchemin gratté rendent cependant la lecture malaisée. Cette observation vaut aussi pour les deux additions insérées en face des années 1030 et 1031 par ce même interpolateur, mais les bavures sont assurément plus importantes là où il $\mathrm{y} \mathrm{a}$ eu grattage (voir la figure $\mathrm{n}^{\circ}$ 2): les fibres du parchemin, mises à vif, ont favorisé la propagation de l'encre. Il est donc difficile, au premier coup d'œil, de faire clairement la distinction entre ce qui subsiste de l'encre du premier texte et les bavures de l'encre du second texte. À y regarder de près, les deux encres ne sont toutefois pas absolument identiques ${ }^{67}$, et les bavures ont tendance à fuir en étoile, en donnant au nouveau texte un aspect «poilu» ou hérissé. En suivant le ductus et le tracé principal du texte Suppo et en écartant le «bruit " généré par les bavures de l'encre consécutives au grattage, il est possible d'isoler plusieurs vestiges de lettres provenant du texte primitif, sans toutefois parvenir à identifier clairement chacun de ces signes. Le recours à la lampe de Wood (lumière ultraviolette) utilisée dans des conditions optimales ${ }^{68}$ a permis de différencier les endroits comportant de l'encre grattée de ceux simplement noircis par les bavures. Nous avons pu ainsi constater que l'initiale du nom originel, devant le "S" de Suppo, correspondait à un "A" majuscule de type oncial, que les deux traits d'un "u" étaient encore visibles entre les deux "p" et que la crosse d'un " $s$ " droit surmontait la panse du second de ces "p". En atténuant les bavures du

67. Vus de loin, les ajouts de l'interpolateur semblent plus foncés, mais examinée de près, l'encre vire un peu plus au bordeaux que le texte de première main, dont les grattages ont légèrement accentué la teinte brunâtre.

68. Il a été possible d'obtenir une obscurité totale en examinant le manuscrit à l'intérieur du coffrefort des manuscrits précieux conservés à la Bibliothèque patrimoniale d'Avranches: la lecture à la lumière ultraviolette a été plus efficace dans ces conditions. 


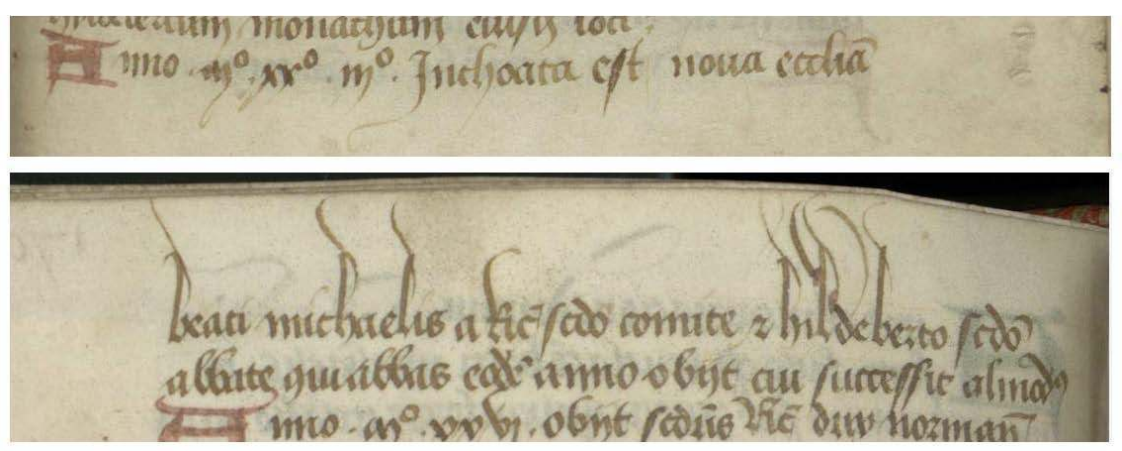

Fig. 3: Aumode, successeur de l'abbé Hildebert II en 1023 dans les Annales mineures du Mont Saint-Michel

$\left(\mathrm{M}_{4}=\mathrm{ms}\right.$ Avranches, Bibl. patrimoniale, 213, fol. 170-170v)

nom Suppo et en exagérant la différenciation des couleurs d'encre - par l'usage du violet pour le texte primitif gratté et du brun pour celui qui l'a surchargé -, une restitution des deux textes devient possible (voir la figure $n^{\circ} 2{ }^{69}$. Le texte gratté correspond bien au nom Almodus.

Cette lecture «difficile» a d'ailleurs pu être confirmée depuis. Nous nous sommes en effet aperçu, dans un second temps, que le texte de l'année 1023 des Annales du Mont Saint-Michel du ms 211 (M2) avait été retranscrit en 1154 dans les Annales pascales du Mont Saint-Michel $\left(\mathrm{M}_{3}{ }^{*}\right)$ avant que l'interpolation du texte eût été réalisée. Ces dernières annales, avant d'être perdues, ont par chance fait l'objet d'une copie au début du XV siècle dans le ms 213, fol. 170-173v ( $\left.\mathrm{M}_{4}\right)$. Or, dans cette copie, la note de l'année 1023 désigne clairement le successeur de l'abbé Hildebert II comme étant Almodus (voir la figure ${ }^{\circ} 3$ ).

Nous allons voir, en étudiant la troisième étape du travail de Robert de Torigni, que les Annales pascales du Mont Saint-Michel $\left(\mathrm{M}_{3}{ }^{*}\right)$ ont été composées par celui-ci en 1154 afin de lui fournir un cadre chronologique lors de la rédaction des notices abbatiales du De abbatibus. Mais avant de passer à l'étude de ces deux dernières étapes, il convient au préalable de formuler deux observations induites des résultats obtenus lors de l'étape 2 :

1. On notera tout d'abord qu'aucune source montoise du XII ${ }^{e}$ siècle ne mentionnait Thierry comme le successeur d'Hildebert II en 1023: toutes concordent, en effet, à faire d'Aumode ce successeur, ce que nous savons aujourd'hui être

69. Il s'agit d'une reconstitution: de très légers décalages peuvent être observés au niveau du tracé de certaines lettres. Même à la lumière ultraviolette, une lecture aussi nette reste impossible: seules des portions de lettre ont été conservées, et du fait de la surcharge, aucune lettre n'est entièrement visible. L'état présenté dans la partie centrale, au bas de la figure $\mathrm{n}^{\circ} 2$, donne cependant une bonne idée de ce qu'il est possible d'observer et de reconstituer en combinant lecture à la lumière blanche et lecture à la lumière ultraviolette. 
une erreur. Ce consensus conduit à dater assez tôt l'interversion des abbatiats de Thierry et d'Aumode dans le catalogue des abbés du Mont Saint-Michel ${ }^{70}$ : au plus tard au début du XII ${ }^{e}$ siècle, à l'époque où le copiste des Annales $d u$ Mont Saint-Michel ( $\left.\mathrm{M}_{2}\right)$ a lui-même enregistré cette erreur dans son texte, c'est-à-dire en 1116; au plus tôt dans le dernier tiers du $\mathrm{XI}^{\text {e }}$ siècle, à l'époque de la grande activité historiographique de l'auteur de l'Introductio monachorum. Le Catalogue du Mont Saint-Michel put, en effet, difficilement être élaboré avant cette époque, l'interversion de deux abbatiats de la période 1023-1033 n'étant guère envisageable moins d'un demi-siècle après les faits, alors que des témoins de l'époque en question étaient toujours en vie. Cette interversion, vraisemblablement introduite dans le catalogue entre 1075 et 1116 environ, n'est donc pas imputable à Robert de Torigni ou à ses contemporains: ces derniers ne furent que les victimes des erreurs transmises par leurs sources. Ce constat permet de caractériser ainsi le travail d'interpolation de Robert de Torigni dans le ms 211: lorsqu'il dispose d'une source écrite, l'abbé du Mont Saint-Michel la suit, qu'elle soit ou non fautive; mais lorsqu'il n'en a pas, il s'est abstenu de combler les vides artificiellement. La fiabilité de ses interpolations est donc directement tributaire de la qualité des sources qu'il avait sous la main et qu'il a mises à contribution.

2. On notera ensuite que malgré son caractère tardif $\left(\mathrm{XV}^{\mathrm{e}}\right.$ siècle), le ms Avranches, Bibl. patrimoniale, 213 se révèle extrêmement précieux: outre le fait qu'il renferme le seul témoin connu du De abbatibus (fol. 178-181v) ainsi qu'une copie des Annales pascales du Mont Saint-Michel (fol. 170-173v) [deux œuvres produites en 1154 par Robert de Torigni], il nous transmet également la plus ancienne copie de la version interpolée du Liber de apparitione sancti Michaelis archangeli in Monte Gargano telle que l'a connue Robert de Torigni (fol. 95-97 $)^{71}$. Il conserve également une copie de la Revelatio ecclesiae sancti Michaelis archangeli in Monte qui dicitur Tumba (fol. [128-129]130-132V). Il contient surtout un état ancien de l'Introductio monachorum (fol. 133-138), ainsi que les plus anciens témoins conservés des Miracula sancti Michaelis (fol. 138-143v et 146-148v) et du De translatione et miraculis beati Autberti (fol. 143v-146), également connus de Robert de Torigni et vraisemblablement copiés directement sur l'original composé dans le dernier tiers du $\mathrm{XI}^{e}$ siècle. Le

70. Notons que l'ordre de la succession abbatiale a été correctement préservé dans le martyrologenécrologe du Mont Saint-Michel, copié au début du XIII ${ }^{e}$ siècle à partir d'un modèle plus ancien, remontant au moins au début du XI siècle, et aujourd'hui perdu (ms Avranches, Bibl. patrimoniale, 214, p. 72-73, XVI Kal. Iun. [= 17 mai]) : «Obierunt Theodericus, Almodus abbates».

71. Ce constat invite à se demander si Robert de Torigni pourrait être le responsable de l'interpolation du Liber de apparitione (Bibliotheca hagiographica latina (BHL) 5948): il est en effet tentant de lui attribuer l'introduction dans ce texte, figurant dans le ms 211, des noms du pape Gelasius, de l'empereur Zeno et de l'évêque de Siponto Laurentius, que l'on retrouve, dans le cas des deux premiers, dans le De abbatibus. Ce type de synchronisme est tout à fait dans l'esprit des autres interpolations imputables à Robert de Torigni. Ces informations figurent d'ailleurs dans l'autre version du Liber de apparitione qui a surtout circulé en Italie (BHL 5949). 
ms 213 semble donc reproduire assez fidèlement l'état des matériaux connus, utilisés et composés par Robert de Torigni lors de la rédaction du De abbatibus en 1154, ce qui en fait, du fait de la perte des originaux, un document d'un très grand intérêt.

\section{Étape 3 : établissement d'une table de concordance destinée à l'exploitation du chartrier et des archives du monastère (création des Annales pascales du Mont Saint-Michel)}

En disposant de la succession des abbés du Mont Saint-Michel dans un catalogue et surtout de la chronologie de leur succession abbatiale dans les Annales $d u$ Mont Saint-Michel (M2), Robert de Torigni était désormais en possession des matériaux indispensables pour constituer l'ossature et la trame du De abbatibus: il pouvait à présent structurer son texte en organisant ses notices par abbatiat, à partir de la date d'accession de chaque abbé. Il ne lui restait alors qu'à enrichir chaque notice grâce aux informations que lui fournissaient les archives de l'abbaye.

Alors qu'il avait à sa disposition ces instruments et ces sources, un fait ne manque pas de surprendre: pour composer son ouvre, Robert de Torigni n'utilisa, le plus souvent, qu'indirectement les Annales du Mont Saint-Michel du ms 211 (M2) pourtant annotées par lui; il préféra en effet se servir prioritairement d'une copie adaptée de celles-ci, introduite en marge d'un tableau de comput: les Annales pascales du Mont Saint-Michel $\left(\mathrm{M}_{3}^{*}\right)$. Il convient donc de s'interroger sur les raisons d'un tel choix.

Les Annales du Mont Saint-Michel (M2 = ms Avranches, Bibl. patrimoniale, 211, fol. $67-77 \mathrm{v}$ ), copiées en $1116^{72}$ par un moine anonyme de ce monastère sur la base des Annales de la cathédrale de Rouen, avaient un inconvénient majeur: leur auteur n'avait pas jugé indispensable de transcrire l'ensemble des données de comput fournies par son modèle. L'annaliste avait pourtant, au départ, commencé son travail en reproduisant fidèlement les tables pascales servant de support aux annales rouennaises: sur le premier feuillet de son cahier (fol. 67-67v: années 1 à 76), il a reproduit le contenu de la première colonne, puis des suivantes, jusqu'à la sixième ${ }^{73}$. Mais il a ensuite rapidement

72. Dom Laporte appelle abusivement ces annales les Annales du Mont de 1214, reculant ainsi d'un siècle l'époque de leur rédaction primitive, en 1116 (1214 est en fait l'année de la dernière addition insérée de manière contemporaine, tandis que 1292 est la dernière année de l'incarnation de la table pascale prévisionnelle). Il leur confère ainsi implicitement une moindre importance par rapport à la copie tardive des Annales pascales du Mont Saint-Michel, qui en dérivent, mais qu'il désigne sous le nom d'Annales du Mont de 1154 (voir LAPORTE, 1967, p. 267-275). Nous verrons plus loin qu'en privilégiant ces dernières annales, Dom Laporte a favorisé la date de 1053 pour la mort de Raoul, date qui n'a aucune raison d'être retenue puisqu'il s'agit d'une erreur de copie introduite tardivement en fin de chaîne des annales montoises.

73. Ces six colonnes contiennent la succession des empereurs romains (Imperatores), le millésime ou année de l'incarnation (Anni domini), l'indiction (Indictio), la date de Pâques ou terme pascal (Termini), les concurrents (Concurr.) et le cycle pascal (Ciclus). 
interrompu ce travail jugé trop fastidieux: juste après avoir reproduit le titre de la septième colonne (Dies de luna), et sans prendre la peine de reporter les informations contenues dans celle-ci, il retranscrit les notes annalistiques d'une huitième colonne à laquelle il ne donne pas de titre. À partir du feuillet suivant, il se contente de mentionner le millésime comme seul repère chronologique. Ainsi, du fol. 68 au fol. $73 \mathrm{v}$ - feuillets couvrant les années 77 à 981 -, il ne reproduit que les années exprimées dans l'ère chrétienne, organisant désormais sa page sur deux colonnes. Dans chaque colonne figure au centre l'année de l'Incarnation, avec de part et d'autre deux espaces réservés, destinés à recevoir des notes annalistiques. Puis, du fol. 74 au milieu du fol. $75 \mathrm{~V}-$ feuillets couvrant les années 982 à 1116 -, les pages ne présentent plus qu'une seule colonne afin de réserver davantage d'espace à des notes annalistiques marginales de plus en plus abondantes. Dans cet objectif, une petite marge - à gauche - et une grande marge - à droite - ont été ménagées de part et d'autre du millésime. Les notes marginales sont de plus en plus nombreuses et de plus en plus longues à mesure que l'on se rapproche de l'année 1116, contemporaine de la rédaction. Les notes annalistiques inscrites de première main s'arrêtent cependant à l'année 1112, et comme nous l'avons vu lors de l'étude de l'étape 2, la note de l'année 1117 a été ajoutée par un continuateur. À partir de ce point, c'est-à-dire du milieu du fol. 75v, jusqu'au fol. $77 \mathrm{v}$ - feuillets couvrant les années 1117 à 1292 -, l'auteur a de nouveau trouvé utile de reproduire intégralement les données de comput que lui fournissait son modèle ${ }^{74}$. Ce choix semble de prime abord étrange, puisqu'il s'était abstenu de les reproduire entre l'année 77 et l'année 1116. Ces informations permettaient en fait de calculer la date mobile de Pâques et celle des principales fêtes chrétiennes qui en découlaient. Le choix de fournir de nouveau les données du comput pascal prouve que le copiste souhaitait prévoir à l'avance la date de Pâques pour les années ultérieures. Cette copie fut donc précisément réalisée en $1116^{75}$. En ne reproduisant pas intégralement les tables pascales de leur modèle et en ne fournissant pas de données de comput sur la période 77-1116, les Annales du Mont Saint-Michel du ms 211 n'offraient pas la possibilité d'établir de synchronismes entre l'ère chrétienne, exprimée en fonction de l'année de l'incarnation du Christ, et les autres formes de datation en usage à cette période - en particulier à l'aide de l'indiction, de l'épacte et du concurrent ${ }^{76}$. Or, sans une table chronologique permettant d'effectuer des synchronismes avec les

74. En réalité, le copiste de 1116 s'est contenté de copier la table pascale sur la période 1116-1173 (fol. 75v-76). Un continuateur a poursuivi cette table de comput prévisionnel sur la période 11741292 (fol. 76v-77v). À ce sujet Garand, Grand et Muzerelle, 1984, p. 77.

75. Le copiste n'a pas jugé utile de conserver les éléments permettant de calculer la date de Pâques pour les années déjà écoulées. La table pascale couvrant la période 1117-1173 a été copiée par lui dès 1116 (inscription de première main), mais les notes annalistiques ajoutées sur cette même période ont été inscrites après 1116 par différents continuateurs (ajouts de seconde main).

76. Le cartulaire du Mont Saint-Michel ( $\mathrm{ms}$ Avranches, Bibliothèque patrimoniale, 210) conserve, par exemple, 17 actes datés à l'aide de l'indiction (KeAts-Rohan, 2006, p. 39). Il est probable que le chartrier contenait de nombreux autres actes, aujourd'hui perdus, eux aussi datés de cette façon ou au moyen d'autres systèmes de datation. 
autres formes de datation en usage avant 1117, il était difficile, voire impossible, d'organiser et d'exploiter convenablement l'ensemble de la documentation produite avant cette date et conservée dans le chartrier et les archives de l'abbaye. L'élaboration des Annales pascales du Mont Saint-Michel $\left(\mathrm{M}_{3}{ }^{*}\right)$ avait donc pour principal objectif de combler ce manque ${ }^{77}$.

Les Annales pascales du Mont Saint-Michel $\left(\mathrm{M}_{3}{ }^{*}\right)$ sont aujourd'hui perdues ${ }^{78}$, mais nous pouvons les reconstituer intégralement grâce à la survivance de quatre autres annales qui leur sont étroitement liées, soit en tant que sources $\left(n^{\text {os }} 1-3\right)$, soit en tant que copie $\left(\mathrm{n}^{\circ} 4\right)$ :

1. les Annales pascales $d u$ Bec (B): des tables pascales couvrant au moins la période 1-1154 et renfermant en marge les Annales $d u$ Bec ont servi de source pour constituer la table de comput servant de support aux Annales pascales du Mont Saint-Michel $\left(\mathrm{M}_{3}^{*}\right)$. Certaines notes marginales mentionnées dans les Annales du Bec pour la période 851-1154 furent, en effet, reproduites en marge des tables pascales du Mont, ce qui a permis d'identifier cette source: parmi ces notes, quelques-unes sont très caractéristiques et ne se trouvent que dans cette famille d'annales ${ }^{79}$. Il existe une copie moderne des notes annalistiques constituant les Annales $d u B e c$, soigneusement relevées par

77. Depuis Dom Laporte, la critique date la confection de ces annales, perdues dans leur forme originale, de l'abbatiat de Bernard et considère que les dernières années, jusqu'en 1154, sont des additions effectuées sous Robert de Torigni (voir LAPORTE, 1967, p. 267; KeATs-Rohan, 2006, p. 27; GAZEAU, 2007, II, p. 218). La présente étude montre que l'ensemble n'a pu être réalisé qu'en 1154, puisque ces annales utilisent comme sources les Annales du Mont Saint-Michel (M2) interpolées par Robert de Torigni à cette dernière date (ainsi que les Annales $d u$ Bec, copiées en 1136 et continuées jusqu'en 1154).

78. Faut-il identifier ces Annales pascales du Mont Saint-Michel $\left(\mathrm{M}_{3}{ }^{*}\right)$ avec l'une des annales contenues dans le Chronicon majus sancti Michaelis de Monte utilisé comme source par dom Jean Huynes et Dom Thomas Le Roy au XVII ${ }^{\mathrm{e}}$ siècle, et qui a depuis disparu (cf. BIsson Marie, 2015)? Ce rapprochement me semble d'autant plus intéressant que ces mêmes auteurs citent également un Chronicon minus sancti Michaelis de Monte qui renferme notamment les Annales du Mont Saint-Michel (M2 = ms Avranches, Bibliothèque patrimoniale, 211, fol. 67-77v). L'enquête sur ce point reste à faire.

79. Ainsi, les notes qui apparaissent aux années 851 et 1047 sont étroitement apparentées aux notes des Annales du Bec. Parmi les annales normandes dérivant de celles de la cathédrale de Rouen, les Annales du Bec sont les seules à formuler ainsi la note de l'année 851: Venit Hastingus in regnum Francorum. Les Annales de Rouen, éditées par Philippe Labbe (LABBE, 1657, p. 365), donnent venerunt Normanni in Sequanam, \& iterum venerunt alii Normanni, information reprise intégralement par les Annales de Jumièges, mais seulement partiellement par les Annales de SaintÉvroult et les Annales de Saint-Étienne de Caen: Hoc tempore venerunt Normanni in Sequanam (voir Holder-EGger, 1882, p. 494-495). De plus, alors que les Annales de Rouen éditées par Labbe et les Annales de Saint-Évroult donnent simplement Bellum apud Vallumdunas à l'année 1047, les Annales du Bec précisent quant à elles: Factum est bellum in loco qui dicitur Walesdunas inter comitem Willelmum Normannorum et Widonem, filium Rainaldi comitis Burgundiae, cognatum ejus. Cela rejoint la note rapportée par les Annales mineures du Mont Saint-Michel (M4: ms 213, fol. 170v), copiée sur les Annales pascales du Mont Saint-Michel $\left(\mathrm{M}_{3}^{*}\right)$ : Factum est bellum apud Walesdunas a Guillermo, duce Normannorum, contra Guidonem comitem, cognatum suum. 
Dom Jouvelin sur l'exemplaire original avant sa perte lors de la Révolution (ms Paris, BnF, lat. 13905, p. 138-139 ou fol. 72v-73). Ces Annales pascales du Bec dérivaient vraisemblablement des Annales pascales de la cathédrale de Rouen (perdues) et elles étaient semble-t-il très proches, surtout du point de vue de la présentation, des Annales pascales de Saint-Évroult (ms Paris, BnF, lat. 10062, fol. 138-160), elles-mêmes issues des annales rouennaises. Ce lien étroit entre les Annales pascales du Mont Saint-Michel $\left(\mathrm{M}_{3}{ }^{*}\right)$ et les Annales $d u$ Bec confirme une nouvelle fois le rôle décisif joué par Robert de Torigni, ancien moine et prieur du Bec devenu abbé du Mont Saint-Michel ${ }^{80}$, dans l'élaboration des matériaux indispensables à la rédaction du De abbatibus.

2. les Brèves annales mineures du Mont Saint-Michel (M1): les Annales pascales du Mont Saint-Michel $\left(\mathrm{M}_{3}{ }^{*}\right)$ ne dérivent qu'indirectement des Brèves annales mineures du Mont Saint-Michel $(\mathrm{M} 1=\mathrm{ms}$ Paris, BnF, lat. 11830, fol. 2v), par l'intermédiaire des annales qui suivent $\left(\mathrm{M}_{2}\right)$. Ces brèves annales seront malgré tout prises en compte ici, car, composées peu après 1035, elles se trouvent à l'origine de la tradition textuelle de plusieurs notes, élaborées de façon contemporaine ou de peu postérieure aux faits rapportés, ce qui leur confère une importance majeure.

3. les Annales du Mont Saint-Michel (M2): les Annales pascales du Mont SaintMichel $\left(\mathrm{M}_{3}{ }^{*}\right)$ furent complétées grâce à de nombreuses notes extraites des Annales du Mont Saint-Michel (M2 = ms 211, fol. 67-77v) copiées en 1116 et interpolées en 1154 par Robert de Torigni (cf. étape 2).

4. les Annales mineures du Mont Saint-Michel (M4): les Annales pascales du Mont Saint-Michel $\left(\mathrm{M}_{3}{ }^{*}\right)$, perdues, ont servi de modèle aux Annales mineures $d u$ Mont Saint-Michel $\left(\mathrm{M}_{4}=\mathrm{ms} 213\right.$, fol. 170-173V), copiées au XVe siècle. L'auteur de cette copie tardive n'a pas reproduit la table pascale de son modèle et n'a conservé que le millésime comme système de datation; il s'est contenté de transcrire les unes à la suite des autres, non sans quelques erreurs et omissions, les notes annalistiques marginales figurant de part et d'autre de cette table pascale.

Un déplacement de note observable entre les Annales du Mont Saint-Michel (M2) et les Annales mineures du Mont Saint-Michel (M4) permet de reconstituer la mise en page adoptée dans les Annales pascales du Mont Saint-Michel $\left(\mathrm{M}_{3}{ }^{*}\right)$, qui dérivent des premières et ont servi de modèle aux secondes. Dans les annales M2 figure, dans la marge de gauche du fol. $74 \mathrm{~V}$ et en face de l'année 1054, une note sur la bataille de Mortemer (Bellum apud Mare Mortuum). Un peu

80. Robert de Torigni, alors qu'il fut moine puis prieur du Bec, semble être intervenu dans la rédaction des Annales du Bec (GAZEAu, 2007, II, p. 221). Dérivant indirectement des Annales de la cathédrale de Rouen, ces annales furent copiées avant 1109 puis complétées de nouvelles notes aux années 1135, 1136, 1142, 1146 et 1154, c'est-à-dire alors que Robert de Torigni était encore moine du Bec (Delisle, 1898, p. 211; Alexander, 2011, p. 149-158). 
plus loin, dans la marge de droite du fol. 75 et en face de l'année 1063, Robert de Torigni a ajouté le début de l'abbatiat de Renouf, neuvième abbé du Mont (Rannulfus, .IX $X^{u s} . a b b a s$ ). Ces informations, enrichies notamment à l'aide du catalogue des abbés du Mont Saint-Michel dans le cas de la note concernant Renouf, se retrouvent l'une à la suite de l'autre à l'année 1053 des annales $\mathrm{M}_{4}$ (ms 213, fol. 170v) : Factum est bellum apud Mortuum Mare. Eodem anno Radulpho abbati successit Rannulphus, monachus ejusdem loci. On observe donc, d'une part, un passage de l'année 1054 à l'année 1053 pour la bataille de Mortemer, d'autre part, un passage de l'année 1063 à l'année 1053 pour le début de l'abbatiat de Renouf ${ }^{81}$. Cette dernière note aurait logiquement dû se retrouver associée à celle de l'année 1063 - présente aussi bien dans M2 (ms 211, fol. $75 \mathrm{r}$ ) que dans $\mathrm{M}_{4}$ (ms 213, fol. 170v): Subjugata est Cenomannis comiti Normannorum Guillelmo -, ce qui ne fut pas le cas. Ce double décalage et cette absence de regroupement ne semblent possibles que si ces trois notes n'avaient pas encore été réunies au moment de la conception des Annales pascales $d u$ Mont Saint-Michel $\left(\mathrm{M}_{3}{ }^{*}\right)$ et si elles figuraient toujours alors séparément dans des marges distinctes. Ce type de décalage et de réunion de notes rapportées à des dates éloignées fut favorisé par un changement de structure d'annales: le passage d'annales pascales (avec des notes marginales inscrites indépendamment de part et d'autre d'une table de comput) à des annales mineures (regroupement de notes marginales indépendantes dans une seule notice annuelle) contribue assurément à la production de ce type d'erreur. Il en résulte que les Annales pascales du Mont Saint-Michel $\left(\mathrm{M}_{3}^{*}\right)$ se présentaient vraisemblablement sous la forme d'une table pascale, avec deux marges destinées à recevoir des notes annalistiques de part et d'autre. La marge de gauche servait vraisemblablement à enregistrer les faits relatifs aux ducs de Normandie ainsi que les événements touchant le monde séculier; la marge de droite était, quant à elle, réservée à l'enregistrement des faits relatifs aux abbés du Mont Saint-Michel ainsi que des événements touchant l'histoire de ce monastère. On retrouve ainsi une partition monde laïque/monde monastique comparable à la partition monde séculier / monde ecclésiastique qui avait été créée dans les Annales de Rouen sous Maurille (1054/1055-1067), puis enrichies sous Jean d'Avranches (1067-1079).

81. Ce glissement est à l'origine de l'hypothèse de la fin d'abbatiat de Raoul en 1051 ou en 1053 et du début de l'abbatiat de Renouf en 1053 ou en 1055. Cette hypothèse repose donc sur une erreur de copie dans des annales se situant en fin de tradition textuelle (les annales du ms 213 [M4] ne sont qu'une copie tardive des Annales pascales du Mont Saint-Michel perdues [ $\left.\mathrm{M}_{3}^{*}\right]$, dérivant ellesmêmes d'une interpolation des annales du ms 211 [M2]). La date de 1063, introduite par Robert de Torigni en 1154, était d'ailleurs déjà erronée, comme nous le verrons plus loin. Il n'y a donc aucune raison de retenir les dates de 1051, 1053 ou 1055 pour les successions abbatiales de Raoul et de Renouf, comme l'a proposé Dom Laporte en 1967 (LAPORTE, 1967, p. 269 et 273-274; nous avons d'ailleurs observé en plusieurs endroits la tendance de Dom Laporte à réduire la période d'abbatiat de Raoul et à rallonger celle de Renouf: alors qu'il parle à la p. 273 de 1055-1056 pour la mort de Raoul et de 1057 ou 1058 pour l'élection de Renouf, il retient dans sa liste critique, p. 269, respectivement 1053 et 1055) et comme l'a fait à sa suite Véronique Gazeau (GAzEAU, 2007, II, p. 207). Au sujet de la date de la mort de Raoul, cette dernière conclut pourtant p. 31, n. 15 : «D’autres dates ont été suggérées, 1053 ou 1055. Celle de 1058 semble préférable». 
Cette partition fut ensuite plus ou moins respectée dans les annales monastiques qui dérivent de ces annales rouennaises, en particulier dans les Annales de SaintÉvroult ${ }^{82}$. Elle se rapproche d'ailleurs de celle encore partiellement observable dans $\mathrm{M}_{2}{ }^{83}$, mais qui n'était déjà plus respectée scrupuleusement par le copiste de 1116, puis par ses continuateurs et ses interpolateurs successifs.

À partir des Annales $d u$ Bec, des Brèves annales mineures du Mont SaintMichel (M1), des Annales du Mont Saint-Michel (M2) et des Annales mineures du Mont Saint-Michel (M4), il est possible de reconstituer les Annales pascales $d u$ Mont Saint-Michel perdues $\left(\mathrm{M}_{3}{ }^{*}\right)$, élaborées en 1154 par l'abbé Robert de Torigni et qui servirent de source principale lors de la composition du De abbatibus (voir la reconstitution synoptique élaborée sous forme de table, en annexe).

Une analyse de l'ensemble des informations fournies dans ces Annales pascales du Mont Saint-Michel $\left(\mathrm{M}_{3}^{*}\right)$ montre que les données transmises sont loin d'avoir toutes été reprises dans le De abbatibus. Seuls les renseignements sur le Mont Saint-Michel et ses abbés ont été systématiquement exploités par Robert de Torigni. Le reste a presque toujours été écarté. C'est en particulier le cas des informations concernant la succession dynastique des comtes de Rouen, ducs de Normandie et rois d'Angleterre, mais aussi les généalogies liant cette puissante famille aux comtes de Rennes et ducs de Bretagne (année 996) ${ }^{84}$. C'est aussi le cas des événements militaires, tels que les batailles et les conquêtes ${ }^{85}$ qui eurent des répercussions importantes sur l'évolution et la réorganisation des espaces tant politiques que religieux ${ }^{86}$. Cela ne signifie pas pour autant que ces informations ne furent pas utiles à l'élaboration du De abbatibus. Ces données constituent, en effet, des repères chronologiques précieux permettant de dater au moins approximativement les documents de la pratique (chartes, diplômes, lettres, etc.) appartenant aux archives de l'abbaye du Mont Saint-Michel. Elles permettent de les situer sur une échelle de temps linéaire exprimée dans l'ère chrétienne. Ces documents, souvent datables uniquement par rapport aux individus mentionnés - grâce en particulier aux noms des bienfaiteurs et des souscripteurs intervenant dans les affaires du monastère -, pouvaient ainsi être rattachés à une période donnée en fonction du règne des comtes de Rouen, des ducs de Normandie et des rois d'Angleterre, ainsi que des comtes de Rennes et des ducs de Bretagne ou encore des abbés du Mont Saint-Michel. À tel point que la réorganisation des archives de l'abbaye pour une meilleure administration du patrimoine du monastère pourrait sembler difficile à entreprendre sans disposer

82. Voir les titres des premières (Imperatores vel reges) et des dernières colonnes (papę romani) dans les Annales de Saint-Évroult (ms Paris, BnF, lat. 10062, fol. 138-160).

83. Titres partiellement reproduits au début des Annales du Mont Saint-Michel (ms 211, fol. 67): seul le titre de la première colonne a été renseigné (Imperatores), la dernière colonne ne portant pas de titre.

84. Tableau généalogique de la dynastie des comtes de Rennes: Guillotel, 2014, p. 140.

85. Bataille de Val-ès-Dunes en 1048 (sic 1047), bataille de Mortemer en 1054, annexion du Maine en 1063, conquête de l'Angleterre en 1066, bataille de Tinchebray en 1106, bataille de Brémule en 1119, prise de Rouen en 1144.

86. Le patrimoine de l'abbaye a, en effet, souffert des conséquences de ces événements. 
d'un outil spécifiant la succession des puissants (comtes, ducs, rois et abbés) en marge de tables pascales. Or, les moines du Mont n'ont disposé de telles tables de comput qu'en 1154 (Annales pascales du Mont Saint-Michel M3 ${ }^{*}$, copiées à partir des tables pascales du Bec) et ne paraissent pas en avoir possédé d'autres auparavant.

Ce constat semble, de prime abord, aller dans le sens de la composition du cartulaire historique du Mont Saint-Michel (ms Avranches, Bibl. patrimoniale, 210) au tout début de l'abbatiat de Robert de Torigni (en 1154-1155), suivant l'opinion de Léopold Delisle ${ }^{87}$, plutôt qu'entre la fin de l'abbatiat de Bernard et le début de celui Geoffroy (vers 1145-1150), comme l'ont proposé plus récemment Katharine Keats-Rohan et Thomas Bisson ${ }^{88}$. L'examen minutieux de ce cartulaire, compte tenu des arguments codicologiques, paléographiques, artistiques et historiques avancés par ces deux chercheurs, leur donne pourtant raison. La difficulté rencontrée par l'auteur du cartulaire pour classer ses chartes dans un ordre chronologique strict prouve qu'il ne disposait pas alors d'un outil aussi fiable que les Annales pascales du Mont Saint-Michel $\left(\mathrm{M}_{3}{ }^{*}\right)$, et qu'il a dû se résoudre à un classement chronologique assez approximatif de ses sources. La réorganisation des archives montoises semble accompagner l'effort de l'abbé Bernard pour la reprise en main de la gestion et de l'administration du patrimoine du monastère ${ }^{89}$. Il faut donc, à mon avis, suivre Katharine Keats-Rohan et surtout Thomas Bisson et considérer avec eux que la rédaction primitive du cartulaire du Mont Saint-Michel se place à la fin de l'abbatiat de Bernard (1131-1149), vraisemblablement peu avant $1149^{90}$, et qu'elle a été poursuivie sous l'abbatiat de Geoffroy jusqu'en $1150^{91}$. Cette rédaction

87. Il s'agit de l'opinion traditionnelle, suivie par la majorité des historiens depuis les travaux de Léopold Delisle sur la Chronique de Robert de Torigni, mais remise en cause par les travaux récents (cf. note suivante).

88. Keats-Rohan, 2006, p. 9-26 (principalement p. 9-11); Bisson Thomas, 2011, p. 61-73, en particulier p. 65-66; BIsson Thomas, à paraître.

89. Ce travail est bien décrit par Robert de Torigni dans la notice du De abbatibus qu'il consacre à cet abbé: d'après ce témoignage, Bernard a mis un terme aux «mauvaises coutumes» imposées par les laïcs, et il s'est efforcé de récupérer les possessions de l'abbaye qui avaient été négligées ou dilapidées par ses prédécesseurs. Pour que ces mesures fussent efficaces, il dut vraisemblablement entreprendre la réorganisation des archives et la rédaction du cartulaire historique (BISsoN Thomas, 2011, p. 61-73).

90. Thomas Bisson fait à juste titre remarquer que l'unité et l'homogénéité de la mise en page, du texte et du décor sur les fol. 4v-112 (même copiste et même artiste tout au long) jouent en faveur d'une réalisation sur une courte période, sans doute de quelques années seulement (approximativement 1145-1150). Cf. Bisson Thomas, 2011, p. 61-73; Bisson Thomas, à paraître.

91. Robert de Torigni aurait difficilement pu se consacrer à la réorganisation des archives et à la rédaction du cartulaire historique dès son arrivée au Mont en mai 1154. La rédaction du ms 210, brusquement interrompue en 1150 au bas du fol. 112 (vraisemblablement au moment de la mort de l'abbé Geoffroy), n'a d'ailleurs été reprise qu'après 1155, et probablement seulement en 1157 , avant le départ de Robert de Torigni pour l'Angleterre (fol. 112V-115). La forme adoptée trahit un projet différent de celui qui avait guidé la confection de l'œuvre primitive. Le contenu - il s'agit de 36 transactions "fiscales", sortes de comptes budgétaires du monastère signalant valeurs courantes, paiements et dettes, portant sur les années 1155-1157 -, le style de l'écriture et le décor du premier continuateur marquent une rupture très nette avec la première partie du cartulaire 
précède donc de quelques années l'élaboration des Annales pascales $d u$ Mont Saint-Michel $\left(\mathrm{M}_{3}^{*}\right)$ et la rédaction primitive du De abbatibus, qu'il convient de situer au tout début de l'abbatiat de Robert de Torigni, en 1154. Le cartulaire historique, brusquement interrompu en 1150, fut à n'en pas douter l'une des sources montoises importantes que connut et utilisa Robert quand il composa ses premières œuvres historiques une fois devenu abbé du Mont ${ }^{92}$.

\section{Étape 4: rédaction de la partie primitive du De abbatibus (période couverte: 506-1153)}

Le catalogue des abbés du Mont Saint-Michel, les Annales du Mont Saint-Michel (M2) et les Annales pascales du Mont Saint-Michel $\left(\mathrm{M}_{3}{ }^{*}\right)$ forment un ensemble de matériaux et d'instruments créés ou complétés par Robert de Torigni en vue, d'une part, de constituer l'ossature et la structure du De abbatibus, d'autre part, d'exploiter au mieux les archives et les livres de son monastère afin d'enrichir les notices abbatiales constituant le cour de cette œuvre. À présent qu'il dispose de bornes lui permettant de déterminer précisément les limites de chacune de ses notices abbatiales, Robert de Torigni va, en effet, mettre abondamment à contribution les livres et les archives du Mont afin de compléter au mieux chaque notice d'abbé. Les Annales pascales du Mont Saint-Michel $\left(\mathrm{M}_{3}{ }^{*}\right)$, grâce aux tables de comput qu'elles renferment et aux repères chronologiques qu'elles indiquent en marge, vont lui permettre de rattacher les documents exploités aux notices correspondantes. Nous allons maintenant suivre pas à pas la façon dont il a procédé, en identifiant les sources qu'il a sollicitées. Notre objectif est également de mettre en évidence les difficultés et les écueils auxquels il fut confronté et de déterminer ainsi les choix qu'il fut amené à faire, afin de lever ou de contourner ces obstacles. Il sera possible, au terme de cette reconstitution, de proposer une actualisation des chronologies abbatiales retenues à ce jour par les historiens (voir l'appendice).

Les deux longues notes portant sur les années 506 et 708 du De abbatibus constituent une sorte d'introduction à l'ouvrage: elles concernent les premières apparitions de l'archange saint Michel en Orient et en Occident. Ces informations n'ont donc qu'un rapport assez lointain avec la succession des abbés du Mont Saint-Michel constituant le cœur de l'œuvre. Pour l'élaboration de la notice relative à l'apparition de saint Michel «en Orient » sur le Mont Gargan en 506, il serait tentant de penser que l'auteur du De abbatibus a directement eu recours à

(fol. 4V-112), dont l'écriture (une caroline arrondie, élancée et archaïque) et les enluminures à pleine page s'inspirent des productions montoises de la première apogée du scriptorium au siècle précédent (période 1033-1085, correspondant aux abbatiats de Suppon, Raoul et Renouf). Une autre main a complété ce premier travail de continuation par l'adjonction de 13 nouvelles transactions opérées entre 1157 et 1159 (fol. 115V-117). Les moines du Mont ont ensuite décidé de reprendre la copie de chartes, et l'on observe de nombreux changements de main jusqu'à la fin du volume (BIsson Thomas, 2011, p. 65-71).

92. Je tiens à remercier Thomas Bisson pour les échanges que nous avons eus sur ces questions, d'abord lors de son passage à Avranches en mai 2016, puis par courriel en septembre et octobre 2016. 
la version interpolée du Liber de apparitione sancti Michaelis in Monte Gargano ${ }^{93}$. En réalité, Robert de Torigni n'a fait que reprendre, en l'adaptant légèrement, l'information déjà transmise par ses soins dans un document dérivant directement de cette version interpolée du Liber de apparitione: l'entrée figurant à l'année 506 des Annales pascales du Mont Saint-Michel $\left(\mathrm{M}_{3}{ }^{*}\right)$. Un constat comparable peut être observé pour l'élaboration de la notice de l'année 708, qui en constitue le prolongement direct, en mentionnant l'apparition de saint Michel en Occident, sur le Mont Tombe. Ce n'est pas non plus la Revelatio ecclesiae sancti Michaelis archangeli in Monte qui dicitur Tumba ${ }^{94}$ qui a directement servi de modèle, mais de nouveau ce même document, qui en dérive (d'ailleurs peutêtre de façon seulement indirecte) ${ }^{95}$. Robert de Torigni a repris, en l'adaptant, l'entrée apparaissant à l'année 708 de ses Annales pascales du Mont Saint-Michel $\left(\mathrm{M}_{3}{ }^{*}\right)$. Cependant cette source ne fut pas exploitée seule: l'auteur s'est servi aussi des Annales du Mont Saint-Michel (M2), afin de compléter son information en établissant deux nouveaux synchronismes. Son objectif était de fournir une information prolongeant celle donnée dans la note précédente, pour l'année 506. Celle-ci mentionnait, en effet, l'empereur et le pape qui exerçaient alors leur autorité temporelle et spirituelle sur la chrétienté. Les Annales du Mont SaintMichel (ms 211, fol. 72) lui fournissent ainsi le nom de l'empereur Justinien, dont le règne est indiqué entre 704 et 710 , et le nom du pape Jean, dont le pontificat est spécifié entre 708 et 710 . Puis Robert de Torigni complète la fin de la note de l'année 708 à l'aide de l'Introductio monachorum. Il en profite au passage pour préciser le nombre d'années ayant séparé l'établissement des chanoines en 708 de leur remplacement en $966^{96}$.

Après cette introduction relative aux apparitions de saint Michel sur le Mont Gargan et sur le Mont Tombe, l'œuvre débute véritablement avec la rédaction des notices des abbés qui se succédèrent à la tête du Mont SaintMichel de 966 à 1153. La longue notice rédigée pour l'année 966 n'est en fait qu'un assemblage d'informations tirées des Annales pascales du Mont SaintMichel $\left(\mathrm{M}_{3}^{*}\right)$ et de l'Introductio monachorum ${ }^{97}$. Pour l'année 991, les Annales pascales du Mont Saint-Michel $\left(\mathrm{M}_{3}^{*}\right)$ sont de nouveau sollicitées, mais Robert

93. Poulle, Bouet et Desbordes, 2009, p. 113-135, en particulier p. 125, n. 2.

94. Ibid., p. 29-109.

95. L'Introductio monachorum (ibid., p. 147-225, en particulier p. 204-205) pourrait, en effet, avoir servi d'intermédiaire entre la Revelatio et les Annales pascales du Mont Saint-Michel.

96. D'après l'Introductio monachorum, dès la dédicace du sanctuaire, l'évêque Aubert y avait installé une communauté de chanoines. Ceux-ci auraient tenu ce sanctuaire pendant «deux cents ans et davantage» avant d'être remplacés par des moines suivant la volonté du duc de Normandie Richard I $^{\text {er }}$ en 965 - année que Robert de Torigni corrige en 966, sans doute d'après le diplôme de Lothaire (Poulle, Bouet et Desbordes, 2009, p. 204-205). En indiquant 263 ans, l'auteur du De abbatibus s'est efforcé de préciser sa source. Toutefois, entre 708 et 966, 258 ans, et non 263, se sont écoulés. Il faut envisager ici soit une erreur de calcul de la part de l'auteur de De abbatibus, c'est-à-dire de Robert de Torigni, soit une erreur de lecture ou de transcription du copiste du $\mathrm{XV}^{\mathrm{e}}$ siècle (substitution du chiffre « $\mathrm{X}$ » au chiffre « V» dans «CCLVIII», ayant conduit au nombre «CCLXIII»).

97. Poulle, Bouet et Desbordes, 2009, p. 202-223, en particulier p. 204-205 et 210-223. 
de Torigni exploite aussi conjointement les archives de son abbaye: elles lui indiquent, d'une part, que Mainard II avait été prieur du Mont sous l'abbatiat de son oncle homonyme ${ }^{98}$, d'autre part, que le monastère et ses bâtiments furent détruits par le feu pendant son abbatiat ${ }^{99}$. La notice de l'année 1009 est élaborée en suivant de nouveau les Annales pascales du Mont Saint-Michel $\left(\mathrm{M}_{3}{ }^{*}\right)$, mais l'auteur la complète d'une brève mention faisant référence à la redécouverte des reliques de l'évêque Aubert: sa source est ici le De translatione et miraculis beati Autberti $i^{100}$. L'élaboration des notes relatives aux années 506-1009 ne pose pas de problèmes particuliers à Robert de Torigni, qui donne sans difficulté les premières successions abbatiales, mais ne fournit toutefois que peu de renseignements sur les actes marquants des abbés Mainard I, Mainard II et Hildebert I. Les sources qu'il utilise pour composer le De abbatibus peuvent être facilement identifiées: elles proviennent exclusivement de traditions écrites ayant pour la plupart survécu.

Robert de Torigni est confronté à une première difficulté au moment d'établir la date du décès d'Hildebert I et celle de l'accession de son neveu homonyme Hildebert II. En précisant qu'il ignore en quelle année cette succession eut lieu, il reconnaît implicitement que les sources écrites à sa disposition sont muettes sur ce point. Cette précision révèle aussi qu'il ne cherche pas à fournir à tout prix une date, quitte à en forger une de toutes pièces ou à en proposer une de façon approximative ou arbitraire. Nous avons donc affaire à un auteur scrupuleux et intègre du point de vue de la chronologie, recherchant des informations exactes et précises, et préférant avertir ses lecteurs des limites de son travail plutôt que de dissimuler son manque d'information. Cette façon de procéder, qui doit théoriquement guider le travail de tout historien, permet de distinguer les endroits où l'auteur dispose de sources écrites de ceux où il n'en possède pas. Ce fait, qu'il convient de garder présent à l'esprit, est important pour l'interprétation des passages qui suivront. Robert de Torigni complète ensuite la notice relative à l'abbatiat d'Hildebert II par une allusion au célèbre miracle de la femme enfantant sur la grève, rapporté dans les Miracula sancti Michaelis ${ }^{101}$.

La première partie de la notice relative à l'année 1023, mentionnant Richard II et Hildebert II et la construction du nouveau monastère, est directement tirée des Annales pascales du Mont Saint-Michel $\left(\mathrm{M}_{3}{ }^{*}\right)^{102}$. Le reste de la

98. La source de cette information reste à identifier. Dans une charte du comte Conan de Rennes datée de 990 et mentionnant l'abbatiat de Mainard Ir apparaît un Mainardus prepositus qui pourrait bien être le neveu et successeur de cet abbé (Keats-Rohan, 2006, nº 3, p. 192-193; Poulle, Bouet et Desbordes, 2009, $\mathrm{n}^{\circ}$ 2, p. 382 ; Gulllotel, 2014, $\mathrm{n}^{\circ}$ 6, p. 161-167).

99. Les documents utilisés comme source n'ont pas survécu. Ils étaient encore connus de Thomas Le Roy au XVII ${ }^{\mathrm{e}}$ siècle, puisque celui-ci précise que l'incendie se produisit peu après l'installation de l'abbé Mainard II, en 992 (I, p. 97-98).

100. Poulle, Bouet et Desbordes, 2009, p. 248-253.

101. Ibid., p. 324-329.

102. Sur les bâtiments monastiques à l'époque ducale, voir SAPIN et al., 2008 et surtout la thèse de doctorat en préparation de Florence Margo (qui s'inscrit dans le prolongement de ses travaux antérieurs: MARGO, 2000, p. 23-31; MARGO, 2010, p. 369-378). 
notice, qui porte sur la période 1023-1033 et concerne les abbés Suppon, Aumode et Thierry, révèle indirectement une seconde difficulté rencontrée par l'auteur du De abbatibus: il s'agit, en effet, d'une reconstitution maladroite faite par Robert de Torigni pour tenter de concilier les informations contradictoires et erronées fournies par les sources dont il disposait. Il convient de passer en revue ces documents afin de comprendre comment l'abbé du Mont en est arrivé à cette reconstruction fautive, sensiblement éloignée des faits historiques tels qu'ils peuvent être aujourd'hui restitués.

Robert de Torigni disposait de deux sources indiquant par erreur Aumode comme le successeur d'Hildebert II : d'une part, le catalogue des abbés du Mont Saint-Michel, d'autre part, les Annales du Mont Saint-Michel (M2), dont la notice fut d'ailleurs reproduite presque à l'identique par ses soins dans les Annales pascales $d u$ Mont Saint-Michel $\left(\mathrm{M}_{3}{ }^{*}\right)^{103}$. Ces deux dernières sources annalistiques précisent l'année 1023 comme celle de cette succession. Le chartrier et le cartulaire de l'abbaye renferment par ailleurs un acte du comte et prince des Bretons Alain III indiquant qu'Aumode est toujours abbé du Mont en 1032 $2^{104}$. Grâce à ces documents, Robert de Torigni était en mesure d'en déduire qu'Aumode dirigea le Mont au moins de 1023 à 1032. Il savait aussi par ailleurs, grâce aux trois annales montoises $\left(\mathrm{M}_{1}, \mathrm{M}_{2}\right.$ et $\left.\mathrm{M}_{3}{ }^{*}\right)$, que Suppon fut consacré abbé en 1033. Il en conclut donc que Thierry, dont la direction du Mont est confirmée dans un acte non daté du cartulaire ${ }^{105}$, dirigea ce monastère seulement pendant quelques mois, entre les abbatiats d'Aumode et de Suppon, soit vers $1032-1033^{106}$. Cependant, dans le De abbatibus, Robert de Torigni s'abstient de mentionner l'année 1023 comme celle de l'accession d'Aumode et l'année 1032 ou 1033 comme celle de l'accession de Thierry. Pourquoi une telle réserve alors que ses sources principales le conduisaient logiquement à

103. Nous la retrouvons en effet dans sa copie $\mathrm{M}_{4}$.

104. Ms Avranches, Bibl. patrimoniale, 210, fol. 46-47; KeAts-Rohan, 2006, n 23, p. 104-105; Poulle, Bouet et Desbordes, 2009, $n^{\circ}$ 21, p. 396-397; Guillotel, 2014, nº 22, p. 209-211.

105. Ms Avranches, Bibl. patrimoniale 210, fol. 47-48; KeAts-Rohan, 2006, nº 24, p. 106-107; Poulle, Bouet et Desbordes, 2009, $\mathrm{n}^{\circ}$ 14, p. 390 ; Guillotel, 2014, n 17, p. 192-193 (charte d'Ansger et d'Hervé, dont la date de rédaction, vers 1023-1027, est précisément déduite de la mention de Thierry comme abbé du Mont).

106. Cette interprétation n'était pas contradictoire avec les Annales de Jumièges, qui placent à tort le décès de Thierry en 1036 (LAPORTE, 1954, p. 54-55). Outre un catalogue des abbés de Jumièges (un tel catalogue figurait autrefois au début du ms Paris, BnF, lat. 6042, comme l'indique encore la table du fol. 1: Nomina abbatum Gemeticensium), Robert de Torigni avait vraisemblablement à sa disposition les annales de ce monastère lorsqu'il écrivit ceci, au plus tard en 1154, dans son De immutatione ordinis monachorum: Willermus, filius ejus, Longa Spata, monasterium Gemmeticense, quod sanctus Philibertus construxerat, sed Hastingus paganus destruxerat, restauravit, in quo fuerunt abbates a sancto Philiberto usque ad exterminium ejusdem monasterii viginti, a restauratione vero, quae sub Martino abbate facta est, quem Gerloc, comitissa Pictavensis, cum duodecim monachis a monasterio Sancti Cypriani Pictavis misit Willermo, fratri suo, duci Normanniae, usque ad annum MCLIIII dominicae incarnationis, quo iste catalogus abbatiarum Normanniae factus est a nobis, fuerunt abbates XIIII, quorum ultimus fuit Eustachius, ejusdem loci monachus (ms Avranches, Bibl. patrimoniale, 159, fol. 172; Delisle, 1872-1873, t. 2, p. 191-192). La chronologie adoptée ici par Robert de Torigni est d'ailleurs celle suivie cinq cents ans plus tard par Arthur du Monstier (cf. DU Monstier, 1663, p. 384, n ${ }^{\text {os }} 4-5$ ). 
adopter de telles datations et que, pour les autres abbés, il s'efforce de donner la date de début d'abbatiat ${ }^{107}$ ? Cette hésitation trahit les incertitudes de l'auteur et révèle que Robert de Torigni, faisant preuve d'esprit critique, a été amené à mettre en doute les dates de 1023 et de 1032-1033 que lui fournissaient ses sources et qui semblaient pourtant s'imposer. Il savait sans doute que Suppon, disciple de Guillaume de Volpiano, avait été choisi par son maitre pour diriger l'abbaye du Mont Saint-Michel ${ }^{108}$. Il en a naturellement conclu que Suppon était intervenu au Mont avant la mort du grand abbé réformateur, donc avant le $1^{\mathrm{er}}$ janvier $1031^{109}$. L'intervention du moine de Fruttuaria au Mont devait donc se placer entre 1023 et 1031, alors qu'Aumode n'était pas encore à la tête du monastère. Bien qu'il soit juste, ce raisonnement va toutefois aboutir à une reconstitution erronée des événements, principalement à cause de l'inversion des abbatiats d'Aumode et de Thierry. Robert de Torigni pense que Suppon a été élu à la tête de la communauté montoise alors qu'Aumode n'était pas encore abbé du Mont. La seule date possible est donc pour lui l'année 1023, lors de la succession d'Hildebert II. Il choisit ainsi d'introduire Suppon à cette date dans le De abbatibus, et se démarque par la même occasion de l'ensemble des sources à sa disposition ${ }^{110}$. D'après ce raisonnement, Aumode n'aurait pas succédé immédiatement à Hildebert II en 1023: il aurait été précédé par Suppon, élu avant lui.

Une autre difficulté surgit dès lors: comment expliquer que Suppon, s'il avait été effectivement élu dès 1023, n'aurait été ordonné abbé que dix ans plus tard, en 1033 ? Un passage polémique de l'Introductio monachorum - auquel Robert de Torigni, ancien moine et prieur du Bec, ne pouvait être insensible - est à l'origine de l'interprétation erronée des raisons de la consécration tardive de Suppon. Vu l'intérêt essentiel de ce passage pour la compréhension du raisonnement ayant induit l'auteur en erreur, il est utile de le reproduire intégralement ici:

On ne saurait manquer de mentionner que saint Michel, le protecteur de ce lieu, n'a pas permis que le Mont soit souillé par l'inhumation du corps d'un de ces individus

107. Les trois seuls cas où Robert de Torigni ne précise pas les dates d'accession des abbés se placent entre 1009 et 1033, pour Hildebert II, Aumode et Thierry ( $4^{\mathrm{e}}, 5^{\mathrm{e}}$ et $6^{\mathrm{e}}$ abbés du catalogue).

108. Sur Suppon, voir Bulst, 1973, p. 124-128 et 169-172; GAZEAU, 2007, II, p. 203 et 205-207. Suppon était commémoré dans les nécrologes du Mont Saint-Michel et de Saint-Bénigne de Dijon, mais aussi à Saint-Blasien, à Saint-Savin/Sabinien de Plaisance, à Saint-Sauveur de Turin, à Villars et à Saint-Martin-des-Champs (Bulst, 1973, p. 172 n. 149; Lecouteux, 2015, t. 2, p. 23 et 55). Sa qualité de disciple de Guillaume de Volpiano était connue au sein du réseau spirituel volpianien: elle est par exemple rappelée dans la Chronique de Saint-Bénigne de Dijon (Bougaud et GARniER, 1875, p. 156-159; LeCOUTEUX, 2015, p. 424-425).

109. Le décès de Guillaume de Volpiano était indiqué à l'année 1030 dans les Annales du Mont SaintMichel (ms Avranches, Bibl. patrimoniale, 211, fol. 74v): Obiit Guillelmus abbas Fiscannensis.

110. L'auteur du De abbatibus fait, en effet, intervenir Suppon pour la première fois dans les sources écrites montoises en 1023: aucune source antérieure à 1154 ne fournit cette date - et seule une interpolation postérieure à 1154, s'appuyant d'ailleurs sur le De abbatibus, l'introduit tardivement dans une des quatre annales montoises: M2 (cf. l'intervention du second interpolateur, étudiée ci-dessus dans l'étape 2). 
[c'est-à-dire «d'un de ces abbés indignes»] ${ }^{111}$, bien que la puissance séculière ait déjà fait entrer de force - pour ainsi dire par-dessus la clôture - non des abbés, mais des loups rapaces. C'est un fait établi qu'aucune des personnes venues de l'extérieur ne s'est approprié le monastère sans qu'il soit bien connu qu'elle l'a perdu, non sans honte, par l'effet, non d'une machination des moines, mais de la vengeance de Dieu et de sa sainte autorité. Mais, Source de miséricorde, daigne pardonner cette faute à ton serviteur l'abbé Raoul, dont tu as voulu que la mort et l'absence nous fassent connaître l'affliction et - hélas! - «suspendre nos harpes aux saules au cœur de Babylone» (XI, 2 [traduction Poulle, Bouet et Desbordes, 2009, p. 220]).

Qui sont donc ces abbés indignes - ces «loups rapaces» venus de l'extérieur et imposés à la tête du Mont par la "puissance séculière» - qui perdirent honteusement la direction de ce monastère et n'y furent pas inhumés? L'auteur de l'Introductio monachorum, qui écrit dans le dernier tiers du $\mathrm{XI}^{\mathrm{e}}$ siècle, nomme le dernier de ces abbés, qu'il a personnellement connu: Raoul (v. 1048-1058). Celui-ci est célèbre pour avoir effectué un pèlerinage expiatoire en Terre Sainte: sans doute est-ce pour cette raison que l'auteur implore la miséricorde de Dieu en faveur de cet abbé repenti, a priori aimé de ses moines. La communauté montoise lui avait, semble-t-il, pardonné son intervention en tant que moine étranger, puisqu'il fut le seul des abbés montois introduits "de force» à la tête du monastère à avoir été inhumé au Mont au cours du $\mathrm{XI}^{\mathrm{e}}$ siècle ${ }^{112}$. Ses trois prédécesseurs immédiats, à savoir Thierry, Aumode et Suppon, n'eurent pas cette chance et ne trouvèrent pas sépulture dans ce monastère ${ }^{113}$. Robert de Torigni a cru pouvoir en déduire que, comme Raoul, les abbés Thierry, Aumode et Suppon venaient aussi de l'extérieur ${ }^{114}$ et devaient par conséquent être comptés au nombre de ces «loups rapaces».

Si Thierry, Suppon et Raoul venaient effectivement d'autres monastères - tous membres du réseau d'établissements réformés par Guillaume de Volpiano: SaintBénigne de Dijon, La Trinité de Fécamp, Saint-Pierre de Jumièges, Notre-Dame de Bernay et Fruttuaria - tel n'était pas le cas d'Aumode: bien que d'origine

111. Allusion aux abbés qui, dans les lignes précédentes, n'ont fait aucun cas de la menace d'excommunication formulée par le pape Jean XIII (dans la pseudo-bulle, insérée dans le diplôme du roi Lothaire du 7 février 966: HALPhen et Lot, 1908, nº 24, p. 53-57; ZimmermanN, 1985, t. I, $\mathrm{n}^{\circ} \dagger 170, \mathrm{p}$. 333-335) à l'encontre de ceux qui n'auraient pas été choisis au sein de la communauté montoise par les moines de l'abbaye pour devenir leur abbé.

112. GAZEAU, 2007, II, p. 207-208: il est enterré in porticu ecclesiae.

113. L'auteur du De abbatibus ne manque d'ailleurs pas de mentionner ce fait (GAZEAU, 2007, II, p. 203, 204 et 205-206, où il est indiqué par erreur qu'Aumode fut enterré au Mont). D'après le témoignage tardif de Dom Thomas le Roy, les abbés Mainard I ${ }^{\text {er }}$ (v. 965-991), Mainard II (991-1009), Hildebert $I^{\text {er }}$ (1009-v. 1017) et Hildebert II (v. 1017-1023) auraient été enterrés dans un petit jardin proche de la cellule réservée au moine gardien du sanctuaire, avoisinant l'abbatiale (GAZEAU, 2007, II, p. 197-202, en particulier p. 200).

114. Plus tard (période 1085-1128), Roger I, Roger II et Richard de Méré, venus eux aussi de l'extérieur, ne conservèrent pas l'abbatiat du Mont et en furent également chassés: ils ne trouvèrent pas davantage sépulture au Mont. Après Raoul (v. 1048-1058), l'abbé Bernard (1131-1149) est donc le deuxième abbé du Mont venu de l'extérieur ( $\mathrm{Le} \mathrm{Bec}$ ) à avoir trouvé sépulture dans ce monastère (GAZEAU, 2007, II, p. 211-216). 
mancelle, il prit, en effet, très tôt l'habit monastique au Mont ${ }^{115}$. Comme Robert de Torigni savait qu'Aumode, Thierry et Suppon furent respectivement abbés de Cerisy ${ }^{116}$, de Jumièges ${ }^{117}$ et de Fruttuaria ${ }^{118}$, et que Raoul et Thierry furent également custodes de Bernay ${ }^{119}$, il en déduisit à tort que c'est en tant qu'abbé ou custos de ces monastères extérieurs qu'ils intervinrent tous successivement au Mont Saint-Michel. Et l'auteur du De abbatibus imagina ainsi que c'est parce qu'il ne pouvait se déterminer à renoncer à son monastère de Fruttuaria - il le supposait abbé de cet établissement avant $1023^{120}$ - pour assumer pleinement la charge du Mont Saint-Michel que Suppon fut un temps remplacé, après son élection de 1023, par Aumode, puis par Thierry. L'idée de l'impossibilité d'un cumul abbatial de Suppon semble avoir profondément influencé la reconstitution des événements de la période 1023-1033 par Robert de Torigni: pour lui, Suppon n'a pu devenir abbé du Mont Saint-Michel sans avoir renoncé auparavant à son abbatiat de

115. Il apparaît en quatorzième position dans la liste des moines vivants dressée entre 1005 et 1009 sous les abbés Mainard II du Mont et Gauzlin de Fleury (ms Orléans, Bibl. mun., 127 [105], p. 361; Poulle, Bouet et Desbordes, 2009, p. 379; pour la datation de la liste, voir Lecouteux, 2015, p. 171-191, en particulier p. 181-186). Dom Laporte met cette identification en doute, estimant qu'Aumode aurait déjà été assez âgé à cette époque. La rareté du nom et l'exemple comparable du cas de Jean de Ravenne, attesté comme moine de Saint-Bénigne de Dijon vers 1015 - il souscrit la charte de fondation de Fruttuaria en $30^{\mathrm{e}}$ position -, puis comme abbé de Fécamp de 1028 à 1078 , montre au contraire que cette identification est très vraisemblable. Autre fait significatif: Aumode, contrairement à Thierry, Suppon et Raoul, n'est enregistré dans aucun nécrologe d'abbayes relevant du réseau spirituel volpianien (hormis celui du Mont); il ne pouvait être comme eux un disciple de Guillaume de Volpiano (GAZEAU, 2007, II, p. 203, 204 et 206), ce qui va là aussi dans le sens de son origine montoise: entre 1023 et 1060/1061, la compétition pour l'abbatiat semble, en effet, opposer principalement des moines du Mont à des moines de communautés extérieures appartenant au réseau spirituel volpianien.

116. Robert de Torigni dispose d'informations précises sur les abbés de Cerisy, qu'il reproduit aussi dans son De immutatione ordinis monachorum. Il indique en particulier: Secundus Almodus, ex abbas Sancti Michaelis de Monte (ms Avranches, Bibl. patrimoniale, 159, fol. 173; DelisLe, 1872-1873, t. 2, p. 195).

117. Nous avons vu dans une note précédente que Robert de Torigni disposait d'une documentation abondante sur Jumièges lorsqu'il composa son De immutatione ordinis monachorum en 1154: il avait vraisemblablement en main le catalogue des abbés de Jumièges et une copie des Annales de Jumièges.

118. Voir ce qu'il dit au sujet de Suppon dans sa Chronique à l'année 1165 (ms Avranches, Bibl. patrimoniale, 159, fol. 215V-216; DeLISLE, 1872-1873, t. 1, p. 358 ; note annalistique reproduite plus loin).

119. Dans son De immutatione ordinis monachorum, Robert de Torigni indique, en inversant l'ordre de Raoul et de Thierry (ms Avranches, Bibl. patrimoniale, 159, fol. 172v): Judith comitissa, uxor secundi Ricardi, fecit monasterium Bernai. Hujus custodes fuerunt Rodulfus, abbas Sancti Michaelis, et post ipsum Theodericus Gemmeticensis... (Delisle, 1872-1873, t. 2, p. 194).

120. Robert de Torigni confirme qu'il considérait que Suppon fut abbé de Fruttuaria avant de devenir abbé du Mont dans une note sur les reliques des saints Laurent, Innocent, Maurice et Agapit rapportée à l'année 1165 de sa Chronique (ms Avranches, Bibl. patrimoniale, 159, fol. 215v-216): Robertus, abbas Montis, in quodam brachio auro et argento optime parato jussit reponi reliquias sancti Laurencii, scilicet os brachii quod eschinum vocant, et alia quattuor minora ossa ejusdem martyris; sicuti antea reposuerat in quadam cuppa, intus et extra deaurata, caput Innocentii, socii sancti Mauricii. Praedictas reliquias et partem corporis sancti Agapiti martyris, scilicet carnem cum costis quattuor, Suppo abbas Montis a monasterio Sancti Benigni Fructuariensis, ubi prius fuerat abbas, et prece et precio ad monasterium Sancti Michaelis adportavit. Est autem Fructuariense monasterium in Langobardia, in episcopatu Vercellensi (Delisle, 1872-1873, t. 1, p. 358). 
Fruttuaria; et c'est donc seulement après avoir abandonné son abbatiat italien en 1033 que Suppon aurait pu être enfin reconnu comme abbé du Mont. Robert de Torigni reconstitue donc les événements des années 1023-1033 en transposant à cette époque ses conceptions du milieu du XII ${ }^{\mathrm{e}}$ siècle. Le contexte des réformes monastiques inspirées par Odon de Cluny, Maïeul de Cluny, Guillaume de Volpiano et leurs disciples entre la première moitié du X $\mathrm{X}^{\mathrm{e}}$ et le milieu du XI $\mathrm{XI}^{\mathrm{e}}$ siècle, à une époque où la pratique du multi-abbatiat était courante, lui échappe en partie $^{121}$. Il était surtout pour lui impensable que Suppon pût cumuler la direction de deux abbayes aussi éloignées l'une de l'autre. En revanche, pour l'auteur du De abbatibus, Aumode et Thierry dirigeaient déjà respectivement Cerisy et Jumièges lors de leur intervention au Mont ${ }^{122}$. En réalité, seul Thierry était déjà abbé de Jumièges lorsqu'il prit la tête du Mont Saint-Michel: il cumula alors les deux abbatiats de 1023 à 1027, et devint même en plus custos de Bernay de 1025

121. Les travaux de Neithard Bulst sur les réformes de Guillaume de Volpiano, ainsi que ceux de Véronique Gazeau, Monique Goullet et d'Isabelle Rosé ont mis en évidence les différents monastères où Guillaume et ses disciples pratiquèrent le multi-abbatiat (BulsT, 1973; GAZEAU, 2002; Gazeau et Goullet, 2008; Rosé, 2010): en même temps que Saint-Bénigne de Dijon, Guillaume dirigea les monastères de Fécamp, Bernay, Fruttuaria, Saint-Èvre de Toul, SaintArnoul de Metz, Gorze, Saint-Germain-des-Prés, etc. Cette pratique était fréquente dans les milieux réformateurs de mouvance clunisienne: on la retrouve chez Odon, Maïeul et Odilon de Cluny, de la première moitié du $\mathrm{X}^{\mathrm{e}}$ siècle au milieu du XI $\mathrm{XI}^{\mathrm{e}}$ siècle. Voir aussi le cas d'Heldric, abbé de Saint-Germain d'Auxerre (987/9-1010), Flavigny et Saint-Jean de Réôme (DeflouLeCA, 2013, p. 407-422; Lecouteux, 2015, t. 2, p. 57-58). Parmi les disciples de Guillaume de Volpiano, Thierry, bras droit de Guillaume en Normandie, fut placé à la tête de toutes les abbayes normandes dont l'abbatiat était devenu vacant durant la période 1015-1027: il dirigea simultanément Jumièges (v. 1017-1027), le Mont Saint-Michel (1023-1027) et Bernay (1025-1027). Widric, le bras droit de la réforme de Guillaume dans le diocèse de Toul, cumula un temps les abbatiats de Saint-Èvre de Toul, Saint-Mansuy de Toul et Moyenmoutier (à partir de 1026). Jean de Ravenne fut abbé de Fécamp (1028-1078) et de Saint-Bénigne de Dijon (1052-1054). En cumulant le Mont Saint-Michel (1033-v. 1048) et Fruttuaria (1042-v. 1061) de 1042 à 1048 (environ), Suppon fut loin d'être le seul disciple de Guillaume à pratiquer le multi-abbatiat.

122. Cette interprétation fautive de Robert de Torigni pourrait même laisser croire que Thierry et Aumode intervinrent l'un et l'autre au Mont, non comme abbés, mais comme simples custodes en l'absence de Suppon. Ce serait une erreur: les custodes étaient généralement établis à la tête de jeunes communautés (fondations ou restaurations) le temps que celles-ci s'affermissent. En 1023, la communauté du Mont était déjà ancienne et bien établie: après près de soixante ans d'existence, elle compte alors une cinquantaine de moines (d'après la liste des moines dressée en 1005-1009: Lecouteux, 2015, t. 1, p. 181-186), dispose d'une église, de bâtiments monastiques et même d'un scriptorium actif, preuve de son dynamisme. Le Mont n'est alors ni une nouvelle fondation ni une restauration, et la réforme de Guillaume de Volpiano et de son disciple Thierry fut donc introduite dans une communauté de moines préexistante: on n'aurait pas pris le risque d'établir un simple custos dans de telles circonstances. Étant à la fois abbé de Jumièges et du Mont, Thierry exerçait en fait un cumul abbatial également pratiqué par Maïeul de Cluny, Guillaume de Volpiano et plusieurs de leurs disciples respectifs (voir la note précédente). Sur la trentaine de monastères réformés par Guillaume, Bernay est le seul établissement connu où il eut recours à un custos. Bernay, jeune fondation, constitue donc une exception, et non la règle. Le cartulaire et les catalogues du Mont Saint-Michel mentionnent d'ailleurs Thierry et Aumode comme des abbés du Mont, ce qui lève les derniers doutes possibles sur la véritable fonction qu'ils y exercèrent ( $\mathrm{ms}$ Avranches, Bibliothèque patrimoniale, 210, fol. 46-48; KeAts-Rohan, 2006, $\mathrm{n}^{\circ}$ 23-24, p. 104-107; Poulle, Bouet et Desbordes, 2009, $\mathrm{n}^{\circ}$ 14, p. 390 et $\mathrm{n}^{\circ}$ 21, p. 396-397; Guillotel, 2014, nº 17, p. 192-193 et $\mathrm{n}^{\circ}$ 22, p. 209-211). 
à $1027^{123}$. Aumode ne prit la direction de Cerisy qu'en 1032, après avoir quitté le Mont ${ }^{124}$. Et Suppon n'était encore qu'un simple moine de Fruttuaria lorsque Guillaume de Volpiano tenta de l'établir à la tête du Mont, non pas en 1023, lors de la succession d'Hildebert II, comme le suppose l'auteur du De abbatibus, mais seulement en 1027, lors de la succession de Thierry ${ }^{125}$. À cette dernière date, le candidat de Guillaume de Volpiano à la succession de Thierry était Suppon, mais les moines du Mont Saint-Michel préférèrent choisir l'un des leurs, Aumode, comme abbé ${ }^{126}$. Les actes et les sources conservés montrent que Suppon ne porte pas le titre d'abbé avant 1033: il intervient encore entre 1028 et 1033 comme simple moine dans un diplôme du duc Robert le Magnifique (1027-1035) en faveur du Mont Saint-Michel ${ }^{127}$. Suppon ne prit en réalité la direction de Fruttuaria qu'en 1042, alors qu'il était déjà abbé du Mont depuis $1033^{128}$. Il cumula donc un temps ces deux abbatiats, entre 1042 et 1048 environ, avant de quitter définitivement le Mont pour se retirer dans son monastère d'origine, près de Turin.

Ainsi s'éclaire un des épisodes les plus obscurs de l'histoire de l'abbaye du Mont Saint-Michel ${ }^{129}$ : Suppon ne fut établi abbé de ce monastère ni en 1023 ni en 1027; à cette dernière date, il fut simplement le candidat malheureux de Guillaume de Volpiano face au moine montois Aumode. S'il fut peut-être soutenu par une partie des moines montois en 1027, il n'accéda pas à l'abbatiat

123. GazeAu, 2007, II, p. 30, 147-149 et 203-204.

124. GazeAu, 2007, II, p. 204-205.

125. En 1023, le candidat de Guillaume de Volpiano était Thierry et non Suppon (il est en effet difficilement concevable que Guillaume de Volpiano ait soutenu en même temps les candidatures de ses deux disciples pour la succession d'Hildebert II en 1023). Thierry sera abbé du Mont de 1023 à 1027. C'est donc en 1027 que Guillaume de Volpiano a soutenu la candidature de son disciple Suppon contre le moine local Aumode (et non en 1023, comme a cru pouvoir l'établir Robert de Torigni, trompé par l'inversion des abbatiats de Thierry et d'Aumode dans ses sources).

126. Lecouteux, 2015, t. 2, annexe $\mathrm{n}^{\circ}$ 5, p. 60-69. Guillaume de Volpiano ne bénéficiait plus alors du soutien du duc (Richard II et Richard III étaient morts respectivement en 1026 et 1027 et des tensions survinrent entre l'abbé réformateur et le duc de Normandie Robert le Magnifique, qui imposa à l'abbé de Fécamp de se trouver un successeur à la tête de ce monastère dès 1028). C'est vraisemblablement en 1027, afin de favoriser l'élection de leur candidat, que les moines du Mont interpolèrent le diplôme de Lothaire du 7 février 966 au moyen d'une pseudo-bulle du pape Jean XIII (Halphen et Lot, 1908, nº 24, p. 53-57; ZimmermanN, 1985, t. I, nº †170, p. 333-335), ce qui explique la mention de ce document dans les Brèves annales du Mont Saint-Michel du ms Paris, BnF, lat. 11830, fol. 2v, élaborées peu après 1035 (voir la planche $\mathrm{n}^{\mathrm{o}} \mathrm{I}$ ).

127. Fauroux, 1961, nº 65, p. 195-196. Cet acte étant souscrit par l'abbé Jean de Fécamp (1028-1078), il doit, de ce fait, être daté d'entre 1028 et 1033.

128. Sur la carrière de Suppon à Fruttuaria, voir les travaux de Neithard Bulst, qui est parvenu à démêler la question délicate des premières successions abbatiales dans le monastère italien (Bulst, 1973, p. 115-128).

129. La reconstitution des faits de la période 1023-1033 était d'une complexité redoutable pour un historien tel que Robert de Torigni, qui ne disposait que de sources imprécises et contradictoires. C'est ce qui explique son échec. Du fait de la complexité du dossier, les chercheurs modernes n'ont eux-mêmes que partiellement résolu le problème: si l'inversion des abbatiats d'Aumode et de Thierry a été mise en lumière il y a un demi-siècle grâce aux travaux de Dom Jean Laporte (confirmés depuis par Neithard Bulst), l'intervention de Suppon en 1023 - avec ou non l'existence d'un premier abbatiat éphémère à cette date - n'a jamais été remise en cause (LAPORTE, 1967, p. 269-275; BULST, 1973, p. 169-172; KeAts-Rohan, 2006, p. 52 ; GAZEAU, 2007, II, p. 203 et 205 207; Poulle, Bouet et Desbordes, 2009, p. 182). 
pour succéder à Thierry et c'est Aumode qui fut établi. Suppon n'exerça donc son abbatiat au Mont que de $1033^{130}$ à 1048 environ ${ }^{131}$.

Le début de la notice de l'année 1033 du De abbatibus a été composé à l'aide des Annales pascales du Mont Saint-Michel $\left(\mathrm{M}_{3}^{*}\right)$. Robert de Torigni se contente d'adapter sa note en tenant compte de sa propre reconstitution de la période 1023$1033^{132}$. Puis il signale que les constructions de l'église abbatiale furent activement poursuivies durant l'abbatiat de Suppon, ajoutant que l'abbé contribua à enrichir le monastère en livres et en ornements (un grand calice, une croix, deux anges argentés et de nombreux autres objets) ${ }^{133}$. L'auteur apporte ensuite, à l'aide des archives, des précisions sur les raisons de l'hostilité des moines envers leur abbé: celui-ci aurait distribué des terres du monastère à des proches et à de grands personnages de la région. Haï d'une partie de sa communauté montoise, il fut contraint de quitter l'abbaye vers 1048, et il rentra dans son abbaye de Fruttuaria ${ }^{134}$. Robert de Torigni n'indique pas qu'il était alors l'abbé du monastère italien: pour lui, Suppon avait renoncé à cet abbatiat en 1033, afin de devenir abbé du Mont. Mais nous savons aujourd'hui, grâce aux travaux de Neithard Bulst, que cette reconstruction ne correspond pas à la réalité des faits ${ }^{135}$.

130. Aumode prit la direction de Cerisy après le 20 juillet 1032 et avant 1033 (GAZEAU, 2007, I, p. 60). Pourquoi, dans ces conditions, avoir attendu 1033 pour ordonner Suppon? Aumode étant mort le 17 mai 1033, on peut émettre l'hypothèse que l'ordination de Suppon, voulue par le duc Robert le Magnifique et l'abbé de Fécamp Jean de Ravenne, ne soit devenue possible qu'après la mort de l'ancien abbé du Mont.

131. Pour l'abbatiat de Suppon, il faut donc revenir aux datations proposées dans les Brèves annales mineures du Mont Saint-Michel, composées peu après $1035(\mathrm{M1})$, reproduites dans les annales de 1116 (M2, avant l'ajout de "Suppo » sur grattage), de $1154\left(\mathrm{M}_{3}^{*}\right)$ et du XV siècle (M4). Il faut en revanche renoncer à suivre la reconstruction erronée et tardive proposée par le De abbatibus (qui introduit pour la première fois la date de 1023 et adapte en conséquence la note de 1033 relative à l'accession de Suppon) ou par le second interpolateur des Annales du Mont Saint-Michel (M2, après l'ajout de «Suppo» sur grattage).

132. Le manuscrit porte ici l'expression ex tegro, qui suggère la forme ex integro, pour indiquer que Suppon fut véritablement consacré abbé en 1033 - bien que, selon Robert de Torigni, il eût été élu dès 1023 .

133. Robert de Torigni a trouvé ces renseignements dans la bibliothèque, les archives et le trésor du monastère. Arthur du Monstier, qui connut certains objets au XVII ${ }^{e}$ siècle, apporte des précisions intéressantes à leur sujet: description du calice et de la patène (avec le texte des inscriptions latines: DU Monstier, 1663, p. 384-385). Suppon légua aussi un chalumeau d'argent à l'abbaye du Mont (Gazeau, 2007, II, p. 207). Les Mauristes rapportent également, sans plus de détails, l'enrichissement de la bibliothèque en livres par Suppon (Gallia Christiana, t. XI, col. 515). Un manuscrit, copié au Mont Saint-Michel par le moine de Fécamp Antonius et décoré sur place par un artiste montois, porte un colophon faisant l'éloge de l'abbé Suppon, qui a fourni au copiste tout ce qui était nécessaire à la réalisation du volume (LECOUTEUX, 2015, t. I, p. 476-479, pièce justificative $\mathrm{n}^{\circ}$ III p. 659-663, planches $\mathrm{n}^{\text {os }}$ III à V). Ce colophon est important: il prouve que les calligraphes et les artistes les plus talentueux du Mont Saint-Michel travaillaient déjà du temps de Suppon et que c'est cet abbé qui les a fait venir dans son monastère. Nous pouvons donc considérer que l'apogée stylistique et artistique du scriptorium montois a été atteint dès les années 1040 grâce aux soins de Suppon.

134. Voir GAzEAU, 2007, II, p. 205-206. Une vacance du siège abbatial pendant plusieurs mois, entre le départ de Suppon et l'établissement de Raoul, est probable.

135. Suppon apparaît comme abbé de Fruttuaria dans des documents datés de 1042 et 1046 (BuLST, 1973, p. 115-128 et 169-172). 
L'abbatiat de Raoul, qui débute à l'année 1048, commence en reprenant la notice correspondante des Annales pascales du Mont Saint-Michel ( $\left.\mathrm{M}_{3}{ }^{*}\right)$. Robert de Torigni apporte ensuite, à l'aide des archives du monastère, des informations précieuses sur les constructions faites par cet abbé. Disposant de renseignements sur la succession des custodes et abbés de Bernay, il précise que Raoul était également custos de ce monastère ${ }^{136}$.

Pour les événements de la période 1048-1085, Robert de Torigni se trouve de nouveau confronté à un problème de sources contradictoires. Les Annales pascales du Mont Saint-Michel $\left(\mathrm{M}_{3}{ }^{*}\right)$, qui ne faisaient que reproduire et compléter les Annales du Mont Saint-Michel (M2), lui donnaient d'une part les décès de Raoul et de Suppon respectivement en 1060 et 1061, d'autre part l'accession de Renouf en 1063. Elles indiquaient enfin la mort de Renouf et son remplacement par Roger $\mathrm{I}^{\mathrm{er}}$ en 1085 . Robert de Torigni trouva toutefois dans les archives de l'abbaye quatre sources qui contredisaient ces datations: en premier lieu, la mort de Raoul au retour de son pèlerinage à Jérusalem en $1058^{137}$; en second lieu, une vacance d'environ deux années du siège abbatial entre le décès de Raoul et l'accession de Renouf; en troisième lieu, l'existence d'une convention passée entre l'abbé Renouf et l'évêque d'Avranches Jean d'Ivry en $1061^{138}$; enfin, une durée d'abbatiat de vingt-trois ans pour l'abbé Renouf ${ }^{139}$. En combinant ces différents éléments, Robert de Torigni fut en mesure de corriger et d'affiner les dates imprécises fournies par sa source principale (les Annales pascales du Mont Saint-Michel) de la façon suivante: il avança à l'année 1058 la date de la mort de Raoul, pourtant rapportée dans les Annales pascales à l'année 1060; comme la vacance du siège abbatial dura environ deux ans et que Renouf était déjà attesté comme abbé en 1061, il reporta la date de son accession en 1060, alors que sa source principale lui indiquait l'année 1063; enfin, comme l'abbatiat de Renouf avait duré 23 ans, il plaça sa mort en [décembre] 1083, et non en 1085. Cela introduisait implicitement une vacance de plus d'un an entre le décès de Renouf et l'accession de Roger I ${ }^{\text {er }}$ en 1085. Ces corrections sont pertinentes, et Robert de Torigni fait preuve à

136. Nous avons vu plus haut que Robert de Torigni disposait d'informations sur les custodes et abbés de Bernay, comme en témoignent les informations transmises à ce sujet dans son De immutatione ordinis monachorum.

137. Le De abbatibus constitue aujourd'hui la plus ancienne source rapportant ce fait. Cette donnée est cependant digne de foi, car l'auteur a montré, à l'occasion de l'accession d'Hildebert II à l'abbatiat à la suite de son oncle homonyme, qu'il préférait ne pas fournir de date plutôt que d'en forger une si l'information lui manquait. La fiabilité de l'information transmise par Robert de Torigini dépend donc de celle de sa source, malheureusement aujourd'hui perdue.

138. Ms Paris, BnF, lat. 14832, f. 183v-184r; Keats-Rohan, 2006, appendix 2, nº 5, p. 195-196; Poulle, Bouet et Desbordes, 2009, p. 375-378.

139. Raoul et Renouf sont les deux seuls abbés du Mont Saint-Michel du XI ${ }^{\mathrm{e}}$ siècle dont le lieu précis de sépulture au Mont (in porticu ecclesiae) était connu de l'auteur du De abbatibus. Robert de Torigni semble donc avoir eu accès à des renseignements précis concernant ces deux abbés. Il est possible qu'il ait connu des épitaphes ou des inscriptions figurant sur leurs tombeaux, précisant, d'une part, la date de la mort de Raoul à son retour de pèlerinage à Jérusalem en 1058 , d'autre part, les vingt-trois années d'abbatiat de Renouf. 
la fois d'esprit critique et d'esprit logique au moment d'exploiter toutes les sources qu'il a entre les mains. Il parvient ainsi, pour la période 1048-1085, à un résultat bien meilleur que pour la période 1023-1033. Il faut dire que ses sources pour la période 1048-1085 étaient certes imprécises (décalages de une, deux, voire trois années), mais non fautives (pas d'inversions d'abbés, comme pour Aumode et Thierry entre 1023 et 1033): il s'agit ici de simples recadrages chronologiques. Apporter les bonnes corrections était donc relativement aisé, ce qui explique son succès ${ }^{140}$.

Les dates fournies par Robert de Torigni sur la période 1048-1085 doiventelles pour autant être suivies sans réserve? Non, car les sources utilisées n'étaient pas toutes elles-mêmes d'une extrême précision. Ainsi la date de 1048 a été donnée à Robert par l'auteur des Annales du Mont Saint-Michel (M2), qui a opéré en 1116, et nous avons vu que les informations fournies par celui-ci sur la période 1040-1100 étaient d'une précision de l'ordre d'une à deux années près. Il est donc préférable de considérer la fiabilité de la date de 1048 avec réserve, en adoptant la forme «vers 1048 » pour bien montrer l'incertitude relative d'une telle datation. La même remarque peut être formulée au sujet de la mention de la mort de Suppon en 1061 dans les Annales du Mont Saint-Michel (M2) : il convient donc là aussi d'adopter prudemment «vers 1061». Si la date de la mort de Raoul en 1058 semble a priori fiable ${ }^{141}$, l'accession de Renouf après deux ans environ de vacance du siège abbatial est plus problématique. Faut-il la placer dès 1060, ce qui semblerait assez logique sur la base de la date précédente, ou seulement en 1061 ? La convention passée entre Renouf et l'évêque d'Avranches Jean d'Ivry à cette dernière date ressemble fort à un compromis consenti par Renouf en vue d'obtenir une consécration abbatiale qu'il espérait sans doute depuis deux ans en qualité de prieur. On apprend ainsi, grâce à ce texte, qu'abbé, moines et chanoines du Mont étaient placés sous l'autorité de l'évêque et que l'abbé, promu archidiacre de ce dernier, n'était au sein du village que le représentant du pouvoir épiscopal. Cet accord paraît donc peu favorable à l'abbé du Mont, et l'évêque d'Avranches semble avoir profité d'une situation avantageuse pour renforcer et imposer son autorité sur l'abbaye. Cela suggère que Renouf aurait accepté cette convention peu favorable à sa communauté contre l'obtention de sa propre bénédiction abbatiale en 1061. Cette démarche pourrait être à l'origine de la sédition qui s'éleva au sein de la communauté montoise au début

140. Notons que, sur la question des dates d'abbatiat de Raoul et Renouf, Robert de Torigni se révèle plus exact que l'érudition moderne, laquelle s'appuie sur les résultats des travaux de Dom Jean Laporte parus en 1967.

141. C’est la seule datation proposée pour la mort de Raoul qui semble valable - nous avons suggéré que Robert de Torigni aurait eu accès à une inscription gravée sur la tombe de Raoul, dont il connaissait l'emplacement. Nous avons vu que les autres datations proposées pour 1051, 1053 et 1055 résultent d'erreurs. 1060 est impossible, car la vacance de deux ans du siège abbatial induirait une accession de Renouf à l'abbatiat en 1062; or, celui-ci était déjà connu comme abbé en 1061. Les dates de 1060 et 1061 proposées par les Mauristes ont toutes chances de dépendre, plus ou moins directement, de la mention introduite dans M2 à l'année 1060. Des décalages dans les calculs de date ont néanmoins pu survenir du fait des repères utilisés par les moines du Moyen Âge pour fixer les débuts d'année (Noël, Pâques, $1^{\mathrm{er}}$ janvier). 
des années 1060: un groupe de moines - parmi lesquels figuraient Robert de Tombelaine et Anastase le Vénitien - fit dissidence et se retira sur l'îlot voisin de Tombelaine, accusant le nouvel abbé du Mont d'avoir obtenu son abbatiat par simonie $^{142}$. Suivant cette hypothèse, il faudrait donc placer l'accession de Renouf au moment de la rédaction de cette convention, soit en 1061 plutôt qu'en 1060. Si Renouf dirigea effectivement pendant vingt-trois ans la communauté du Mont, comme l'indique l'auteur du De abbatibus, c'est en décembre 1084, non en décembre 1083, que cet abbé serait mort. Cette reconstitution a l'avantage de supprimer la longue période de vacance du siège abbatial (qui aurait duré plus d'un an), non attestée par ailleurs et introduite dans le De abbatibus entre cet événement et l'accession de Roger $\mathrm{I}^{\mathrm{er}}$ en 1085.

Pour l'abbatiat de Renouf, l'auteur du De abbatibus met une nouvelle fois à contribution les archives du monastère, et il livre de précieuses informations sur les réalisations de cet abbé en termes d'architecture (nef de l'église, "galerie » [crypto-portique?], cimetière des moines, porche [ou portique] situé au-dessus, mur du cloître [ou clôture ?], demeure des tailleurs, mur nord de la forteresse) ${ }^{143}$ et d'ornement (candélabres en argent et or, panneau d'autel). Puis Robert de Torigni mentionne le départ de quatre moines du Mont Saint-Michel qui prirent chacun la direction d'un monastère en Angleterre au cours des années 1070: le prieur Rivallon / Ruauld, abbé de Hyde Abbey/New Minster (1072-17/01/1088) près de Winchester; le trésorier Scolland, abbé de Saint-Augustin de Cantorbéry (1072-09/09/1087); Serlon, abbé de Saint-Pierre de Gloucester (1072-03/03/1104), et Guillaume d'Agon, abbé de Saint-Pierre de Cerne (1075-28/01/1093). Il exploite pour cela des renseignements inscrits dans le martyrologe-nécrologe du monastère ${ }^{144}$.

L'auteur se sert ensuite des Annales pascales du Mont Saint-Michel $\left(\mathrm{M}_{3}{ }^{*}\right)$ pour effectuer un synchronisme à l'année 1083 entre la mort de la reine Mathilde

142. L'abbé du Mont Saint-Michel auquel s'oppose vigoureusement Robert de Tombelaine en tant que prieur de Saint-Vigor de Bayeux (apr. 1063?-1082) ne peut être que Renouf (1060/1061-1083/1084). Sur ces événements et leur datation, voir Arnoux, 1995, p. 55-78; LeCouteux, 2015, annexe $\mathrm{n}^{\circ} 5$, p. 6o-69.

143. Arthur du Monstier et les Mauristes connurent certaines de ces sources au XVII ${ }^{\mathrm{e}}$ siècle, puisqu'ils furent capables d'apporter quelques précisions au sujet du cimetière: la Neustria pia indique, p. 385, que Renouf fit creuser le rocher pour aménager une grotte souterraine (subterraneum specum, rupe incisa, in monachorum sepulturam parat), tandis que la Gallia Christiana parle d'un cimetière subter majori ecclesia.

144. Ces quatre moines du Mont devenus chacun abbé d'un établissement anglais sont, en effet, inscrits au martyrologe-nécrologe du Mont Saint-Michel, qui date des années 1207-1212, mais reproduit le fond d'un nécrologe plus ancien n'ayant pas survécu ( $m s$ Avranches, Bibliothèque patrimoniale, 214, pagination 3, p. 1-196; pour son étude, voir Lecouteux, 2015, t. I, p. 171-191). Leur lieu d'abbatiat est précisé pour Guillaume d'Agon (ms 214, p. 20, 28 janvier: Guillermus abbas sancti Petri Cerneliensis) et Serlon (ms 214, p. 37, 3 mars: Serlo abbas Sancti Petri Gloecestriae); il ne l'est que partiellement pour Scolland (ms 214, p. 136, 9 septembre: Scollandus Sancti Augustini abbas) et ne l'est pas pour Rivallon ( $\mathrm{ms} \mathrm{214}$, p. 14, 17 janvier: [R] iuallonus abbas). Il est très probable que ces informations aient été systématiquement spécifiées dans l'original encore en usage du temps de Robert de Torigni. Au sujet de ces quatre abbés, voir Knowles, Brooke et London, 2009, p. $36,37,52,82,244$ et 258 . 
et celle de l'abbé Renouf. Il en profite pour faire l'éloge de l'administration de l'abbé, grâce à qui de nombreux domaines furent restitués et le patrimoine de l'abbaye fut considérablement augmenté ${ }^{145}$. Le lieu de sépulture de l'abbé, sous le porche / portique de l'église, est aussi précisé: originaire du Mont et enterré dans ce monastère, l'abbé Renouf n'était donc pas visé par l'auteur de l'Introductio monachorum, lorsque ce dernier parlait des «loups rapaces» venus de l'extérieur pour s'emparer de la direction du monastère et qui ne furent pas inhumés en ce lieu.

Pour l'abbatiat de Roger I ${ }^{\text {er }}$, Robert de Torigni exploite principalement les Annales pascales du Mont Saint-Michel $\left(\mathrm{M}_{3}{ }^{*}\right)$, qui reproduisent fidèlement ici les Annales du Mont Saint-Michel composées en $1116\left(\mathrm{M}_{2}\right)$ : l'accession à l'abbatiat du moine de Caen, Roger, en 1085, l'apparition de saint Michel sous la forme d'une colonne de feu en 1102, l'effondrement de la voûte de la nef de l'abbatiale en 1103, le départ de l'abbé Roger I ${ }^{\text {er }}$ pour l'abbaye de Cerne sur décision du roi Henri d'Angleterre en 1106 sont évoqués d'après cette source. L'auteur donne cependant à l'occasion quelques précisions complémentaires: il indique à l'année 1085 que Roger avait été auparavant chapelain de Guillaume le Conquérant; pour le miracle de 1102, il rappelle, en s'appuyant sur un passage des Miracula sancti Michaelis, que la même chose s'était produite du temps de l'abbé Mainard [II] et de l'évêque d'Avranches Norgod ${ }^{146}$. Enfin, lors de l'effondrement ayant touché l'abbatiale en 1103, il précise que c'est le ciborium tocius navis ecclesiae construit par l'abbé Roger Ir qui s'est écroulé.

Pour l'abbatiat de Roger II, les Annales pascales du Mont Saint-Michel $\left(\mathrm{M}_{3}{ }^{*}\right)$ sont de nouveau utilisées: les indications concernant son accession en 1106 et l'incendie du monastère en 1112 proviennent de cette source. L'auteur se sert en outre du chartrier ou du cartulaire de l'abbaye (ms Avranches, Bibl. patrimoniale, 210) pour faire, dans la notice de l'année 1106, l'éloge de l'administration du temporel par l'abbé. Il décrit ensuite les travaux monumentaux réalisés par Roger II entre 1112 et 1123 (réparation de la couverture de toute l'église, réparation des bâtiments brûlés lors de l'incendie de 1112, construction sur trois niveaux des écuries, d'une salle et de chambres, ainsi que du cloître). L'auteur est manifestement ici le témoin oculaire de ces réalisations, encore visibles en son temps.

Ainsi, la période 506-1123 a été majoritairement composée à partir de sources écrites, dont la plupart peuvent être facilement identifiées et ont survécu soit dans leur forme originale, soit à l'état de copies. Le recours à cette documentation écrite était indispensable à l'auteur, qui travaillait plus de trente ans après les faits rapportés. Pour les dernières années du récit (période 1123-1154), les choses changent radicalement: ce sont désormais des récits oraux de témoins oculaires

145. Le Cartulaire du Mont Saint-Michel est vraisemblablement la source de cette note: le ms Avranches, Bibl. patrimoniale, 210, fol. 81-89 contient des chartes de donation et de restitution relatives à l'abbatiat de Renouf. Il y eut toutefois aussi des amputations du temporel au cours de cet abbatiat.

146. Poulle, Bouet et Desbordes, 2009, p. 312-315. 
qui sont exploités en priorité par l'auteur (même si les Annales pascales $d u$ Mont Saint-Michel $\left[\mathrm{M}_{3}{ }^{*}\right]$ fournissent toujours la trame et le cadre du récit, qui continue d'être structuré par abbatiat: les successions abbatiales mentionnées aux années 1123, 1124, 1131, 1149 et 1150 dérivent directement de cette source, qui continue à fournir les bornes indispensables à la structuration du texte). Les informations entrant dans chaque notice abbatiale proviennent désormais majoritairement de témoignages oraux émanant de personnes ayant vécu entre 1123 et 1154. Quand il ne connaissait pas lui-même ces informations, Robert de Torigni les a vraisemblablement obtenues en 1154 auprès de moines du Mont Saint-Michel contemporains des abbés Richard de Méré (1125-1128), Bernard (1131-1149) et Geoffroy (1149-1150/1151).

Pour l'époque «récente » (trente à quarante dernières années), les témoignages oraux ont donc été privilégiés, tandis qu'au-delà (avant 1123), le recours aux sources écrites était indispensable.

\section{Conclusion}

Au terme de cette enquête sur la méthode de travail et l'identification des sources utilisées par Robert de Torigni, chroniqueur des abbés du Mont Saint-Michel, il est possible de dresser le bilan suivant.

Nous constatons tout d'abord que les sources exploitées au Mont SaintMichel par Robert de Torigni pour composer le De abbatibus sont très proches de celles sollicitées avant 1154 par ce même auteur lors de ses travaux historiques réalisés au $\mathrm{Bec}^{147}$. Ces résultats mettent en évidence l'usage combiné de sources historiographiques, hagiographiques, diplomatiques, liturgiques et commémoratives, en particulier des annales, des calendriers (martyrologes et nécrologes) et des catalogues de puissants. Les sources sollicitées par Robert de Torigni au milieu du XII ${ }^{e}$ siècle sont comparables à celles utilisées par de nombreux autres chroniqueurs et historiens tout au long du Moyen Âge ${ }^{148}$. L'abbé du Mont Saint-Michel tire davantage son originalité du nombre et de la variété des sources mises à contribution que de leur typologie. L'intérêt qu'il porte aux sources écrites, l'autorité qu'il leur confère, sa curiosité ainsi que son souci d'exhaustivité expliquent vraisemblablement cette variété et cette abondance.

Les principaux apports de l'enquête me semblent toutefois d'ordre méthodologique, puisqu'ils ont mis en lumière les outils et les instruments utilisés et confectionnés par Robert de Torigni pour l'élaboration de son œuvre. L'étude se révèle ainsi riche d'enseignements pour la connaissance des pratiques des historiens et des chroniqueurs des IX ${ }^{e}$-XIV ${ }^{e}$ siècles. Les méthodes de travail de ces auteurs étaient sans doute analogues ou comparables à celles adoptées par l'ancien moine du Bec devenu abbé du Mont Saint-Michel. L'enquête confirme en particulier l'importance de certains outils et matériaux pour l'élaboration

147. Mes travaux convergent en effet avec ceux de Benjamin Pohl (PoHL, 2016, p. 324-372). 148. Pour une synthèse, voir GuenÉE, 1980. Les exemples pourraient être multipliés. 
de chroniques ou d'œuvres historiographiques: catalogues de puissants ${ }^{149}$; annales et tables pascales ${ }^{150}$.

Ces catalogues et ces tables pascales annotées furent assurément des instruments précieux, sinon incontournables, pour nombre d'historiens et de chroniqueurs médiévaux soucieux de mieux maîtriser le temps grâce à l'usage de l'ère chrétienne, qui s'impose progressivement en Occident entre le $\mathrm{VI}^{\mathrm{e}}$ et le XIII ${ }^{\mathrm{e}}$ siècle ${ }^{151}$. Les annotations ajoutées dans les marges des tables pascales (désignées sous le nom d'annales pascales par les historiens modernes) correspondent en réalité à des repères chronologiques permettant d'établir des synchronismes entre différents systèmes de datation alors en usage. Ainsi, les tables pascales, qui servaient à l'origine exclusivement à calculer la date mobile de Pâques et qui étaient primitivement dépourvues d'annotations marginales, se sont bientôt muées en tables de concordance sous l'impulsion conjointe de notaires / chanceliers et d'historiens / chronographes. Ce sont ces personnes qui ajoutèrent des événements-repères dans les marges de ces tables dans l'objectif d'établir des synchronismes. Ce constat est décisif pour la compréhension de l'évolution de l'usage des tables pascales au Moyen Âge. Ces instruments, une fois enrichis d'annotations marginales, permettaient en effet de faire coïncider l'année de l'incarnation, l'indiction, l'épacte, les concurrents (ainsi que les autres données liées au calcul de la date de Pâques) avec les années de règne des élites laïques (empereurs, rois, ducs, comtes, etc.) et religieuses (papes, évêques, abbés, etc.) introduites en marge. D’autres repères mnémotechniques (événements de la vie personnelle de l'auteur, guerres, phénomènes climatiques, météorologiques et astronomiques, épidémies, etc.) ont souvent aussi été insérés en marge de ces documents, toujours dans l'objectif de créer des synchronismes et des concordances.

Cette meilleure compréhension de l'évolution de l'usage des tables pascales n'est pas sans conséquence pour l'historien. Dans son ouvrage consacré à la typologie des annales du Moyen Âge, Michael Mc Cormick affirme que «sur le double plan de la richesse de vocabulaire et de la complexité (par là, de la diversité) de la syntaxe, les annales pascales font bien pauvre figure». S'il explique en partie ce phénomène par le manque de place disponible pour accueillir ces notes marginales, il poursuit toutefois son raisonnement en insistant sur «la pauvreté culturelle qui pouvait marquer les milieux où naquirent les annales pascales». Selon lui, «l'auteur, en s'efforçant de combler les lacunes de sa culture littéraire et afin d'éviter les bévues, emploie une langue stéréotypée». Il conclut en observant que «les annales nous confrontent avec une langue très simple et au surplus, pétrie de clichés» ${ }^{152}$. Paradoxalement, ces notes inscrites en marge

149. Dont le rôle essentiel avait déjà été souligné par Bernard Guenée au cours des années 1970 (GuenÉE, 1980, p. 150-166).

150. Sur lesquelles j'ai déjà eu l'occasion d'attirer l'attention dans mon mémoire de Master 2 puis lors de ma thèse de doctorat (Lecouteux, 2011, p. 91-190; Lecouteux, 2015, t. 2, annexe ${ }^{\circ} 7$, p. 147-336).

151. À ce sujet, Guyotjeannin et Tock, 1999, p. 41-109; GuyotjeAnnin, 2011, p. 37-59.

152. MC CORMick, 1975, p. 31. 
de tables pascales ou de calendriers, bien qu'effectivement d'une langue et d'une syntaxe peu élaborées, dépourvues de toute rhétorique et de recherche stylistique, et fréquemment copiées rapidement et sans grand soin, ont souvent été écrites par des historiens, des notaires ou des écolâtres célèbres ${ }^{153}$. D’un côté, la tradition érudite moderne veut que les notes insérées en marge des tables pascales soient les productions de milieux culturellement pauvres. De l'autre, nous constatons au contraire qu'un grand nombre de ces notes ont été écrites par des intellectuels appartenant aux élites culturelles du Moyen Âge. Comment expliquer un tel paradoxe?

Ces notes marginales n'ont en réalité aucune prétention littéraire, pas même historiographique. Il ne s'agit bien souvent que d'événements-repères ajoutés pêle-mêle les uns à la suite des autres pour permettre l'établissement de synchronismes. Parler de pauvreté intellectuelle ou culturelle en se fondant sur ces seules annotations paraît à la fois abusif et erroné. Ces annotations n'étaient pas destinées à être lues et utilisées par d'autres personnes que leur auteur, voire leur entourage immédiat (en particulier dans le cas d'un écolâtre enseignant le comput à des élèves). C'est un peu comme si l'on jugeait aujourd'hui notre culture en se fondant exclusivement sur les notes rapides que chacun d'entre nous inscrit parfois en marge de textes, au fil de ses lectures: ces annotations ont uniquement une fonction pratique (outils); elles n'ont aucune prétention littéraire; elles ne sont pas destinées à être publiées (surtout pas!); c'est à peine si l'on y soigne l'orthographe, la grammaire et l'aspect de notre écriture. Il en était sans doute de même dans l'esprit des annotateurs des tables pascales du Moyen Âge. Et si ces notes sont aussi précieuses pour nous aujourd'hui, c'est qu'elles ont gagné, avec le temps, une dimension historiographique et prosopographique ${ }^{154}$, voire biographique, qu'elles n'avaient probablement pas à l'origine ${ }^{155}$.

Fort de ce constat, nous ne pouvons qu'encourager la réalisation de comparaisons paléographiques entre manuscrits historiographiques autographes, chartes originales et annotations marginales de tables pascales. Cette démarche ouvre, à mon avis, la perspective de belles découvertes ${ }^{156}$. L'identification récente de la main d'Hugues de Flavigny dans les annotations marginales des tables pascales de l'abbaye de Saint-Bénigne de Dijon, en Bourgogne, en fournit déjà un très bon exemple ${ }^{157}$.

153. Citons notamment Willibrord d'Echternach, Godescalc de Liège, Pacificus de Vérone, Agobard de Lyon, Walahfrid Strabon, Heiric d'Auxerre, Martin Scot, Mannon de Laon, Bernard de Laon, Adelhelme de Laon, Adémar de Chabannes, Hugues de Flavigny, Orderic Vital et Robert de Torigni, auxquels il convient vraisemblablement d’ajouter Réginon de Prüm, Dudon de SaintQuentin et Gérard de Cambrai (LecouteuX, 2011, p. 91-19o, en particulier p. 119-125 et 161-173).

154. Elles ont par exemple servi de sources à de nombreux auteurs médiévaux et modernes; un grand nombre de travaux modernes remontent directement ou indirectement à ces sources anciennes.

155. LeCouteux, 2011, p. 128.

156. Cf. «Une source d'histoire à revisiter: annales pascales et annales mineures du Moyen Âge», à paraitre en 2019 dans l'Annuaire-bulletin de la Société d'Histoire de France (publication de la communication donnée lors de l'assemblée générale de la SHF le 22 juin 2017).

157. LeCouteuX, 2011, p. 161-162 ; LeCouteuX, 2015, t. 2, annexe $n^{\circ}$ 7, 223-242 et planches XXIa, XXIb et XXIc. 

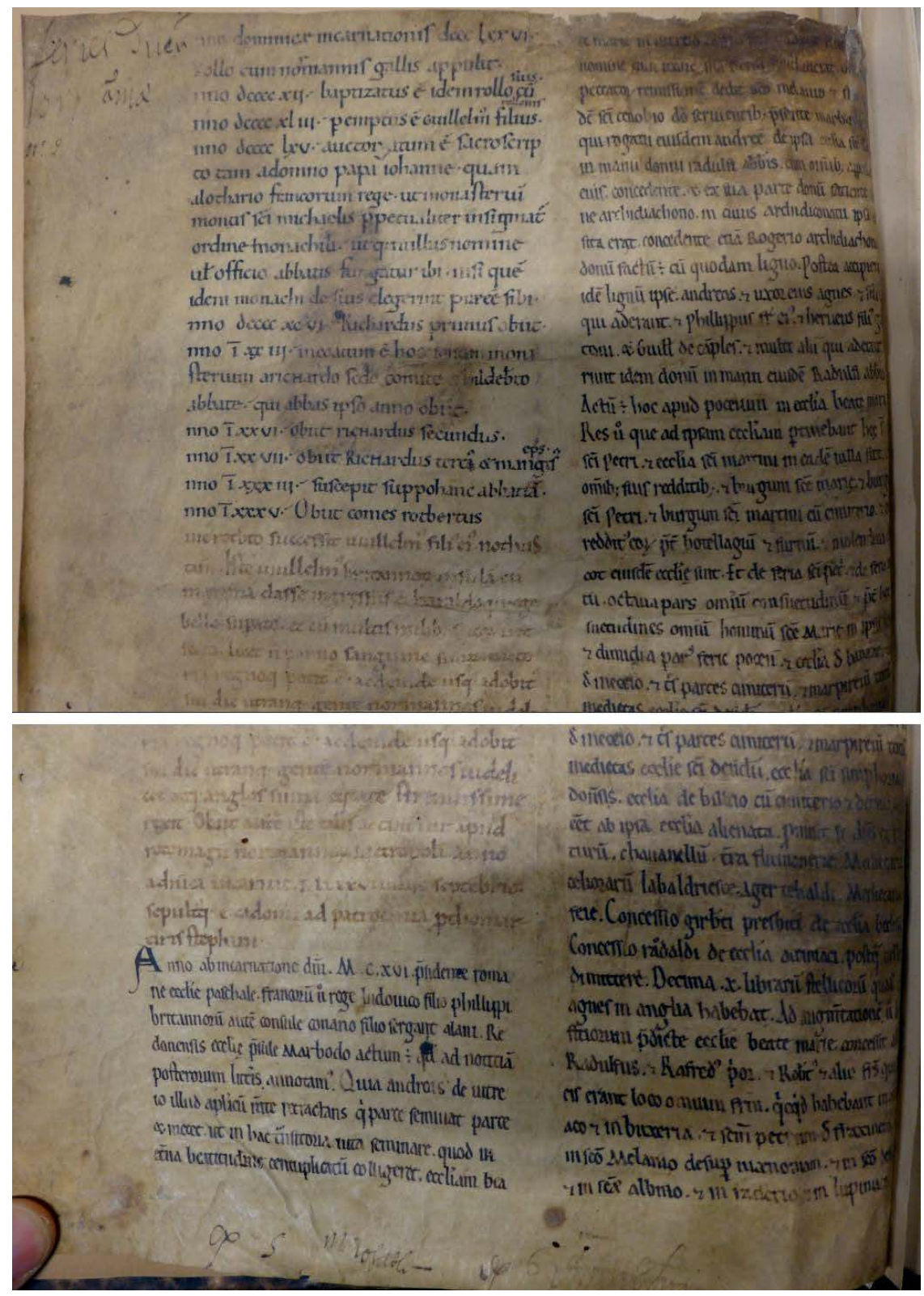

Planche $\mathrm{n}^{\mathrm{o}} \mathrm{I}$ : les Brèves annales mineures du Mont Saint-Michel [M1] (ms Paris, BnF, lat. 1183o, fol. 2v, col. A; reproduction personnelle sur original) 


\section{Bibliographie}

\section{Sources manuscrites}

Les reproductions des manuscrits du Mont Saint-Michel conservés à Avranches sont consultables sur le site de la Bibliothèque virtuelle du Mont Saint-Michel, ceux conservés à la BnF sont consultables sur Gallica (utilisez les hyperliens pour accéder à ces reproductions; dernière consultation 29 mars 2018).

Avranches, Bibl. patrimoniale, ms. 159, fol. 170v-174v (1154): De immutatione ordinis monachorum.

Avranches, Bibl. patrimoniale, ms 159, fol. 180v-236 (v. 1150-1186): Chronique de Robert de Torigni.

Avranches, Bibl. patrimoniale, ms 210, fol. 4V-10 (vers 1150): Revelatio ecclesiae sancti Michaelis archangeli in Monte qui dicitur Tumba.

Avranches, Bibl. patrimoniale, ms 210, fol. 10-19 (vers 1150): Introductio monachorum.

Avranches, Bibl. patrimoniale, ms 210, fol. 19v-112 (vers 1150) : cartulaire du Mont Saint-Michel.

Avranches, Bibl. patrimoniale, ms 211, fol. 67-77v (1116, avec interpolations et additions $\mathrm{XII}^{\mathrm{e}}-\mathrm{XV}^{\mathrm{e}}$ s.) : Annales du Mont Saint-Michel [M2].

Avranches, Bibl. patrimoniale, ms 211, fol. 156-161 (fin $\mathrm{X}^{\mathrm{e}}$-début $\mathrm{XI}^{\mathrm{e}} \mathrm{s}$.): Liber de apparitione sancti Michaelis archangeli in Monte Gargano.

Avranches, Bibl. patrimoniale, ms 211, fol. 180v-188v (fin X'e-début $\mathrm{XI}^{\mathrm{e}} \mathrm{s}$.): Revelatio ecclesiae sancti Michaelis archangeli in Monte qui dicitur Tumba.

Avranches, Bibl. patrimoniale, ms 213, fol. 95-97 (début XV ${ }^{\mathrm{e}}$ s.) : Liber de apparitione sancti Michaelis archangeli in Monte Gargano.

Avranches, Bibl. patrimoniale, ms 213, fol. [128-129v]130-132V (début XV s.): Revelatio ecclesiae sancti Michaelis archangeli in Monte qui dicitur Tumba.

Avranches, Bibl. patrimoniale, ms 213, fol. 133-138 (début XV ${ }^{\mathrm{e}}$ s.) : Introductio monachorum.

Avranches, Bibl. patrimoniale, ms 213, fol. 138-143v et 146-148v (début XV s.) : Miracula sancti Michaelis (I-VI et VII-XI).

Avranches, Bibl. patrimoniale, ms 213, fol. 143V-146 (début XVe s.): De translatione et miraculis beati Autberti.

Avranches, Bibl. patrimoniale, ms 213, fol. 150-153 (début XV s.): De scuto et gladio de Baudri de Bourgueil.

Avranches, Bibl. patrimoniale, ms 213, fol. 170-173v (début $\mathrm{XV}^{\mathrm{e}} \mathrm{s}$.): Annales mineures du Mont Saint-Michel [M4].

Avranches, Bibl. patrimoniale, ms 213, fol. 178-181v (début XV ${ }^{\mathrm{e}}$ s., avec continuation du milieu du XV ${ }^{\mathrm{e}}$ s.): De abbatibus hujus loci rubrica abreviata.

Avranches, Bibl. patrimoniale, ms 214, partie 3, p. 1-196 (1207-1212): martyrologenécrologe du Mont Saint-Michel.

Avranches, Bibl. patrimoniale, ms 214, partie 4, p. 109-199 (début du XIII s.) : nécrologe du Mont Saint-Michel.

Paris, BnF, ms lat. 6042, fol. 1v (v. 116o) : catalogue des abbés du Mont Saint-Michel.

URL: http://journals.openedition.org/tabularia/2973 | DOI: 10.4000/tabularia.2973 
Paris, BnF, ms lat. 10062, fol. 138-160 (XII siècle): Annales de Saint-Évroult.

Paris, BnF, ms lat. 1183o, fol. 2v (v. 1040): Brèves annales mineures du Mont Saint-Michel $\left[\mathrm{M} 1 ;\right.$ cf. planche $\left.\mathrm{n}^{\mathrm{o}} \mathrm{I}\right]$.

Paris, BnF, ms lat. 13905, p. 138-139 ou fol. 72V-73 (fin XVII ${ }^{\mathrm{e}}$-début XVIII s. ): Annales du Bec (copie de Dom Jouvelin).

Paris, BnF, ms lat. 14832, f. 183V-184r (copie du XII ${ }^{e}$ siècle): Convention entre l'abbé Renouf du Mont Saint-Michel et l'évêque Jean d'Avranches (1061).

\section{Sources imprimées}

Bisson, Marie, Une édition numérique structurée à l'aide de la Text Encoding Initiative des textes montois de dom Thomas Le Roy: établissement critique des textes, recherches sur les sources, présentation littéraire et historique, thèse de doctorat de littérature et lettres anciennes, Caen, UFR HSS (dir. Catherine Jacquemard et Véronique Gazeau), 2015.

Bisson, Thomas (éd. et trad.), «On the Abbots of Le Mont Saint-Michel. An Edition and Translation", The Haskins Society Journal (Studies in Medieval History, 22, 2010), 2012, p. 163-191.

Bouet, Pierre et Desbordes, Olivier (éd. et trad.), Cartulaire du Mont-Saint-Michel. Fac-similé du manuscrit 210 de la Bibliothèque municipale d'Avranches, Le MontSaint-Michel, Les Amis du Mont-Saint-Michel, 2005.

Bougaud, Louis-Emile et Garnier, Joseph (éd.), Chronique de l'abbaye de SaintBénigne de Dijon, suivie de la Chronique de Saint-Pierre de Bèze, Dijon, Darantière (Analecta Divionensia, 9), 1875.

Delisle, Léopold (éd.), De immutatione ordinis monachorum, in Chronique de Robert de Torigni, abbé du Mont Saint-Michel, Rouen, A. Le Brument, 1872-1873, t. 2, p. 184-205.

Delisle, Léopold (éd.), Chronique de Robert de Torigni, abbé du Mont-Saint-Michel, Rouen, A. Le Brument, 1872-1873, 2 vol.

Du Monstier, Arthur (éd.), Neustria pia, seu de omnibus et singulis Abbatiis et Prioratibus totius Normaniae, Rothomagi, apud Ioannem Berthelin, 1663.

Fauroux, Marie (éd.), Recueil des actes des ducs de Normandie de 911 à 1066, Caen, Caron (Mémoires de la Société des Antiquaires de Normandie, 36), 1961.

Guillotel, Hubert (éd.), Les actes des ducs de Bretagne (944-1148), Rennes, Presses universitaires de Rennes (Sources médiévales de l'histoire de Bretagne, 3), 2014.

Halphen, Louis et Lot, Ferdinand (éd.), Recueil des actes de Lothaire et de Louis V, rois de France (954-987), Paris, Imprimerie nationale - Librairie C. Klincksieck, 1908.

Holder-Egger, Oswald (éd.), «Ex annalibus normannicis», Monumenta Germaniae Historica, Scriptorum [MGH SS], Hannovre, t. XXVI, 1882, p. 488-50o.

Howlett, Richard (éd.), The Chronicle of Robert of Torigni, Abbot of the Monastery of St. Michael-in-Peril-of-the-Sea, in Chronicles of the Reigns of Stephen, Henry II, and Richard I, Vol. IV, London, Eyre and Spottiswoode (Rerum britannicarum medii aevi scriptores, 82), 1889 (réimpr. Cambridge, Cambridge University Press, 2012).

Keats-Rohan, Katharine S.B. (éd.), The Cartulary of the Abbey of Mont-Saint-Michel, Donington, Shaun Tyas, 2006. 
[Labbe, Philippe (éd.)] Philippi Labbaei S. J. Novae Bibliothecae manuscript(orum) librorum tomus primus, Historias, chronica, sanctorum, sanctarumque vitas, translationes, miracula, stemmata genealogica [...] repraesentans. Opera ac studio Philippi Labbe, [...] Parisiis, apud Sebastianum Cramoisy [...] et Gabrielem Cramoisy, 1657, p. 350-352, De abbatibus Montis Sancti Michaelis in periculo maris (rééd. in Patrologia Latina, 202, col. 1325-1328).

LAPORTE, Jean (éd.), Inventio et miracula sancti Vulfranni, Rouen-Paris, Société de l'histoire de Normandie (Mélanges; $14^{\mathrm{e}}$ série), 1938, p. 7-87.

Lauer, Philippe (éd.), Annales de Flodoard, Paris, Picard, 1906.

LAporte, Jean (éd. et trad.), Annales de l'abbaye Saint-Pierre de Jumièges, Chronique universelle des origines au XIII siècle, Rouen, Imprimerie Lecerf, 1954.

Poulle, Emmanuel (préf.), Bouet, Pierre et Desbordes, Olivier (trad.), Chroniques latines du Mont Saint-Michel (IX ${ }^{e}-X I I^{e}$ siècle), Caen, Presses universitaires de Caen, 2009.

ZimmermanN, Harald (éd.), Papsturkunden 896-1046, 3 vol. (t. I: 896-996; t. II : 996-1046; t. III : Register), Wien (Österreichische Akademie der Wissenschaften, Philosophisch-historische Klasse, Denkschriften, 174, 177 et 198), 1984, 1985 et 1989.

\section{Études}

Alexander, Alison, Annalistic Writing in Normandy, c. 1050-1225, thèse de doctorat d'histoire médiévale, Emmanuel College, université de Cambridge (dir. Elisabeth van Houts), Cambridge, 2011.

Allen, Richard, The Norman episcopate, 989-1110, thèse de doctorat d'histoire, Université de Glasgow, 2009, consultable en ligne: http://theses.gla.ac.uk/1218/.

Allen, Richard, «Les actes des évêques d'Avranches, ca. 990-1253: esquisse d'un premier bilan», Tabularia [En ligne], Actes épiscopaux et abbatiaux en Normandie et dans le grand Ouest européen, mis en ligne le 20 décembre 2012. URL: http:// journals.openedition.org/tabularia/639.

Arnoux, Mathieu, «Un Vénitien au Mont-Saint-Michel: Anastase, moine, ermite et confesseur († vers 1085)», Médiévales, 28, 1995, p. 55-78.

Arnoux, Mathieu, «Before the Gesta Normannorum and beyong Dudo. Some Evidence on Early Norman Historiography», Anglo-Norman Studies, 22, 1999, p. 29-48.

Bisson, Thomas, "The "annuary" of Abbot Robert de Torigni (1155-1159)», AngloNorman Studies, 33, 2011 p. 61-73.

Bisson, Thomas, "A Micro-Economy of Salvation: Further Thoughts on the "Annuary" of Robert of Torigni", à paraître en 2018 dans Anglo-Norman Studies.

Bulst, Neithard, Untersuchungen zu den Klosterreformen Wilhelms von Dijon (9621031), Bonn, L. Röhrscheid, 1973 (Pariser historische Studien, 11). Traduction italienne = Ricerche sulle riforme monastiche di Guglielmo da Volpiano (962-1031), «Supplemento: Fonti e bibliografia, 1973-2014» (p. 331-341), Foglizzo, Byte and Type, 2014.

Chédeville, André et Guillotel, Hubert, La Bretagne des saints et des rois ( $V^{e_{-}}$ $X^{e}$ siècle), Rennes, Éditions Ouest-France (Université), 1984. 
Deflou-Leca, Noëlle, «De l'Italie à la Bourgogne, la carrière monastique d'un aristocrate italien: Heldric, abbé réformateur ( $\dagger 1010)$ ", in Forgerons, élites et voyageurs d'Homère à nos jours, Mélanges en mémoire d'Isabelle Ratinaud-Lachkar, M.-C. Ferriès, M.-P. Castiglioni, F. Letoublon (éd.), Grenoble, Presses universitaires de Grenoble (La pierre et l'écrit; 59), 2013, p. 407-422.

Delisle, Léopold, «Annales de Rouen et textes qui en dérivent», in Histoire littéraire de la France, Paris, t. 32, 1898, p. 194-212.

GANDy, George N., «Who built what at Mont Saint-Michel during the 1oth Century?», Annales de Normandie, 65, 2015, p. 155-182.

GANDy, George N., «Retour sur la fondation de l'Abbaye du Mont Saint-Michel et le rôle du duc Richard I ${ }^{\text {er }}$ de Normandie », Annales de Bretagne et des Pays de l'Ouest, $123 / 1,2016$, p. 7-33.

Garand, Monique-Cécile, Grand, Geneviève et Muzerelle, Denis, Ouest de la France et Pays de la Loire, in Catalogue des manuscrits en écriture latine portant des indications de date, de lieu ou de copiste, C. Samaran et R. Marichal (éd.), Paris, Éditions du CNRS, t. 7, 1984.

Gazeau, Véronique, "Guillaume de Volpiano en Normandie: état des questions ", Tabularia [En ligne], Guillaume de Volpiano: Fécamp et l'histoire normande, mis en ligne le 22 juillet 2002. URL: http://journals.openedition.org/tabularia/1756.

Gazeau, Véronique, Normannia monastica ( $X^{e}-X I^{e}$ siècle), 2 vol. (t. I: Princes normands et abbés bénédictins; $\mathrm{t}$. II: Prosopographie des abbés bénédictins), Caen, Publications du Crahm, 2007.

Gazeau, Véronique, «Die Werke des Robert von Torigni als Quellen zur Erstellung einer Prosopographie der normannischen Äbte», in „Eure Namen sind im Buch des Lebens geschrieben". Antike und mittelalterliche Quellen als Grundlage moderner prosopographischer Forschung (actes du colloque de Mayence, 23-25 mars 2011), éd. Rainer Berndt, Münster/Westf., Aschendorff (Erudiri Sapientia, 11), 2014, p. 241-259.

Gazeau, Véronique et Goullet, Monique (éd. et trad.), Guillaume de Volpiano. Un réformateur en son temps (962-1031). Vita domni Willelmi de Raoul Glaber, Caen, Publications du Crahm, 2008.

GuenéE, Bernard, Histoire et culture historique dans l'Occident médiéval, Paris, Aubier Montaigne (Collection historique), 1980.

Guyotjeannin, Olivier, «La conquête du millésime: un art notarial du temps dans l'Occident médiéval», Micrologus, 19, 2011, p. 37-59.

Guyotjeannin, Olivier et Tock, Benoît-Michel, «"Mos presentis patrie”: les styles de changement du millésime dans les actes français (XI'-XVI ${ }^{\mathrm{e}}$ siècle)», Bibliothèque de l'École des Chartes, 157, 1999, p. 41-109.

Keats-Rohan, Katharine S. B., «Une charte de l’abbé Mayeul de Cluny et la réforme du Mont Saint-Michel», in La Normandie vers l'an mil, François DE BEAUREPAIRE et Jean-Pierre Chaline (dir.), Rouen, Société de l'Histoire de Normandie, 200o, p. 159-169.

KeAts-Rohan, Katharine S. B., «L'histoire secrète d'un sanctuaire célèbre. La réforme $\mathrm{du}$ Mont Saint-Michel d'après l'analyse de son cartulaire et de ses nécrologes », in Culte et pèlerinages à saint Michel en Occident. Les trois monts dédiés à l'archange, Pierre Bouet, Giorgio Otranto et André Vauchez (dir.), Rome, École française de Rome (Collection de l'École française de Rome, 316), 2003, p. 139-159. 
Knowles, David, Brooke, C. N. L. et London, Vera C. M., The Heads of Religious Houses. England and Wales (940-1216), Cambridge, Cambridge University Press, 2009.

LAPORTE, Jean, «Les séries abbatiale et priorale du Mont Saint-Michel», in Millénaire monastique du Mont Saint-Michel, t. I, Histoire et vie monastiques, Paris, P. Lethielleux (Bibliothèque d'histoire et d'archéologie chrétiennes), 1967, p. 267-281.

Lecouteux, Stéphane, Les Annales de Flodoard de Reims (919-966) dans la tradition historiographique du Moyen Âge. Travail de l'annaliste et de l'historien, perception et maîtrise du temps (VIII ${ }^{e}$-XII ${ }^{e}$ siècles), Mémoire de Master 2 de l'EPHE, dir. AnneMarie Turcan-Verkerk, Paris, 2011.

Lecouteux, Stéphane, Réseaux de confraternité et histoire des bibliothèques. L'exemple de l'abbaye bénédictine de la Trinité de Fécamp, thèse de doctorat d'histoire médiévale, Caen, UFR Histoire (dir. Catherine Jacquemard et Anne-Marie TurcanVerkerk), 2015, 2 vol., HAL Id: tel-01572371.

Lecouteux, Stéphane, «Écrire l'histoire des abbés du Mont Saint-Michel. 1. Les auteurs du De abbatibus», Tabularia [En ligne], Sources en ligne, mis en ligne le 24 novembre 2017. URL: http://journals.openedition.org/tabularia/2927.

Lecouteux, Stéphane, «Sur le risque de sur-interprétation des silences de l'historien. L'exemple des Brèves annales du Mont Saint-Michel», à paraître aux Presses universitaires de Caen.

Margo, Florence, «L'abbaye romane: du bien-fondé d'une nouvelle recherche sur l'abbaye du Mont Saint-Michel à l'époque ducale», Les amis du Mont Saint-Michel, 105,2000, p. 23-31.

MARgo, Florence, «Les cryptes romanes du mont Saint-Michel: ordonnance des espaces", in Espace ecclésial et liturgique au Moyen Âge, Anne Baud (éd.), Lyon, Maison de l'Orient et de la Méditérranée, 2010 (Travaux de la Maison de l'Orient et de la Méditerranée, 53), p. 369-378.

Margo, Florence, L'abbaye du Mont Saint-Michel à l'époque ducale. Étude historique et archéologique des bâtiments monastiques et chapelles inférieures, thèse de doctorat en préparation à l'université de Lyon.

Mc Cormick, Michael, Les annales du haut Moyen Âge, Turnhout, Brepols, 1975 (Typologie des sources du Moyen Âge occidental, 14).

Morelle, Laurent, «Pratiques médiévales de l'écrit documentaire», Annuaire de l'École pratique des hautes études (EPHE), Section des sciences historiques et philologiques (Conférences de l'année 2011-2012), 144, 2013, p. 110-114.

PoHL, Benjamin, «Abbas qui et scriptor? The Handwriting of Robert of Torigni and his Scribal Activity as Abbot of Mont-Saint-Michel (1154-1186)», Traditio, 69, 2014, p. 45-86.

PoHL, Benjamin, «The "Bec Liber Vitae”. Robert of Torigni’s sources for Writing the History of the Clare Family at Bec, c. 1128-1154", Revue bénédictine, 126, 2016, p. 324-372.

Poulle, Emmanuel, «À propos des Annales du Mont-Saint-Michel», Revue de l'Avranchin et du Pays de Granville, 8o, 2003, fasc. 394 (mars), p. 61-69.

Rosé, Isabelle, «Circulation abbatiale et pouvoir monastique de l'époque carolingienne au premier âge féodal (IX ${ }^{\mathrm{e}}-\mathrm{XI}^{\mathrm{e}}$ siècle)», in Des sociétés en mouvement. Migrations et mobilité au Moyen Âge, XL ${ }^{\mathrm{e}}$ Congrès de la SHMESP (Nice, 4-7 juin 2009), Paris, Publications de la Sorbonne (Histoire ancienne et médiévale, 104), 2010, p. 251-266. 
Sapin, Christian, Baylé, Maylis, Büttner, Stéphane, Guibert, Pierre, Blain, Sophie, Lanos, Philippe, Chauvin, Annick, Dufresne, Philippe, Oberlin, Christine, "Archéologie du bâti et archéométrie au Mont-Saint-Michel, nouvelles approches de Notre-Dame-sous-Terre», Archéologie Médiévale, 38, 2008, p. 71-122.

Stirnemann, Patricia, «Two Twelfth-Century Bibliophiles and Henry of Huntingdon's Historia Anglorum», Viator, 24, 1993, p. 121-142. 
Reconstitution des Annales pascales du Mont Saint-Michel (M3*) élaborées en 1154 par Robert de Torigni ${ }^{158}$

\begin{tabular}{|c|c|c|}
\hline \multirow{2}{*}{$\begin{array}{l}\text { Sources de } \mathrm{M}^{*} \\
\text { (extraits): } \\
\text { Annales du Bec (B) et } \\
\text { Annales du Mont Saint- } \\
\text { Michel (M2) }\end{array}$} & $\begin{array}{l}\text { Reconstitution des } \\
\text { Annales pascales } d u \\
\text { Mont Saint-Michel }\left(\mathrm{M}_{3}^{*}\right)\end{array}$ & $\begin{array}{l}\text { Annales mineures } d u \\
\text { Mont Saint-Michel } \\
\left(\mathrm{M}_{4}=\text { copie de } \mathrm{M}_{3}^{*}\right)\end{array}$ \\
\hline & $\begin{array}{l}\text { 506. Facta est revelatio } \\
\text { beati Michaelis in monte } \\
\text { Gargano sub Zenone } \\
\text { imperatore et Gelasio } \\
\text { papa }^{159} \text {. }\end{array}$ & $\begin{array}{l}\text { 506. Facta est revelatio } \\
\text { beati Michaelis in monte } \\
\text { Gargano sub Zenone } \\
\text { imperatore et Gelasio } \\
\text { papa. }\end{array}$ \\
\hline $\begin{array}{l}\text { M2 } 708 \text {. Hoc tempore } \\
\text { revelatio huius loci facta } \\
\text { est sub Alberto, Abrincis } \\
\text { episcopo. }\end{array}$ & $\begin{array}{l}\text { 7o8. Facta est revelatio } \\
\text { beati Michaelis in } \\
\text { monte Tumba sub } \\
\text { Childeberto, rege } \\
\text { Francorum, et Autberto, } \\
\text { episcopo Abrincensi }{ }^{160} \text {. }\end{array}$ & $\begin{array}{l}\text { 708. Facta est revelatio } \\
\text { beati Michaelis in } \\
\text { monte Tumba sub } \\
\text { Childeberto, rege } \\
\text { Francorum, et Autberto, } \\
\text { episcopo Abrincensi. }\end{array}$ \\
\hline $\begin{array}{l}\text { B 851. Venit Hastingus in } \\
\text { regnum Francorum. }\end{array}$ & $\begin{array}{l}\text { 851. Venit Hastingus in } \\
\text { regnum Francorum. }\end{array}$ & $\begin{array}{l}\text { 851. Venit Hastingus in } \\
\text { regnum Francorum. }\end{array}$ \\
\hline $\begin{array}{l}\text { B 876. Venit Rollo in } \\
\text { Normannia } X V^{\circ} \text { kalendas } \\
\text { decembris. }\end{array}$ & $\begin{array}{l}\text { 876. Venit Rollo in } \\
\text { Normannia, } X V^{\circ} \text { kalen- } \\
\text { das decembris. }\end{array}$ & $\begin{array}{l}\text { 876. Venit Rollo in } \\
\text { Normannia, } V^{\circ} \text { kalendas } \\
\text { decembris. }\end{array}$ \\
\hline $\begin{array}{l}\text { B 917. Obiit Rollo, cui } \\
\text { successit Willelmus, filius } \\
\text { eius. }\end{array}$ & $\begin{array}{l}\text { 917. Obiit Rollo, cui } \\
\text { successit Willelmus, filius } \\
\text { ejus }^{161} \text {. }\end{array}$ & $\begin{array}{l}\text { 917. Obiit Rollo, cui } \\
\text { successit Guillermus, } \\
\text { filius ejus. }\end{array}$ \\
\hline
\end{tabular}

158. En gras dans la première colonne: les notes ajoutées de la main de Robert de Torigni dans M2. En gras dans la deuxième colonne: les notes de $\mathrm{M}_{3}{ }^{*}$ ayant servi de source au De abbatibus. Lorsque la graphie des noms diverge entre B, $\mathrm{M}_{2}$ et $\mathrm{M}_{4}$, j'adopte dans $\mathrm{M}_{3}{ }^{*}$ (XII ${ }^{\mathrm{e}}$ s.) la graphie de $\mathrm{B}$ et $\mathrm{M}_{2}$ $\left(\mathrm{XII}^{\mathrm{e}} \mathrm{s}\right.$.), plus proche dans le temps que celle de $\mathrm{M}_{4}\left(\mathrm{XV}^{\mathrm{e}} \mathrm{s}\right.$.).

159. Source utilisée: version interpolée du Liber de apparitione sancti Michaelis in Monte Gargano, telle qu'on la trouve dans le ms Avranches, Bibl. patrimoniale, 213, fol. 95 (Poulle, Bouet et Desbordes, 2009, p. 113, n. 4, et 125, n. 2).

160. Sources utilisées: les annales M2 ont été complétées soit avec l'incipit de la Revelatio ecclesiae sancti Michaelis archangeli in Monte qui dicitur Tumba (Poulle, Bouet et Desbordes, 2009, p. 90-91), soit avec le début du second chapitre de l'Introductio monachorum (Poulle, Bouet et Desbordes, 2009, p. 204-205).

161. Source utilisée: Annales du Bec plutôt que les annales M2 - qui ajoutent primus dux Normannorum après Rollon. 


\begin{tabular}{|c|c|c|}
\hline $\begin{array}{l}\text { B 942. Occisus est } \\
\text { Willelmus, filius Rollonis, } \\
\text { cui successit filius eius } \\
\text { Richardus vetulus. } \\
\text { M2 943. Hoc anno } \\
\text { occiditur Guillelmus, } \\
\text { filius Rollonis, cui } \\
\text { successit Richardus, filius } \\
\text { eius, qui Vetus dicitur. }\end{array}$ & $\begin{array}{l}\text { 942. Occisus est } \\
\text { Willelmus, filius Rollonis, } \\
\text { cui successit Richardus, } \\
\text { filius ejus, qui Vetus } \\
\text { dicitur }^{162} \text {. }\end{array}$ & $\begin{array}{l}\text { 942. Occisus est } \\
\text { Guillermus, filius } \\
\text { Rollonis, cui successit } \\
\text { Richardus, filius ejus... }\end{array}$ \\
\hline $\begin{array}{l}\text { M2 965. Mainardus.I., } \\
\text {.I. abbas. }\end{array}$ & $\begin{array}{l}\text { 966. Richardus primus } \\
\text { posuit monachos in } \\
\text { ecclesia Sancti Michaelis } \\
\text { in periculo maris, } \\
\text { Mainardum scilicet } \\
\text { primum abbatem, qui } \\
\text { fuerat abbas Sancti } \\
\text { Wandregisili per V } \\
\text { annos, et alium } \\
\text { Mainardum, nepotem } \\
\text { suum, cum ceteris } \\
\text { monachis }{ }^{163} \text {. }\end{array}$ & $\begin{array}{l}{[\ldots] \text { qui primus posuit }} \\
\text { monachos in ecclesia } \\
\text { Sancti Michaelis in } \\
\text { periculo maris, anno } \\
\text { Domini IXc LXVI, } \\
\text { Mainardum scilicet } \\
\text { primum abbatem, qui } \\
\text { fuerat abbas Sancti } \\
\text { Wandregisili per V annos, } \\
\text { et alium Mainardum, } \\
\text { nepotem suum, cum } \\
\text { ceteris monachis. }\end{array}$ \\
\hline
\end{tabular}

162. La source utilisée est ici difficile à identifier: les Annales $d u$ Bec donnent la même année (942), mais la note des Annales du Mont Saint-Michel, bien que rapportée à l'année 943, paraît plus proche. Les deux sources furent peut-être utilisées conjointement.

163. Sources utilisées: les Annales M2, complétées à l'aide de l'Introductio monachorum (Poulle, BOUET et DESBORDES, 2009, p. 208-223), de l'Inventio et miracula sancti Vulfranni (LAPORTE, 1938, chap. 14-16 p. 32-33: Robert de Torigni connaissait cette source: ibid., p. 34, n. 32), des Annales de Saint-Wandrille (ms Den Haag, Koninklijke Bibliotheek, 128 E 14, qui donne à l'année 960 [fol. 8v] : "Mainardus abbas Fontanellam reedificat»), et d'un catalogue des abbés de Fontenelle/SaintWandrille. Robert de Torigni disposait de ces mêmes sources relatives à Fontenelle/Saint-Wandrille lorsqu' il composa son De immutatione ordinis monachorum en 1154. Ces sources lui permirent, en effet, d'écrire les informations suivantes (ms Avranches, Bibl. patrimoniale, 159, fol. 172V): Secundus Ricardus, dux Normanniae, ex integro abbatiam Sancti Wandregisili, quam Fontinellam antiquitus vocaverunt, reaedificavit. A sancto Wandregisilo usque ad Mainardum, qui tempore primi Ricardi coeperat eundem locum pro posse suo emendare, fuerunt abbates XXIIII. A Mainardo usque ad praesens tempus, duodecim, quorum ultimus fuit Rogerus (sic Rogerius), monachus ejusdem loci, qui adhuc superest (DelisLe, 1872-1873, t. 2, p. 194). Pour obtenir douze successeurs à Mainard, Robert de Torigni tient compte des trois rectores qui lui ont fait suite et ont précédé le réformateur Gérard, venu de Lagny et Saint-Arnoul de Crépy-en-Valois (Laporte, 1938, chap. 16, p. 34). Robert de Torigni avait indiqué un peu plus haut le texte suivant, sans doute d'après Dudon de Saint-Quentin (Dudon, IV, 126, p. 290): Primus Ricardus, filius Willermi ducis, tria monasteria, unum Fiscanni in honorem summae Trinitatis, aliud in monte Tumba in honorem sancti Michaelis, tercium Rothomagi in veneratione sancti Petri sanctique Audoeni, multas possessiones quae eis a Paganis ablatae fuerant restituendo, restauravit (ms Avranches, Bibl. patrimoniale, 159, fol. 172-172v; DeLISLE, 1872-1873, t. 2, p. 192). Le glissement de l'année 965 à l'année 966 s'explique vraisemblablement par la connaissance du diplôme interpolé de Lothaire, daté de l'année 965 par l'auteur de M1 (date reprise par le copiste de M2, mais corrigée par Robert de Torigni lors de l'élaboration des Annales pascales du Mont Saint-Michel: ce diplôme est, en effet, du 7 février 966; HALPHEN et Lot, 1908, nº 24, p. 53-57). 


\begin{tabular}{|l|l|l|}
\hline $\begin{array}{l}\text { M2 991. Mainardus.II., } \\
\text {.II. abbas. }\end{array}$ & $\begin{array}{l}\text { 991. Successit Mainardo } \\
\text { abbati Mainardus, } \\
\text { nepos eius. }\end{array}$ & $\begin{array}{l}\text { 991. Successit Mainardo } \\
\text { abbati Mainardus, nepos } \\
\text { eius. }\end{array}$ \\
\hline $\begin{array}{l}\text { M2 996. Richardus, } \\
\text { Normannorum dux, } \\
\text { filius Guillelmi, obiit. } \\
\text { Cui successit Richardus } \\
\text { secundus, filius eius. }\end{array}$ & $\begin{array}{l}\text { 996. Obiit primus } \\
\text { Richardus, dux } \\
\text { Normannorum, cui } \\
\text { successit secundus } \\
\text { Richardus, filius eius }{ }^{164} .\end{array}$ & $\begin{array}{l}\text { 996. Obiit primus } \\
\text { Richardus, dux } \\
\text { Normannorum, cui } \\
\text { successit secundus } \\
\text { Ricardus, filius ejus. }\end{array}$ \\
\hline & $\begin{array}{l}\text { Hic Richardus duxit } \\
\text { Iudit, sororem comitis } \\
\text { Britanniae, ex qua } \\
\text { genuit duos filios, } \\
\text { Richardum et Robertum, } \\
\text { qui ei successerunt. } \\
\text { Gaufridus uero, comes } \\
\text { Britanniae, Hadevisam, } \\
\text { sororem praedicti } \\
\text { Richardi, ex qua genuit } \\
\text { duos filios, Alanum et } \\
\text { Eudonem } 165\end{array}$ & $\begin{array}{l}\text { Hic Ricardus duxit Iudit, } \\
\text { sororem comitis } \\
\text { Britanniae, ex qua } \\
\text { genuit duos filios, } \\
\text { Ricardum et Robertum, } \\
\text { qui ei successerunt. } \\
\text { Gaufridus uero, comes } \\
\text { Britanniae, Hadevisam, } \\
\text { sororem praedicti } \\
\text { Ricardi, ex qua genuit } \\
\text { duos filios, Alanum et } \\
\text { Eudonem. }\end{array}$ \\
\hline
\end{tabular}

164. Source utilisée: les annales M2 plutôt que les Annales du Bec (qui donnent: Moritur Ricardus vetus, ei succedit filius ejus Ricardus secundus).

165. Sources utilisées: archives de l'abbaye (notamment les actes des ducs de Normandie Richard II et Robert, et surtout ceux du comte Alain III de Bretagne reproduits dans le cartulaire: ms Avranches, Bibl. patrimoniale, 210, fol. 19-23v, 24-25, 26-27v, 40-42, 46-47, 47-48 et 71V-72v; FAUROUX, $1961, \mathrm{n}^{\circ} 12$ p. $85-86, \mathrm{n}^{\circ} 17$ p. $98-100, \mathrm{n}^{\circ} 47$, p. $155-156, \mathrm{n}^{\circ} 49$, p. $158-162, \mathrm{n}^{\circ} 65$, p. $195-197$, $\mathrm{n}^{\circ} 73$, p. 210-214; Keats-Rohan, 2006, ${ }^{\circ}$ 2-5, p. 76-83, $\mathrm{n}^{\circ} 17$, p. 97-99, ${ }^{\circ}$ 23, p. 104-105, $\mathrm{n}^{\circ} 52$, p. 135-136; Bouet et Desbordes, 2009, $\mathrm{n}^{\circ} 7$, p. 386, $\mathrm{n}^{\circ} 13$, p. 389-39o, $\mathrm{n}^{\text {os }} 15-18$, p. 391-394 et $\mathrm{n}^{\text {os }}$ 20-21, p. 395-397; Guillotel, 2014, $\mathrm{n}^{\circ}$ 17, 18 et 22) et généalogie des ducs de Normandie, connue de Robert de Torigni (voir par exemple dans son De immutatione ordinis monachorum (ms Avranches, Bibl. patrimoniale, 159, fol. 172v et 173): Judith comitissa, uxor secundi Ricardi; Robertus, dux Normanniae, filius secundi Ricardi; Delisle, 1872-1873, t. 2, p. 194 et 195). Voir aussi ses interpolations à Guillaume de Jumièges. On remarquera que cette généalogie s'efforce de mentionner les principaux membres des familles ducale normande et comtale/ducale bretonne attestés comme bienfaiteurs du Mont Saint-Michel ou mentionnés dans les actes produits entre la fin du $\mathrm{X}^{\mathrm{e}}$ siècle et 1035 , en précisant les liens matrimoniaux les unissant - la note indique que le duc de Normandie Richard II épousa Judith, sœur du comte de Bretagne Geoffroy, avec laquelle il eut deux fils, Richard et Robert, qui lui succédèrent; elle précise ensuite que ce comte Geoffroy de Bretagne épousa Hadevise, la sœur du même Richard II, avec laquelle il eut deux fils, Alain et Eudes. Nous retrouvons tous ces noms sans exception dans le cartulaire du Mont Saint-Michel. 


\begin{tabular}{|c|c|c|}
\hline $\begin{array}{l}\mathrm{M} 2 \text { 1009. Hildebertus .I., } \\
. I I I^{u s} . \text { abbas. }\end{array}$ & $\begin{array}{l}\text { 10o9. Concilio ducis } \\
\text { Richardi secundus } \\
\text { Mainardus, iam } \\
\text { gravatus senio, elegit } \\
\text { successorem sibi } \\
\text { domnum Hildebertum, } \\
\text { monachum ejusdem } \\
\text { loci }{ }^{166} \text {. }\end{array}$ & $\begin{array}{l}\text { 1009. Concilio ducis } \\
\text { Ricardi secundus } \\
\text { Mainardus, iam } \\
\text { gravatus senio, elegit } \\
\text { successorem sibi domnum } \\
\text { Hyldebertum, monachum } \\
\text { ejusdem loci. }\end{array}$ \\
\hline $\begin{array}{l}\text { M2 1023. Hoc anno } \\
\text { inchoatum est hoc } \\
\text { novum monasterium a } \\
\text { Richardo secundo comite } \\
\text { et Hildeberto abbate; qui } \\
\text { abbas ipso anno obiit. } \\
\text { Eodem anno abbas. } V^{u s} \text {. } \\
\text { Almodus suscepit hanc } \\
\text { abbatiam }{ }^{167} \text {. }\end{array}$ & $\begin{array}{l}\text { 1023. Inchoata est nova } \\
\text { ecclesia Beati Michaelis a } \\
\text { Richardo secundo comite } \\
\text { et Hildeberto secundo } \\
\text { abbate; qui abbas eodem } \\
\text { anno obiit; cui successit } \\
\text { Almodus. }\end{array}$ & $\begin{array}{l}\text { 1023. Inchoata est nova } \\
\text { ecclesia Beati Michaelis a } \\
\text { Ricardo secundo comite } \\
\text { et Hildeberto secundo } \\
\text { abbate; qui abbas eodem } \\
\text { anno obiit; cui successit } \\
\text { Almodus. }\end{array}$ \\
\hline $\begin{array}{l}\mathrm{M} 2 \text { 1026. Obiit } \\
\text { Richardus secundus, dux } \\
\text { Normannorum. Cui } \\
\text { successit Richardus } \\
\text { tercius, qui eodem anno } \\
\text { mortuus est. Robertus, } \\
\text { frater eius, suscepit } \\
\text { regimen. }\end{array}$ & $\begin{array}{l}\text { 1026. Obiit } \\
\text { secundus Richardus } \\
\text { dux Normannorum. } \\
\text { Cui successit tertius } \\
\text { Richardus, filius ejus, qui } \\
\text { eodem anno mortuus est. } \\
\text { Cui successit Rotbertus, } \\
\text { frater ejus }{ }^{168} \text {. }\end{array}$ & $\begin{array}{l}\text { 1026. Obiit } \\
\text { secundus Ricardus } \\
\text { dux Normannorum. } \\
\text { Cui successit tertius } \\
\text { Ricardus, filius ejus, qui } \\
\text { eodem anno mortuus est. } \\
\text { Cui successit Robertus, } \\
\text { frater ejus. }\end{array}$ \\
\hline $\begin{array}{l}\text { M2 1033. Ordinatus est } \\
\text { abbas.VII }{ }^{u s} \text {. Suppo } \\
\text { huius loci }{ }^{169} \text {. }\end{array}$ & $\begin{array}{l}\text { 1033. Ordinatus est } \\
\text { Suppo, abbas monasterii } \\
\text { Sancti Michaelis. }\end{array}$ & $\begin{array}{l}\text { 1033. Ordinatus est } \\
\text { Suppo, abbas monasterii } \\
\text { Sancti Michaelis. }\end{array}$ \\
\hline
\end{tabular}

166. Sources utilisées: les annales M2, complétées par la charte de Richard II reproduite dans le cartulaire du Mont Saint-Michel (ms Avranches, Bibl. patrimoniale, 210, fol. 71v-72v; Fauroux, 1961, no 12 ; Poulle, Bouet et Desbordes, 2009, p. 386).

167. Cette note de M2 a été reprise des Brèves annales mineures du Mont Saint-Michel (M1 1023:Inc[h] oatum est hoc novum monasterium a Richardo secundo comite et Hildeberto abbate, qui abbas ipso anno obiit) et complétée à l'aide du catalogue des abbés du Mont Saint-Michel - qui donne par erreur Aumode après Hilderbert II. Almodus a plus tard été gratté et remplacé par Suppo (interpolation opérée dans la seconde moitié du XII ${ }^{e}$ siècle, après 1154; pour la démonstration, voir l'étape 2).

168. Source utilisée: les annales M2 plutôt que les Annales du Bec, qui donnent: Obiit Richardus secundus et successit Richardus tercius, qui eodem anno mortuus est, ei successit Robertus, frater ejus.

169. Cette note de M2 dérive des Brèves annales mineures du Mont Saint-Michel (M1 1023: Suscepit Suppo hanc abbatiam). 


\begin{tabular}{|c|c|c|}
\hline $\begin{array}{l}\text { M2 1035. Hic Robertus, } \\
\text { Normannorum princeps, } \\
\text { ab Hierosolimis rediens, } \\
\text { obiit. Cui in regnum } \\
\text { successit filius eius } \\
\text { Guillelmus in puerili } \\
\text { ętate. }\end{array}$ & 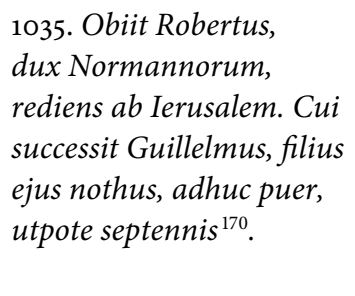 & $\begin{array}{l}\text { 1035. Obiit Robertus, } \\
\text { dux Normannorum, } \\
\text { rediens ab Ierusalem. Cui } \\
\text { successit Willermus, filius } \\
\text { ejus nothus, adhuc puer, } \\
\text { utpote septennis. }\end{array}$ \\
\hline $\begin{array}{l}\text { B 1047. Factum est } \\
\text { bellum in loco qui } \\
\text { dicitur Valesdunae inter } \\
\text { comitem Willelmum } \\
\text { Normanniae et } \\
\text { Widonem, filium } \\
\text { Rainaldi comitis } \\
\text { Burgundiorum, } \\
\text { cognatum suum. } \\
\text { M2 1048. Bellum Valles } \\
\text { Dunę. }\end{array}$ & $\begin{array}{l}\text { 1048. Factum est bellum } \\
\text { apud Valesdunas a } \\
\text { Guillelmo, duce } \\
\text { Normannorum, contra } \\
\text { Guidonem comitem, } \\
\text { cognatum suum }{ }^{171} \text {. }\end{array}$ & $\begin{array}{l}\text { 1048. Factum est bellum } \\
\text { apud Walesdunas a } \\
\text { Guillermo, duce } \\
\text { Normannorum, contra } \\
\text { Guidonem comitem, } \\
\text { cognatum suum. }\end{array}$ \\
\hline $\begin{array}{l}\text { M2 1048. Hoc anno abbas } \\
\text { Radulfus.VIII }{ }^{u s} \text {. suscepit } \\
\text { hanc abbatiam vivente } \\
\text { Suppone. }\end{array}$ & $\begin{array}{l}\text { 1048. Suppo dimisit } \\
\text { abbatiam Montis, et } \\
\text { successit ei Radulphus } \\
\text { monachus } \\
\text { Fiscannensis }^{172} \text {. }\end{array}$ & $\begin{array}{l}\text { Eodem anno, Suppo } \\
\text { dimisit abbatiam Montis, } \\
\text { et successit ei Radulphus } \\
\text { monachus Fiscannensis. }\end{array}$ \\
\hline $\begin{array}{l}\text { B 1054. Facit bellum apud } \\
\text { Mortuum Mare. } \\
\text { M2 1054. Bellum apud } \\
\text { Mare Mortuum. }\end{array}$ & $\begin{array}{l}\text { 1054. Factum est bellum } \\
\text { apud Mortuum Mare }{ }^{173} \text {. }\end{array}$ & $\begin{array}{l}1053 \text { (sic). Factum est } \\
\text { bellum apud Mortuum } \\
\text { Mare }^{174} \text {. }\end{array}$ \\
\hline $\begin{array}{l}\text { M2 1063. Hoc anno } \\
\text { subiugata est } \\
\text { Cenomannis comiti } \\
\text { Normannorum } \\
\text { Guillelmo. }\end{array}$ & $\begin{array}{l}\text { 1063. Subjugata est } \\
\text { Cenomannis comiti } \\
\text { Normannorum } \\
\text { Guillelmo. }\end{array}$ & $\begin{array}{l}\text { 1063. Subjugata est } \\
\text { Cenomannis comiti } \\
\text { Normannorum } \\
\text { Guillermo. }\end{array}$ \\
\hline
\end{tabular}

170. Source utilisée: les annales M2 plutôt que les Annales du Bec (qui ajoutent apud Niceam).

171. Ce sont les Annales du Mont Saint-Michel (M2) qui fournissent l'année erronée (1048 pour 1047), mais la source principale reste ici les Annales $d u$ Bec.

172. Source utilisée: les annales M2, mais une autre source indéterminée, précisant la démission de Suppon et l'origine fécampoise de Raoul, a peut-être été sollicitée.

173. Source utilisée: les Annales $d u$ Bec ou les annales M2 - qui placent l'une et l'autre l'événement en 1054.

174. Le copiste de $\mathrm{M}_{4}$ a reporté par erreur la note sur la succession de Renouf à Raoul à l'année 1053 au lieu de 1063 (voir l'étape 3). 


\begin{tabular}{|c|c|c|}
\hline $\begin{array}{l}\text { M2 1063. Rannulfus } . I X^{u s} \text {. } \\
\text { abbas. }\end{array}$ & $\begin{array}{l}\text { 1063. Radulpho abbati } \\
\text { successit Ranulphus, } \\
\text { monachus ejusdem } \\
\text { loci }^{175} \text {. }\end{array}$ & $\begin{array}{l}\text { Eodem anno ( } 1053 \\
\text { pour 1063) Radulpho } \\
\text { abbati successit } \\
\text { Ranulphus, monachus } \\
\text { ejusdem loci }{ }^{176} \text {. }\end{array}$ \\
\hline $\begin{array}{l}\text { M2 1066. [...] Guillelmus, } \\
\text { dux et princeps } \\
\text { Normannorum, transiit } \\
\text { mare cum ingenti } \\
\text { apparatu navium et } \\
\text { conflixit cum Anglis, } \\
\text { quos et devicit, interfecto } \\
\text { eorum rege Heroldo, } \\
\text { cum xv milibus militum, } \\
\text { II idus octobris, die } \\
\text { sabbati. Et in die Natalis } \\
\text { Domini rex gentis illius } \\
\text { effectus est. }\end{array}$ & $\begin{array}{l}\text { 1066. Guillelmus dux } \\
\text { Normannorum, mare } \\
\text { transiens, victo Heraldo, } \\
\text { regnum Anglorum } \\
\text { subjugavit }^{177} \text {. }\end{array}$ & $\begin{array}{l}\text { 1066. Guillermus, dux } \\
\text { Normannorum, mare } \\
\text { transiens, victo Heraldo, } \\
\text { regnum Anglorum } \\
\text { subjugavit. }\end{array}$ \\
\hline $\begin{array}{l}\text { M2 1083. Obiit Mathildis, } \\
\text { nobilis regina Anglorum, } \\
\text { de cuius nobilitate } \\
\text { largiflua multa apud } \\
\text { plures ecclesias habentur } \\
\text { beneficia. }\end{array}$ & $\begin{array}{l}\text { 1083. Obiit } \\
\text { Mathildis, nobilis } \\
\text { regina Anglorum }{ }^{178} \text {. }\end{array}$ & \\
\hline 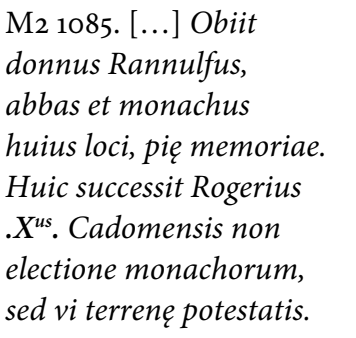 & $\begin{array}{l}\text { 1085. Obiit donnus } \\
\text { Rannulfus, abbas et } \\
\text { monachus hujus loci, } \\
\text { piae memoriae. Huic } \\
\text { successit Rogerius } \\
\text { X Cadomensis }^{179} \text {. }\end{array}$ & \\
\hline
\end{tabular}

175. Robert de Torigni a complété sa source $\left(\mathrm{M}_{2}\right)$ à l'aide du catalogue des abbés du Mont SaintMichel, qui lui donne le nom de Raoul comme prédécesseur de Renouf. Cette note de $\mathrm{M}_{3}{ }^{*}$ a servi de source au De abbatibus pour l'année 1060, mais a été adaptée par Robert de Torigni, confronté à des sources contradictoires (voir l'étape 4 pour la démonstration).

176. Le copiste a rapporté par erreur cette note, portant sur l'année 1063, à l'année 1053 (MLXIII $\rightarrow$ MLIII), comme nous l'avons expliqué dans l'étape 3 .

177. Robert de Torigni se contente ici d'abréger sa source, M2.

178. Note omise par le copiste de $\mathrm{M}_{4}$.

179. Cette note de $\mathrm{M}_{3}{ }^{*}$ a servi de source au De abbatibus pour les années 1083 et 1085 (adaptation due à Robert de Torigni, confronté à des sources divergentes: voir l'étape 4 pour la démonstration). Le copiste de $\mathrm{M}_{4}$ a omis de la reproduire. 


\begin{tabular}{|c|c|c|}
\hline $\begin{array}{l}\text { M2 1087. Obiit } \\
\text { Guillelmus, rex } \\
\text { Anglorum [...]. Cui } \\
\text { successerunt filii eius } \\
\text { Guillelmus, qui } \\
\text { cognomine dictus est } \\
\text { Rufus, in Anglia et } \\
\text { Robertus in Normannia. }\end{array}$ & $\begin{array}{l}\text { 1087. Obiit Guillelmus, } \\
\text { rex Anglorum, et } \\
\text { successerunt ei filii } \\
\text { ejus, Willelmus Rufus } \\
\text { in Anglia et Robertus, } \\
\text { primogenitus, dux in }_{\text {Normannia }}{ }^{180} \text {. }\end{array}$ & $\begin{array}{l}\text { 1087. Obiit Guillermus, } \\
\text { rex Anglorum, et } \\
\text { successerunt ei filii } \\
\text { ejus, Willelmus Rufus } \\
\text { in Anglia et Robertus, } \\
\text { primogenitus, dux in } \\
\text { Normannia. }\end{array}$ \\
\hline $\begin{array}{l}\text { M2 109o. Obsessio } \\
\text { montis huius, que facta } \\
\text { est a Guillelmo Rufo, rege } \\
\text { Anglorum, et a Roberto, } \\
\text { comite Normannorum, } \\
\text { Henrico, fratre eorum, in } \\
\text { hoc monte incluso. }\end{array}$ & $\begin{array}{l}\text { 109o. Obsessio montis } \\
\text { hujus facta est a } \\
\text { Guillelmo rege Anglorum } \\
\text { et Roberto duce, } \\
\text { Henrico, eorum fratre, in } \\
\text { hoc monte incluso. }\end{array}$ & $\begin{array}{l}\text { 109o. Obsessio montis } \\
\text { hujus facta est a } \\
\text { Guillermo rege Anglorum } \\
\text { et Roberto duce, } \\
\text { Henrico, eorum fratre, in } \\
\text { hoc monte incluso. }\end{array}$ \\
\hline $\begin{array}{l}\text { B 1095. Urbannus Papa } \\
\text { concilium tenuit apud } \\
\text { Clarum Montem. } \\
\text { M2 1095. Hoc anno } \\
\text { apud Clarum Montem } \\
\text { Urbanus papa concilium } \\
\text { tenuit [...]. }\end{array}$ & $\begin{array}{l}\text { 1095. Papa Urbannus } \\
\text { tenuit concilium apud } \\
\text { Clarum Montem. }\end{array}$ & $\begin{array}{l}\text { 1095. Papa Urbanus } \\
\text { tenuit concilium apud } \\
\text { Clarum Montem. }\end{array}$ \\
\hline $\begin{array}{l}\text { B 1096. Iter facit } \\
\text { Jerusalem. } \\
\text { M2 1096. Hoc anno } \\
\text { Hierosolimitanum iter } \\
\text { inchoatum est monitu } \\
\text { Urbani papae. }\end{array}$ & $\begin{array}{l}\text { 1096. Iter Jerosalem a } \\
\text { Christianis. }\end{array}$ & $\begin{array}{l}\text { 1096. Iter Jerusalem a } \\
\text { Christianis inchoatum } \\
\text { est. }\end{array}$ \\
\hline $\begin{array}{l}\text { M2 110o. Hoc anno } \\
\text { occisus est Guillelmus, } \\
\text { rex Anglorum, } \\
\text { Rufus [...]. Hoc } \\
\text { anno Henricus effectus } \\
\text { est rex Anglorum. }\end{array}$ & $\begin{array}{l}\text { 110o. Occissus est } \\
\text { Guillelmus Ruffus, rex } \\
\text { Anglorum, et successit ei } \\
\text { Henricus, frater ejus. }\end{array}$ & $\begin{array}{l}\text { 110o. Occisus est } \\
\text { Guillermus, rex } \\
\text { Anglorum, Ruffus, } \\
\text { et successit ei Henricus, } \\
\text { frater ejus. }\end{array}$ \\
\hline
\end{tabular}

180. Robert de Torigni abrège ici M2. 


\begin{tabular}{|c|c|c|}
\hline $\begin{array}{l}\text { M2 } 1102 . \text { Hoc anno visus } \\
\text { est a nonnullis prope ac } \\
\text { procul positis sanctus } \\
\text { Michael archangelus, } \\
\text { prout credimus, in figura } \\
\text { columpnę rutilantis, } \\
\text { nocte scilicet ultimę sue } \\
\text { festivitatis, penitrasse } \\
\text { basicam }^{181} \text { huius montis. }\end{array}$ & $\begin{array}{l}\text { 1102. Visus est a } \\
\text { nonnullis prope ac } \\
\text { procul positis sanctus } \\
\text { Michael archangelus, } \\
\text { prout credimus, in } \\
\text { figura columnae igneae, } \\
\text { [in] nocte scilicet } \\
\text { ultimae suae festivitatis, } \\
\text { penetrasse basilicam } \\
\text { huius montis }^{182} \text {. }\end{array}$ & $\begin{array}{l}\text { 1102. Visus est a } \\
\text { nonnullis prope ac } \\
\text { procul positis sanctus } \\
\text { Michael archangelus, } \\
\text { prout credimus, in figura } \\
\text { colunnae igneae, in nocte } \\
\text { scilicet suae festivitatis, } \\
\text { penetrasse ecclesiam } \\
\text { hujus montis }{ }^{183} \text {. }\end{array}$ \\
\hline $\begin{array}{l}\text { M2 1103. Hoc anno } \\
\text { pars non modica ęcclesię } \\
\text { Montis Sancti Michaelis } \\
\text { corruit in sabbato vigilię } \\
\text { Pasche, }[\text { a] monachis } \\
\text { more solito matutinis } \\
\text { peractis. In cuius } \\
\text { runa portio quedam } \\
\text { dormitorii monachorum } \\
\text { non minima destructa } \\
\text { atque eversa est cum } \\
\text { omnibus thoris et pannis, } \\
\text { monachis tamen in } \\
\text { eisdem requiescentibus } \\
\text { gratia Dei et patrocinio } \\
\text { sancti Michaelis absque } \\
\text { lesione liberatis }{ }^{184} \text {. }\end{array}$ & $\begin{array}{l}\text { 1103. Hoc anno pars non } \\
\text { modica ecclesiae Montis } \\
\text { Sancti Michaelis corruit } \\
\text { in sabbato vigiliae } \\
\text { Paschae, a monachis } \\
\text { more solito matutinis } \\
\text { peractis. In cujus } \\
\text { ruina portio quaedam } \\
\text { dormitorii monachorum } \\
\text { non minima destructa } \\
\text { atque eversa est cum } \\
\text { omnibus thoris et pan- } \\
\text { nis, monachis tamen in } \\
\text { eisdem requiescentibus } \\
\text { gratia Dei et patrocinio } \\
\text { sancti Michaelis absque } \\
\text { laesione liberatis }{ }^{185} \text {. }\end{array}$ & \\
\hline
\end{tabular}

181. Delisle corrige "penitrasse basicam» en "penetrasse basilicam» (DeLISLE, 1873, t. 2, p. 224), ce qu'a visiblement fait aussi Robert de Torigni.

182. On observe un glissement du sens lors de l'élaboration des Annales pascales du Mont SaintMichel: la colonne brillante / éclatante de M2 (colonne de lumière?) est devenue une colonne de feu dans $\mathrm{M}_{3}^{*}$ (remplacement de rutilantis par igneae).

183. On remarquera le remplacement de basilicam par ecclesiam et l'omission d'ultimae.

184. Note rapportée par erreur à l'année 1100 dans l'édition de M2 par Léopold Delisle (DelisLe, $1872-1873$, t. 2, p. 223)

185. Note omise par le copiste de $\mathrm{M}_{4}$. 


\begin{tabular}{|c|c|c|}
\hline $\begin{array}{l}\text { M2 1106. Hoc anno } \\
\text { factum est bellum } \\
\text { apud Tenechebrai } \\
\text { inter Henricum, regem } \\
\text { Anglorum, et Robertum, } \\
\text { comitem Normannorum, } \\
\text { et Willelmum, comitem } \\
\text { Moritonii, in quo idem } \\
\text { ambo comites capti sunt } \\
\text { et multi alii proceres } \\
\text { Normannię capti sunt. }\end{array}$ & $\begin{array}{l}\text { 1106. Factum est bellum } \\
\text { apud Tenechebrai inter } \\
\text { Henricum regem } \\
\text { Anglorum et Robertum } \\
\text { ducem Normannorum, } \\
\text { fratrem suum, in quo } \\
\text { idem dux et Willelmus } \\
\text { comes Moritonii et multi } \\
\text { alii capti sunt. }\end{array}$ & $\begin{array}{l}\text { 1106. Factum est bellum } \\
\text { apud Tenerchebrai }(\mathrm{sic}) \\
\text { inter Henricum, regem } \\
\text { Anglorum, et Robertum, } \\
\text { ducem Normannorum, } \\
\text { fratrem suum, in quo } \\
\text { idem dux et Willermus } \\
\text { comes Moritonii, et multi } \\
\text { alii capti sunt. }\end{array}$ \\
\hline $\begin{array}{l}\text { M2 1106. Hoc ętiam anno } \\
\text { Rotgerius Cadomensis, } \\
\text { abbas huius loci, fecit capi } \\
\text { de monachis nostris a rege } \\
\text { Anglorum et distribui } \\
\text { per abbatias Normannie. } \\
\text { Qua re indignatione non } \\
\text { modica commoti sunt } \\
\text { cetteri monachi, regem } \\
\text { adierunt eique desola- } \\
\text { tionem et expoliationem } \\
\text { extirpationemque sui loci } \\
\text { viva racione ostenderunt. } \\
\text { Quo audito, rex mandavit } \\
\text { abbati ut ad se apud } \\
\text { Cadomum veniret, } \\
\text { monachisque praecipiens } \\
\text { ut cum eo redirent. Ierunt } \\
\text { utrique. Quibus coram } \\
\text { rege positis, sciens abbas se } \\
\text { reum in omnibus existere, } \\
\text { cum monachis contendere } \\
\text { noluit; verum propria } \\
\text { sponte nulloque cogente } \\
\text { regi baculum pastoralem } \\
\text { reddidit ac dimisit. } \\
\text { Huic successit Rotgerius } \\
\text {.XI., quidam monachus } \\
\text { Gemmeticensis, rursum } \\
\text { non voluntate neque } \\
\text { electione monachorum, } \\
\text { sed vi regiae potestatis. }\end{array}$ & $\begin{array}{l}\text { 1106. Rogerius abbas } \\
\text { dimisit abbatiam Sancti } \\
\text { Michaelis, et rex Henricus } \\
\text { fecit eum abbatem } \\
\text { Cerneliensem. Huic } \\
\text { successit Rogerius, prior } \\
\text { Gemeticensis }^{186} \text {. }\end{array}$ & $\begin{array}{l}\text { Eodem anno, Rogerius } \\
\text { abbas dimisit abbatiam } \\
\text { Sancti Michaelis, et } \\
\text { rex Henricus fecit eum } \\
\text { abbatem Cerneliensem. } \\
\text { Huic successit Rogerius, } \\
\text { prior Gementicensis. }\end{array}$ \\
\hline
\end{tabular}

186. La façon dont Robert de Torigni a abrégé sa source mériterait une étude spécifique. Le transfert

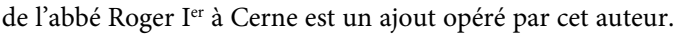




\begin{tabular}{|c|c|c|}
\hline $\begin{array}{l}\text { M2 1112. Hoc anno } \\
\text { combusta est hęc aecclesia } \\
\text { Sancti Michaelis igne } \\
\text { fulmineo cum omnibus } \\
\text { officinis monachorum, } \\
\text { monachis tamen gratia } \\
\text { Dei nullam lesionem } \\
\text { pacientibus, VII kalendas } \\
\text { maii, feria VI ebdomadę } \\
\text { Paschę, monachis } \\
\text { matutinas canentibus. }\end{array}$ & $\begin{array}{l}\text { 1112. Combusta est } \\
\text { ecclesia Sancti Michaelis } \\
\text { igne fulmineo, cum } \\
\text { omnibus officinis } \\
\text { monachorum, burgo } \\
\text { illeso, cum esset subtus } \\
\text { monasterium, quod } \\
\text { mirum est. }\end{array}$ & $\begin{array}{l}\text { 1112. Combusta est } \\
\text { ecclesia Sancti Michaelis } \\
\text { igne fulmineo cum } \\
\text { omnibus officinis } \\
\text { monachorum, burgo } \\
\text { illeso, cum esset subtus } \\
\text { monasterium, quod } \\
\text { mirum est. }\end{array}$ \\
\hline \multirow[t]{2}{*}{$\begin{array}{l}\text { M2 1117. Hoc anno a } \\
\text { multis circa mediam } \\
\text { noctem visa est luna } \\
\text { tota sanguinolenta. } \\
\text { Post non modicum vero } \\
\text { temporis visum est cęlum } \\
\text { ita rubeum ut pene } \\
\text { ardere videretur. Dehinc } \\
\text { vigilia Natalis Domini } \\
\text { subsecutus est ventus ita } \\
\text { vehemens cum } \\
\text { praecedente nocte ut } \\
\text { multarum aecclesiarum } \\
\text { turres et pinnacula } \\
\text { cum signis destrueret et } \\
\text { maximas silvarum atque } \\
\text { nemorum arbores } \\
\text { radicitus evelleret et } \\
\text { domus firmas corrui } \\
\text { compelleret et plurima } \\
\text { pericula in terra faceret. }\end{array}$} & $\begin{array}{l}\text { 1117. Factus est ventus } \\
\text { validus in vigilia } \\
\text { nativitatis Domini. }\end{array}$ & $\begin{array}{l}\text { 1117. Factus est ventus } \\
\text { validus in vigilia } \\
\text { nativitatis Domini. }\end{array}$ \\
\hline & $\begin{array}{l}\text { 1119. Factum est bellum } \\
\text { inter Henricum regem } \\
\text { Anglorum et Ludovicum } \\
\text { regem Francorum, in } \\
\text { quo bello multi optimates } \\
\text { Franciae capti sunt }{ }^{187} \text {. }\end{array}$ & $\begin{array}{l}\text { 1119. Factum est bellum } \\
\text { inter Henricum, regem } \\
\text { Anglorum, et Ludovicum, } \\
\text { regem Francorum, in } \\
\text { quo bello multi optimates } \\
\text { Franciae capti sunt. }\end{array}$ \\
\hline
\end{tabular}

187. Source utilisée: le récit de la bataille de Brémule (1119) est rapporté plus en détail dans la Chronique de Robert de Torigni (ms 159, fol. 187; Delisle, 1872-1873, t. 1, p. 156-158). 


\begin{tabular}{|c|c|c|}
\hline & $\begin{array}{l}\text { 1120. Submersus est in } \\
\text { mari ante Barbeflutum } \\
\text { Willermus, filius hujus } \\
\text { regis Anglorum, et multi } \\
\text { alii cum eo }{ }^{188} \text {. }\end{array}$ & $\begin{array}{l}\text { 1120. Submersus est in } \\
\text { mari ante Barbeflutum } \\
\text { Willermus, filius hujus } \\
\text { regis Anglorum, et multi } \\
\text { alii cum eo. }\end{array}$ \\
\hline & $\begin{array}{l}\text { 1123. Rogerius abbas } \\
\text { dimisit abbatiam } \\
\text { Montis }^{189} \text {. }\end{array}$ & $\begin{array}{l}\text { 1123. Rogerius abbas } \\
\text { dimisit abbatiam Montis. }\end{array}$ \\
\hline $\begin{array}{l}\text { M2 1124. Ricardus } \\
\text { abbas.XII. }\end{array}$ & $\begin{array}{l}\text { 1124. Richardus de Mere, } \\
\text { monachus Cluniacensis, } \\
\text { factus est abbas Montis, } \\
\text { quem tenuit per tres } \\
\text { annos. }\end{array}$ & $\begin{array}{l}\text { 1124. Ricardus de Mere, } \\
\text { monachus Cluniacensis, } \\
\text { factus est abbas Montis, } \\
\text { quem tenuit per tres } \\
\text { annos. }\end{array}$ \\
\hline \multirow[t]{2}{*}{$\begin{array}{l}\text { B 1128. Occisus est } \\
\text { Willelmus, comes } \\
\text { Flandrensis, filius Roberti } \\
\text { Normannorum ducis. }\end{array}$} & $\begin{array}{l}\text { 1128. Occisus est } \\
\text { Willelmus, comes } \\
\text { Flandrensis, filius Roberti } \\
\text { ducis Normannorum }{ }^{190} \text {. }\end{array}$ & $\begin{array}{l}\text { 1128. Occisus est } \\
\text { Willermus, comes } \\
\text { Flandrensis, filius Roberti } \\
\text { ducis Normannorum. }\end{array}$ \\
\hline & $\begin{array}{l}\text { 1128. Robertus de } \\
\text { Thorigneio, qui postea } \\
\text { factus est abbas Montis, } \\
\text { assumpsit habitum } \\
\text { religionis Becci }{ }^{191} \text {. }\end{array}$ & $\begin{array}{l}\text { Eodem anno Robertus } \\
\text { de Thorigneio, qui postea } \\
\text { factus est abbas Montis, } \\
\text { assumpsit habitum } \\
\text { religionis Becci. }\end{array}$ \\
\hline $\begin{array}{l}\text { M2 1131. Bernardus } \\
\text { XIII }{ }^{u s} \text { abbas, } \\
\text { monachus Becci. }\end{array}$ & $\begin{array}{l}\text { 1131. Bernardus, } \\
\text { monachus Becci, factus } \\
\text { est abbas Montis. }\end{array}$ & $\begin{array}{l}\text { 1131. Bernardus, } \\
\text { monachus Becci, factus } \\
\text { est abbas Montis. }\end{array}$ \\
\hline $\begin{array}{l}\text { M2 1135. Obiit Henricus, } \\
\text { rex Anglorum et dux } \\
\text { Normannorum }<\ldots>^{192} .\end{array}$ & $\begin{array}{l}\text { 1135. Obiit Henricus, } \\
\text { rex Anglorum et dux } \\
\text { Normannorum, cui } \\
\text { successit Stephanus } \\
\text { comes. }\end{array}$ & $\begin{array}{l}\text { 1135. Obiit Henricus, } \\
\text { rex Anglorum et dux } \\
\text { Normannorum, cui } \\
\text { successit Stephanus } \\
\text { comes. }\end{array}$ \\
\hline
\end{tabular}

188. Source utilisée: le naufrage de la Nef Blanche (1120) est également rapporté dans la Chronique de Robert de Torigni, sans toutefois mentionner le nom de Barfleur (ms 159, fol. 187-187v; Delisle, 1872-1873, t. 1, p. 159).

189. Source utilisée: non identifiée. Possible tradition orale.

190. Source utilisée: Les Annales du Bec.

191. Source utilisée: non identifiée - Robert de Torigni est la personne la mieux placée pour écrire une telle note en 1154 .

192. La fin de la note a été rognée par le relieur dans M2. 


\begin{tabular}{|c|c|c|}
\hline & $\begin{array}{l}\text { 1138. Debacatione } \\
\text { Abrincatensium } \\
\text { furentium combustum } \\
\text { est castrum Montis, } \\
\text { excepta ecclesia et } \\
\text { officinis monachorum, } \\
\text { mense augusto }{ }^{193} \text {. }\end{array}$ & $\begin{array}{l}\text { 1138. Debacatione } \\
\text { Abrincatensium } \\
\text { furentium combustum } \\
\text { est castrum Montis, } \\
\text { excepta aecclesia et } \\
\text { officinis monachorum, } \\
\text { mense augusto. }\end{array}$ \\
\hline $\begin{array}{l}\text { M2 1140. Stephanus, } \\
\text { rex Anglorum, captus } \\
\text { est in Purificatione } \\
\text { sanctae Mariae, apud } \\
\text { Lincolniam, a Roberto, } \\
\text { comite Gloecestrie, } \\
\text { et Rannulfo, comite } \\
\text { Cestrensi. }\end{array}$ & $\begin{array}{l}\text { 1140/1. Captus est } \\
\text { Stephanus, rex Anglorum, } \\
\text { apud Lincolniam in bello } \\
\text { a Roberto comite. }\end{array}$ & $\begin{array}{l}\text { 1141. Captus est } \\
\text { Stephanus, rex Anglorum, } \\
\text { apud Lincolniam in bello } \\
\text { a Roberto comite. }\end{array}$ \\
\hline $\begin{array}{l}\text { M2 1143. Civitas } \\
\text { Rothomagi reddita est } \\
\text { comiti Andegavensi } \\
\text { Gaufrido. }\end{array}$ & $\begin{array}{l}\text { 1143/4. Reddita est turris } \\
\text { Rothomagi Gaufredo } \\
\text { comiti Andegavensi, et } \\
\text { exinde factus est comes } \\
\text { Normannorum. }\end{array}$ & $\begin{array}{l}\text { 1144. Reddita est turris } \\
\text { Rothomagi Gaufredo } \\
\text { comiti Andegavensi, et } \\
\text { exinde factus est comes } \\
\text { Normannorum. }\end{array}$ \\
\hline $\begin{array}{l}\text { M2 1144. Ceperunt } \\
\text { homines prius apud } \\
\text { Carnotum carros } \\
\text { lapidibus honustos } \\
\text { et aliis rebus humeris } \\
\text { trahere ad opus ecclesiae, } \\
\text { et ibi et in aliis ecclesiis } \\
\text { miracula fiebant. }\end{array}$ & $\begin{array}{l}\text { 1144/5. Coeperunt viri et } \\
\text { mulieres humeris carros } \\
\text { honustos lapidibus et } \\
\text { alia materia humiliter et } \\
\text { cum magna devotione ad } \\
\text { opus ecclesiarum trahere. } \\
\text { Et ibi eveniebant multa } \\
\text { miracula. }\end{array}$ & $\begin{array}{l}\text { 1145. Coeperunt viri et } \\
\text { mulieres humeris carros } \\
\text { honustos lapidibus et } \\
\text { alia materia humiliter et } \\
\text { cum magna devotione ad } \\
\text { opus ecclesiarum trahere. } \\
\text { Et ibi eveniebant multa } \\
\text { miracula. }\end{array}$ \\
\hline $\begin{array}{l}\text { M2 1146. Ludovicus, } \\
\text { rex Francorum, } \\
\text { Jherosolimam profectus, } \\
\text { parum profecit. }\end{array}$ & $\begin{array}{l}\text { 1146/7. Ludovicus, rex } \\
\text { Francorum, et socii } \\
\text { eorum, Jherosolimam, } \\
\text { ubi parvum vel nichil } \\
\text { profecerunt. }\end{array}$ & $\begin{array}{l}\text { 1147. [...] Ludovicus, } \\
\text { rex Francorum, et } \\
\text { socii eorum, Jerusalem, } \\
\text { ubi parvum vel nichil } \\
\text { profecerunt. }\end{array}$ \\
\hline $\begin{array}{l}\text { M2 1149. Obiit } \\
\text { Bernardus, abbas } \\
\text { Montis, et successit } \\
\text { Gaufredus, monachus } \\
\text { eiusdem loci. } \\
\text { M2 1150. Obiit } \\
\text { Gaufridus, abbas Montis. }\end{array}$ & $\begin{array}{l}\text { 1149. Obiit Bernardus, } \\
\text { abbas Montis, et } \\
\text { successit ei Gaufredus, } \\
\text { monachus ejusdem } \\
\text { loci, qui sequenti anno } \\
\text { mortuus est. }\end{array}$ & $\begin{array}{l}\text { 1149. Obiit Bernardus, } \\
\text { abbas Montis, et successit } \\
\text { ei Gaufredus, monachus } \\
\text { ejusdem loci, qui sequenti } \\
\text { anno mortuus est [...]. }\end{array}$ \\
\hline
\end{tabular}

193. Source utilisée: non identifiée. Possible tradition orale. 


\begin{tabular}{|c|c|c|}
\hline & $\begin{array}{l}\text { 1149. De discordia quae } \\
\text { fuit inter Richardum } \\
\text { de Musca et Robertum } \\
\text { Harditum propter } \\
\text { abbatiam Montis, } \\
\text { nichil attinet dicere nisi } \\
\text { quia ipsi et Richardus } \\
\text { Abrincensis episcopus in } \\
\text { itinere Romae obierunt } \\
\text { peregre }^{194} \text {. }\end{array}$ & $\begin{array}{l}\text { [...] De discordia quae } \\
\text { fuit inter Ricardum de } \\
\text { Musca et Robertum } \\
\text { Harditum propter } \\
\text { abbatiam Montis, } \\
\text { nichil attinet dicere nisi } \\
\text { quia ipsi et Ricardus, } \\
\text { Abrincensis episcopus, } \\
\text { in itinere Romae } \\
\text { obierunt peregre. }\end{array}$ \\
\hline $\begin{array}{l}\text { M2 1150. Obiit } \\
\text { Gaufridus, dux } \\
\text { Normannorum, et } \\
\text { successit Henricus, } \\
\text { filius eius. }\end{array}$ & $\begin{array}{l}\text { 115o. Obiit Gaufredus, } \\
\text { dux Normannorum et } \\
\text { comes Andegavorum, } \\
\text { et successit ei Henricus, } \\
\text { filius ejus, natus ex } \\
\text { Matilde imperatrice, } \\
\text { filia primi Henrici, } \\
\text { regis Anglorum. }\end{array}$ & $\begin{array}{l}\text { 1151. Obiit Gaufredus, } \\
\text { dux Normannorum et } \\
\text { comes Andegavorum, } \\
\text { et successit ei Henricus, } \\
\text { filius ejus, natus ex } \\
\text { Matilde imperatrice, } \\
\text { filia primi Henrici, } \\
\text { regis Anglorum. }\end{array}$ \\
\hline $\begin{array}{l}\text { M2 1152. Stephanus, rex } \\
\text { Anglorum, et Henricus, } \\
\text { dux Normannorum, } \\
\text { cognatus eius, } \\
\text { concordati sunt. }\end{array}$ & $\begin{array}{l}\text { 1152. Concordati sunt } \\
\text { Stephanus, rex Anglorum, } \\
\text { et Henricus, cognatus } \\
\text { ejus, dux Normannorum. }\end{array}$ & $\begin{array}{l}\text { 1153. Concordati sunt } \\
\text { Stephanus, rex Anglorum, } \\
\text { et Henricus, cognatus } \\
\text { ejus, dux Normannorum. }\end{array}$ \\
\hline $\begin{array}{l}\text { M2 1154. Robertus de } \\
\text { Torigneio, monachus } \\
\text { Becci, electus ab omni } \\
\text { conventu Montis, factus } \\
\text { est abbas eiusdem loci. }\end{array}$ & $\begin{array}{l}\text { 1154. Mense maio, } \\
\text { VI kalendas junii, feria } \\
\text { quinta infra octabas } \\
\text { Penthecostes, electus est } \\
\text { Robertus de Thorigneio, } \\
\text { prior claustralis Becci, } \\
\text { ad regimen ecclesiae } \\
\text { Sancti Michaelis ab omni } \\
\text { conventu. }\end{array}$ & $\begin{array}{l}\text { 1154. Mense maio, } \\
\text { VI kalendas junii, feria } \\
\text { quinta infra octabas } \\
\text { Penthecostes, electus est } \\
\text { Robertus de Thorigneio, } \\
\text { prior claustralis Becci, } \\
\text { ad regimen ecclesiae } \\
\text { Sancti Michaelis ab omni } \\
\text { conventu. }\end{array}$ \\
\hline $\begin{array}{l}\text { M2 1154. Obiit } \\
\text { Stephanus, rex } \\
\text { Anglorum, et successit } \\
\text { Henricus, dux } \\
\text { Normannorum, nepos } \\
\text { Henrici regis ex } \\
\text { Matillide imperatrice. }\end{array}$ & $\begin{array}{l}\text { 1154. Obiit Stephanus, } \\
\text { rex Anglorum; successit } \\
\text { ei Henricus secundus, } \\
\text { dux Normannorum. }\end{array}$ & $\begin{array}{l}\text { Eodem anno obiit } \\
\text { Stephanus, rex } \\
\text { Anglorum; successit ei } \\
\text { Henricus secundus, dux } \\
\text { Normannorum. }\end{array}$ \\
\hline
\end{tabular}

194. Source utilisée: non identifiée. 


\section{Appendice}

\section{Actualisation des dates d'abbatiat des abbés du Mont Saint-Michel}

L'enquête menée sur le De abbatibus et sur les sources utilisées par Robert de Torigni permet de revoir les dates de début et de fin d'abbatiat de plusieurs abbés du Mont Saint-Michel pour les $\mathrm{X}^{\mathrm{e}}, \mathrm{XI}^{\mathrm{e}}$ et $\mathrm{XII}^{\mathrm{e}}$ siècles et de proposer ainsi une chronologie réactualisée par rapport à celles retenues par Dom Jean Laporte (en 1967) ${ }^{195}$, Neithard Bulst (en 1973) $)^{196}$, Katharine Keats-Rohan (en 2006) ${ }^{197}$ et Véronique Gazeau (en 2007) ${ }^{198}$. Les principales divergences s'observent sur les abbatiats des $\mathrm{X}^{\mathrm{e}}$ et $\mathrm{XI}^{\mathrm{e}}$ siècles (période 965/6-1085). Avant de dresser un tableau de synthèse, reprenant l'ensemble des datations proposées par ces historiens, revenons brièvement sur les cas des abbés Mainard $\mathrm{I}^{\mathrm{er}}$, Hildebert $\mathrm{I}^{\mathrm{er}}$, Hildebert II, Thierry, Aumode, Suppon, Raoul et Renouf.

Concernant Mainard $I^{\mathrm{er}}$, la date de son accession se déduit des témoignages combinés du diplôme de Lothaire datant du 7 février 966 et de l'Inventio et miracula sancti Vulfranni ${ }^{199}$. Longtemps acceptée, l'authenticité du diplôme de Lothaire a fait l'objet ces dernières années de vifs débats chez les historiens. Du fait de la présence d'une interpolation (insertion d'une pseudo-bulle du pape Jean XIII au cours du XI ${ }^{e}$ siècle), l'authenticité de l'ensemble a été rejetée par plusieurs auteurs dans des contributions publiées entre 1984 et $2006^{200}$. Néanmoins, depuis 2009, ce document a été réhabilité grâce aux travaux critiques approfondis de Pierre Bouet, Laurent Morelle et Georges N. Gandy ${ }^{201}$. Ancien moine de Saint-Pierre de Gand, puis rector de Saint-Wandrille sous l'abbé Womard de Saint-Pierre de Gand (953-981), Mainard, en sollicitant et en obtenant du roi Lothaire un diplôme de confirmation en tant qu'abbé du Mont Saint-Michel, n'a fait qu'adopter une pratique identique à celle employée à la même époque par son ancien abbé ${ }^{202}$. La teneur du diplôme ne confère que peu d'avantages aux moines, et plusieurs indices laissent penser que cet acte, qu'on le juge ou non interpolé ou remanié, témoigne d'un substrat sincère (aucune entorse aux pratiques de la chancellerie royale de l'époque n'est décelable). La seule réserve émise par Laurent Morelle sur ce diplôme concerne le thème du préambule: «formellement de bon aloi (on y relève des tournures peu communes en usage

195. LAPORTE, 1967 , p. 267-281, en particulier la liste p. 269 et l'analyse p. 270-275.

196. Bulst, 1973, p. 167-172 (uniquement les premiers abbatiats, sur la période 966-1048).

197. Keats-Rohan, 2006, p. 52.

198. GazeAu, 2007, II, p. 197-225.

199. Halphen et Lot, $1908, n^{\circ} 24$, p. 53-57; LAPORTE, 1938, p. 7-87, en particulier chap. 16; GANDY, 2016, p. 18-20.

200. Chédeville et Guillotel, 1984, p. 336; Arnoux, 1999, p. 38 ; Keats-Rohan, 2006, p. 18-22. Sur le jugement parfois hypercritique de Guillotel, qui est le premier auteur à avoir véritablement mis en doute l'authenticité de ce diplôme, voir la mise en point de Cyprien Henry dans Guillotel, 2014, p. 9-19, en particulier p. 12 b.

201. Poulle, Bouet et Desbordes, 2009, p. 155-159, en particulier p. 159, n. 28; Morelle, 2013, p. 110-114, paragraphe 13; GANDY, 2016, p. 7-32, en particulier 17-18.

202. Cf. Halphen et Lot, $1908, \mathrm{n}^{\text {os }} 21-22$, p. 43-49. 
sous Charles le Chauve)», il porte «sur la confirmation par le roi [Lothaire] des actions de ses prédécesseurs", ce qui pourrait sembler, a priori, hors de propos. Mais il faut peut-être voir là une allusion à une intervention du roi Charles le Chauve lors de l'installation d'une première communauté de moines au Mont Saint-Michel peu avant $87 \mathrm{O}^{203}$.

Pour ce qui est du décès et de la succession d'Hildebert $\mathrm{I}^{\text {er }}$, rappelons que la date de l'accession de Hildebert II en 1017 est une addition faite par Robert de Torigni après 1154 dans les annales $\mathrm{M}_{2}$ : il ne connaissait pas encore cette date au moment de la rédaction du De abbatibus, et il a fait le choix de ne pas l'y reporter plus tard, ce qui pose la question, d'une part, de la source à laquelle il eut finalement accès pour obtenir cette date, d'autre part, du contexte dans lequel la date de 1017 fut finalement adoptée dans M2, et donc de la fiabilité de cette information ${ }^{204}$.

Thierry est inscrit au 16 mai dans les nécrologes de Saint-Bénigne de Dijon, de Jumièges et de Saint-Arnoul de Metz. Mais il est inscrit au 17 mai dans les nécrologes du Mont Saint-Michel et de Saint-Germain-des-Prés. Il semble que sa date de commémoration ait en fait été déplacée du 16 au 17 mai dans le nécrologe du Mont afin de la réunir avec celle de son successeur Aumode, mort le 17 mai 1033: «Obierunt Theodericus, Almodus abbates». L'ordre de la succession abbatiale est ici respecté (ce qui n'est plus le cas dans les documents produits au Mont à partir du début du XII ${ }^{e}$ siècle: catalogues, annales, De abbatibus, etc.), ce qui sous-entend la réunion précoce de ces deux noms dans la documentation nécrologique montoise.

Concernant Suppon, nous avons montré plus haut qu'il n'y avait pas d'abbatiat en 1023 ou en 1027 et qu'il fut simplement le candidat malheureux de Guillaume de Volpiano à cette dernière date.

Au sujet de la date de la mort de l'abbé Raoul le 25 juillet 1053, il s'agit d'une erreur introduite par Dom Laporte: aucune source médiévale ne fournit le 25 juillet comme jour de décès, et nous avons vu que l'année 1053 n'apparaissait que dans une copie tardive d'annales manifestement fautives $\left(\mathrm{M}_{4}=\right.$ Annales mineures du Mont Saint-Michel). Les nécrologes donnent le 27 juillet (Jumièges)

203. La présence au Mont Saint-Michel d'un abbé Phinimontius - déformation possible de Finoé du Mont - est en effet attestée vers 870 (Keats-Rohan, 2003, p. 143-144; voir néanmoins GANDY, 2016, p. 15-16). Il est possible qu'une première communauté de moines ait été installée au Mont sous Charles le Chauve peu avant 870 , mais qu'elle ait été rapidement contrainte à l'exil dans le contexte troublé des raids scandinaves qui sévirent dans la région entre la fin des années 880 et les années 920. Parmi les autres ancêtres de Lothaire qui auraient pu intervenir en faveur du Mont Saint-Michel, on pourrait envisager le cas du roi Louis IV d'Outremer. Il aurait en effet pu intervenir en faveur de ce monastère à l'occasion de la cession de la Terra Brittonum in ora maritima sita à Guillaume Longue-épée en 933, rapportée par Flodoard dans ses Annales (LAUER, 1906, année 933). Force est néanmoins de reconnaître que nous manquons de sources précises sur l'histoire de la communauté entre la rédaction de la Revelatio au IX ${ }^{e}$ siècle (vraisemblablement entre 851 et 867 : GANDY, 2016, p. 8-10) et l'installation des moines bénédictins en 965/966.

204. Dom Laporte va même jusqu'à mettre en doute l'existence de Hildebert II: il propose d'en faire un «prétendant» ou un coadjuteur de son prédécesseur. 
ou le 29 juillet (Saint-Bénigne de Dijon et le Mont Saint-Michel). Cette dernière date semble être la bonne: le nécrologe de Jumièges, plus récent, réunit artificiellement les obiit de deux abbés.

Enfin, la date de début d'abbatiat de Roger I Ir, proposée par Keats-Rohan, ne tient pas: Roger I ${ }^{\text {er }}$ a été imposé du temps de Guillaume le Conquérant, mort en 1087. 


\begin{tabular}{|c|c|c|c|c|c|c|c|c|c|c|c|c|c|c|}
\hline 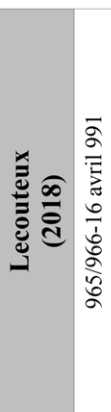 & 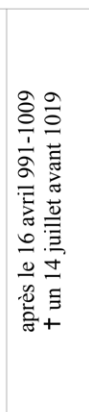 & 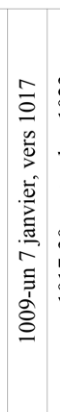 & 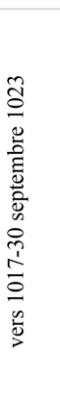 & 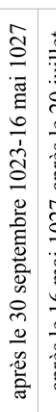 & 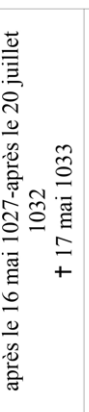 & 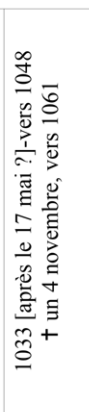 & 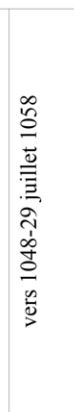 & 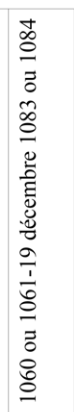 & 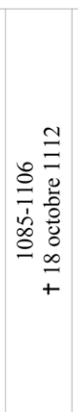 & 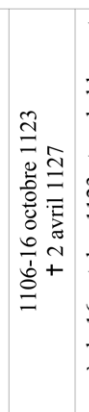 & 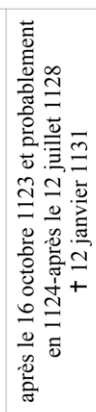 & 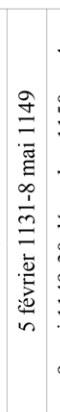 & 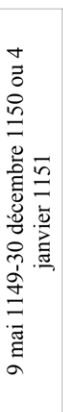 & 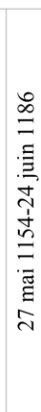 \\
\hline 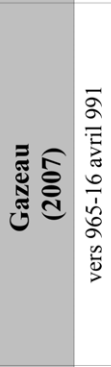 & 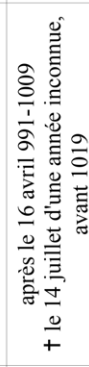 & 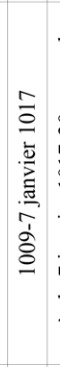 & 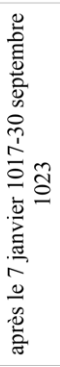 & 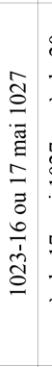 & 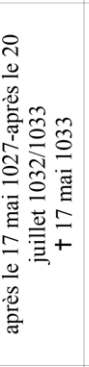 & 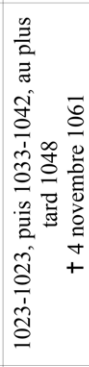 & 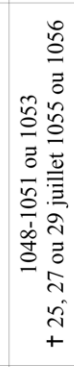 & 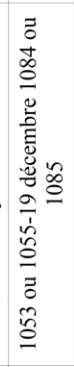 & 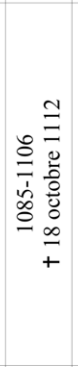 & 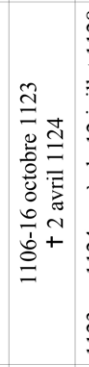 & 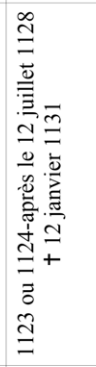 & 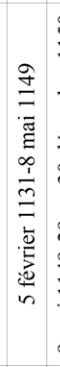 & 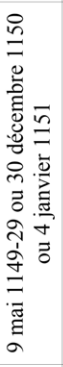 & 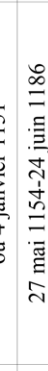 \\
\hline 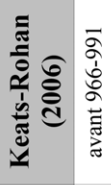 & $\frac{\text { oे }}{\frac{1}{\partial}}$ & 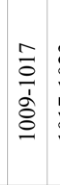 & $\frac{\widetilde{\Xi}}{\frac{1}{5}}$ & 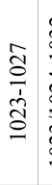 & 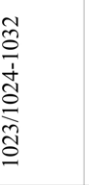 & 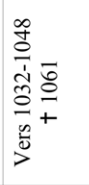 & 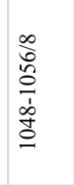 & 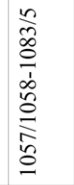 & 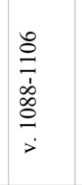 & 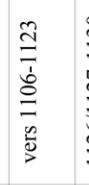 & 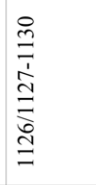 & $\begin{array}{l}\frac{g}{\partial} \\
\frac{1}{M} \\
\Xi\end{array}$ & & \\
\hline 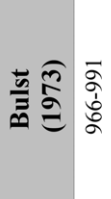 & $\frac{\text { के }}{\frac{1}{\dot{a}}}$ & $\begin{array}{l}\overline{\hat{a}} \\
\frac{1}{\dot{d}} \\
\stackrel{a}{a}\end{array}$ & 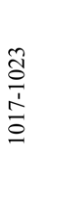 & 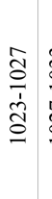 & 奥 & $\begin{array}{l}\frac{0}{1} \\
\tilde{e} \\
\frac{\tilde{c}}{\tilde{m}}\end{array}$ & 䯩 & . & . & ' & & ' & & \\
\hline 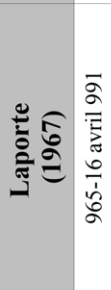 & 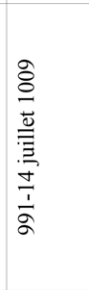 & 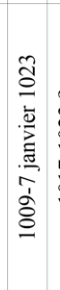 & 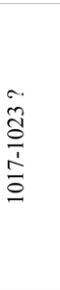 & 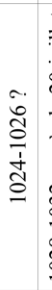 & 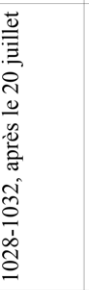 & 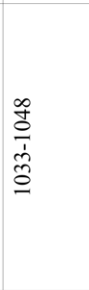 & 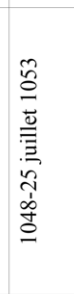 & 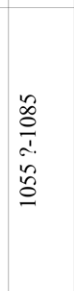 & 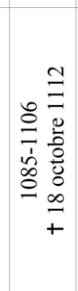 & 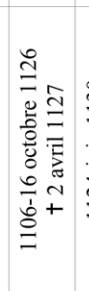 & 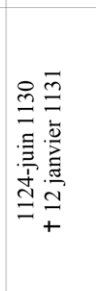 & 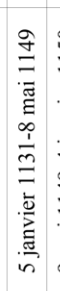 & 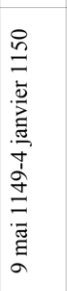 & 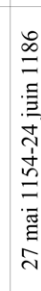 \\
\hline & 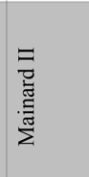 & 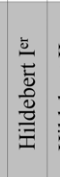 & 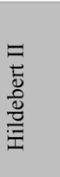 & . & 妾 & $\tilde{n}$ & $\begin{array}{l}\overline{\bar{G}} \\
\stackrel{\Xi}{\dddot{N}}\end{array}$ & $\begin{array}{l}\text { 言 } \\
\overline{\bar{E}}\end{array}$ & $\begin{array}{l}\overline{\overline{\mathrm{g}}} \\
\stackrel{0}{0} \\
\stackrel{0}{0}\end{array}$ & 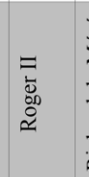 & 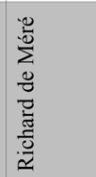 & 离 & & $\begin{array}{l}\overline{\bar{g}} \\
\bar{g} \\
\bar{g}\end{array}$ \\
\hline- & & $\mathrm{m}$ & & in & & r & $\infty$ & a & $\stackrel{\circ}{1}$ & $=$ & & & & $\underline{n}$ \\
\hline
\end{tabular}

